\title{
Modelo para crear un sistema de Gestión Integrada de Calidad, Medioambiente y Prevención de Riesgos Laborales en una Biblioteca Universitaria
}

\author{
Apolonia Millán Castro \\ Master Universitario en Prevención de \\ Riesgos Laborales \\ Curso 2014-2016 \\ Universidad de Granada
}

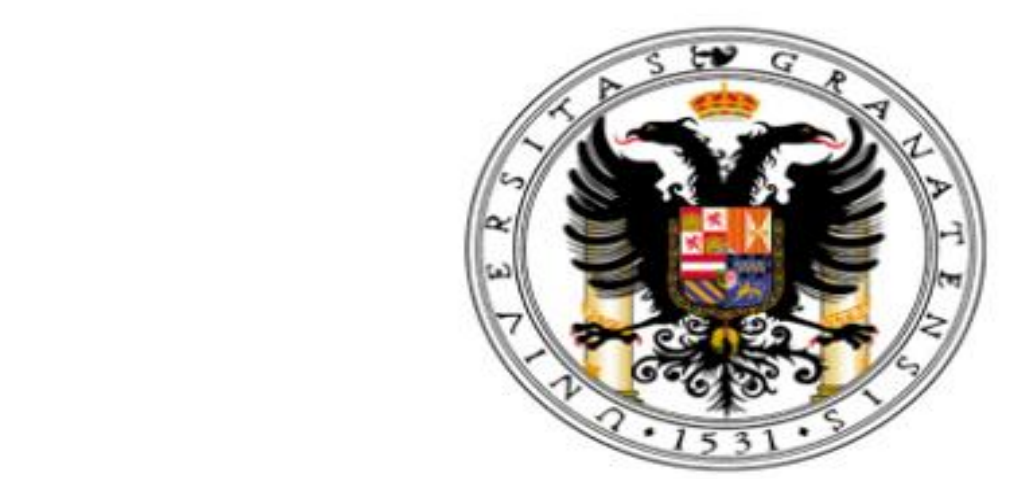

\section{Universidad de Granada}

Tutor Trabajo Fin de Máster

D. Javier Machado Santiago

Servicio de Salud y

Prevención de Riesgos Laborales de la

Universidad de Granada 


\title{
Modelo para crear un Sistema de Gestión
}

\author{
Integrada \\ de Calidad, Medioambiente y \\ Prevención de Riesgos Laborales \\ en una biblioteca universitaria
}

\author{
Apolonia Millán Castro \\ Máster Universitario de \\ Prevención de Riesgos Laborales
}




\section{RESUMEN}

Las exigencias del mercado y la globalización de la economía, han hecho que en la actualidad, sea raro el sector o producto de ámbito internacional que no se encuentre normalizado en alguno de sus aspectos (composición, forma, etc.). Un ejemplo claro, lo tenemos en las tarjetas de crédito. Son utilizadas en todo el mundo gracias a una norma internacional ISO que define sus características y su grosor $(0,76$ $\mathrm{mm})$.

Hoy en día, ni los clientes/usuarios, ni la administración quieren ni tienen tiempo para inspeccionar los artículos/ emisiones/ riesgos...por lo que hacen recaer esta responsabilidad en sus proveedores. Ello hace que las empresas, busquen nuevas alternativas para garantizar el cumplimiento de los requisitos legales y del usuario incorporando de esta forma, la calidad, el medioambiente y la prevención de riesgos en su proceso productivo. Esto se consigue mediante la introducción de sistemas de gestión normalizados que permiten que este cumplimiento se pueda demostrar a otras instituciones mediante la documentación y los registros adecuados.

Las Bibliotecas Universitarias, han sido pioneras dentro de la institución certificando su Sistema de Gestión de Calidad. Debido a esto, han conseguido diversos premios. Podemos citar como referente a la Biblioteca Universitaria de Granada. Certificó su Sistema de Gestión de Calidad con la norma ISO 9001 y ha seguido manteniéndolo desde el año 2007 hasta el día de hoy. Además obtuvo el Sello de Excelencia Europea 500+ otorgado por la Fundación Europea para la Gestión de la Calidad (EFQM) en el año 2012 y renovándolo en 2014, y fue galardonada con el premio Plata de Calidad en la XXIII Cumbre Iberoamericana de Jefes de Estado y de Gobierno. Esto demuestra, que las bibliotecas, a pesar de ser unas instituciones con una gran carga de tradición en sus actividades, también se preocupan de actualizar sus servicios, ya que la profesión del bibliotecario es a demanda social, y ahora se demanda una buena gestión de los recursos.

Por esto, nos planteamos conseguir integrar la gestión del medioambiente y la prevención de riesgos en un solo sistema junto con el de Calidad, y demostrar las grandes ventajas que esto traería a la institución.

Analizando las normas ISO 9001 y 14001 y OHSAS 18001 se podrá averiguar si esto es posible y si así es cómo hacerlo.

Palabras Clave: Gestión Calidad, Medioambiente, Prevención de Riesgos, Normas ISO

Normas OHSAS, Gestión Integrada. 


\section{Contenido}

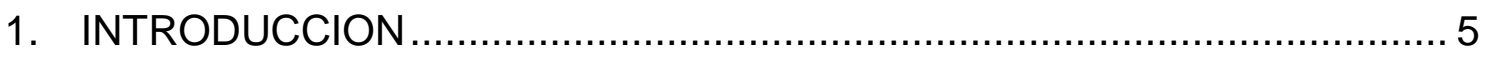

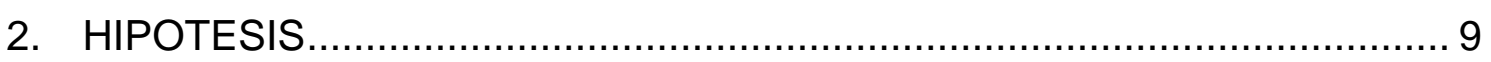

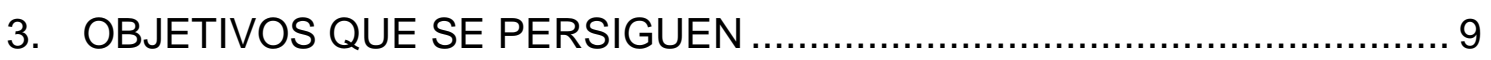

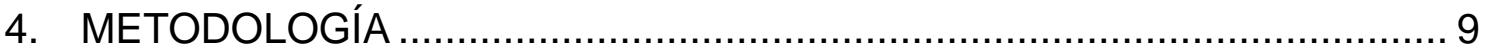

5. SISTEMA DE GESTION DE LA CALIDAD ..................................... 10

6. SISTEMAS DE GESTIÓN DE LA CALIDAD. ISO 9001:2015. REQUISITOS

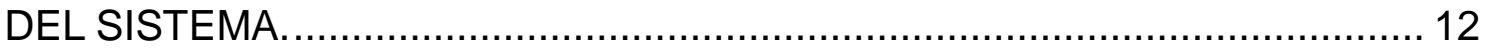

7. SISTEMA DE GESTION MEDIOAMBIENTAL ..................................... 33

UNE EN ISO 14001:2015 Sistemas de Gestión Ambiental. Requisitos con orientación para su uso...................................................................... 36

8. GESTION DE LA PREVENCIÓN DE RIESGOS LABORALES ................ 51

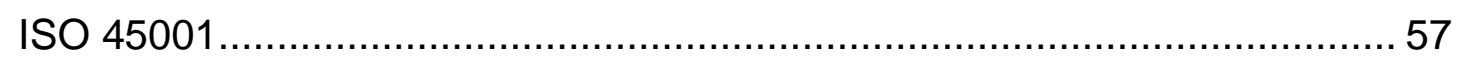

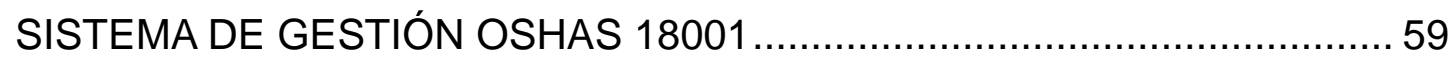

9. GESTIÓN INTEGRADA DE SISTEMAS DE GESTIÓN DE CALIDAD,

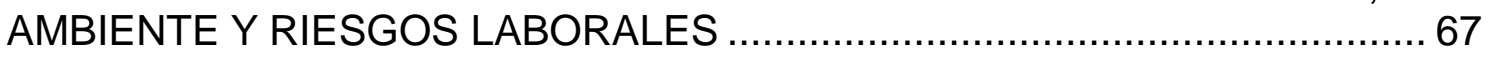

10. MODELO DE SISTEMA DE GESTIÓN INTEGRADO ......................... 76

11. MODELO DE SISTEMA DE GESTIÓN INTEGRADO DE CALIDAD,

AMBIENTAL Y SEGURIDAD Y SALUD PARA LA BIBLIOTECA DE LA UGR. 80

12. CONCLUSIONES ................................................................. 106

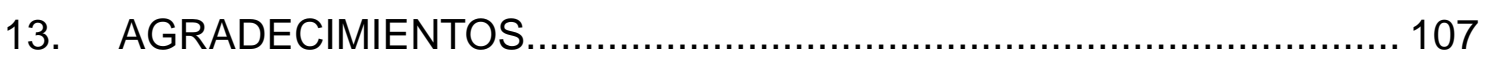

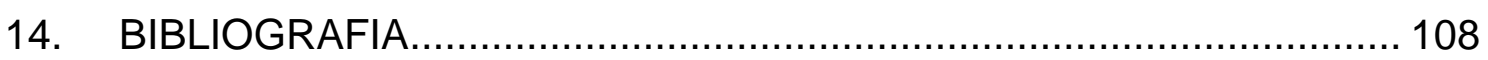




\section{INTRODUCCION}

Las exigencias del mercado y la globalización de la economía, han hecho que en la actualidad, sea raro el sector o producto de ámbito internacional que no se encuentre normalizado en alguno de sus aspectos (composición, forma, etc.). Un ejemplo claro, son las tarjetas de crédito. Son utilizadas en todo el mundo gracias a una norma internacional ISO que define sus características y su grosor $(0,76 \mathrm{~mm})$.

Hoy en día, ni los clientes/usuarios, ni la administración quieren ni tienen tiempo para inspeccionar los artículos/ emisiones/ riesgos...por lo que hacen recaer esta responsabilidad en sus proveedores. Ello hace que las empresas, busquen nuevas alternativas para garantizar el cumplimiento de los requisitos legales y del usuario incorporando de esta forma, la calidad, el medioambiente y la prevención de riesgos en su proceso productivo. Esto se consigue mediante la introducción de sistemas de gestión normalizados que permiten que este cumplimiento se pueda demostrar a otras instituciones mediante la documentación y los registros adecuados.

Se entiende por sistema de Gestión la estructura organizada, la planificación de las actividades, las responsabilidades, las prácticas, los procedimientos, los procesos y los recursos para desarrollar, implantar, llevar a cabo, revisar y mantener al día la política de la empresa. En otras palabras, es una herramienta que permite sistematizar la gestión de la empresa, contribuyendo a optimizarla y, en consecuencia, ayudando a la toma de decisiones. Además, ayuda al cumplimiento estructurado de cualquier legislación.

En cualquier firma coexisten diferentes sistemas de gestión relacionados con distintos aspectos de la política de la empresa: Calidad, Medio Ambiente, Prevención de Riesgos Laborales, Financiero, Comercial, etc. Estos sistemas de gestión en muchos casos se han definido cada uno de ellos de forma autónoma defendiendo estructuras, prácticas o recursos de forma independiente y en numerosas ocasiones, sin aprovechar las ventajas que puede suponer definir un sistema que tenga en consideración los aspectos comunes a unos y a otros, en aumento de la optimización de recursos, la eficiencia, la simplificación de procesos, eliminación de operaciones innecesarias, etc.

Sea cual sea el sistema de gestión, su objetivo es:

- garantizar el cumplimiento de las políticas, especificaciones, normativa y legislación

- favorecer la mejora continua

- permitir que este cumplimiento sea demostrable a otras instituciones mediante la documentación y los registros adecuados. 
Para algunos de estos sistemas de gestión, existen normas que definen ciertos requisitos que han de cumplir: las normas ISO 9000 para Sistemas de Gestión de la Calidad, las normas ISO 14000 para los sistemas de gestión medioambiental o las normas OSHAS 18001 para sistemas de Gestión de Prevención de Riesgos Laborales.

Según la ISO (Organismo Internacional de Normalización) la normalización es "el proceso de formular y aplicar reglas con el propósito de realizar en orden una actividad específica para el beneficio y con la obtención de una economía de conjunto óptimo teniendo en cuenta las características funcionales y los requisitos de seguridad. Se basa en los resultados consolidados de la ciencia, la técnica y la experiencia. Determina no solamente la base para el presente sino también para el desarrollo futuro y debe mantener su paso acorde con el progreso".

Una norma es toda especificación técnica o documento accesible al público establecido por consenso de las partes interesadas y aprobado por un organismo cualificado y reconocido a nivel nacional (AENOR, en España), comunitario (CEN, CENELC y ETSI) o internacional (ISO, EIC...), que proporciona para uso común y repetido, reglas directrices o características para ciertas actividades o sus resultados, con el fin de conseguir un grado óptimo en un contexto dado.

Todas estas normas son normas convencionales y no se pueden confundir con las normas legales. En Derecho, se habla de leyes y reglamentos para referirse a aquellas disposiciones que han sido aprobadas por entes soberanos. El conjunto de todas ellas integran el ordenamiento jurídico de un país.

Estas normas convencionales son emitidas en calidad de recomendaciones por parte de organizaciones internacionales, comunitarias 0 nacionales. Estas organizaciones basan su funcionamiento en la agrupación de expertos que representan los distintos sectores interesados en el área que cubre la norma en concreto.

En la medida que las decisiones de estas organizaciones no sean aprobadas por órganos soberanos, sus normas no son obligatorias.

Muchas normas legales también regulan aspectos de la técnica, la industria o la ciencia. Como ejemplo, podemos encontrar reglamentaciones que contienen especificaciones técnicas sobre composición de productos, tratamiento de materiales, seguridad de las máquinas o incluso la gestión de ciertas materias en las empresas. En estos aspectos, ambas normas pueden coexistir, ya sea de manera armonizada o bien en conflicto.

En cualquier caso, siempre prevalecen las normas legales debido a su carácter soberano, su obligatoriedad, y su incorporación al ordenamiento jurídico nacional o comunitario. Luego, una norma convencional, será obligatoria cuando un gobierno la 
apruebe y recoja en su ordenamiento jurídico. Esto ha ocurrido en el caso de la homologación de productos, donde muchas normas de carácter técnico se han convertido en obligatorias al estar integradas (por ratificación u adopción) en Leyes nacionales, Reales Decretos, y sobre todo, Directivas.

Esto nos da una idea del prestigio internacional de estas organizaciones en el ámbito del comercio, la industria y la economía. Prestigio, que sin duda, proporciona la confianza necesaria para que los países acepten sus normas como si de normas internacionales se trataran. Esta confianza, junto con la necesidad de unificar criterios a nivel internacional, es lo que mueve a los gobiernos a ratificar estas normas en sus países.

Por todos estos motivos, cada vez más empresas optan por utilizar estas normas internacionales como garantía de calidad.

En el caso de la Universidad y sobre todo, del Plan Nacional de Evaluación de la Calidad de las universidades, la Universidad española está implantando y desarrollando procesos de evaluación de sus tres ámbitos más relevantes: enseñanza, investigación y servicios. Estos procesos responden por un lado al objetivo de proporcionar información a la sociedad sobre la calidad de los servicios que ofrece su Universidad, y por otro, detectar los puntos fuertes y débiles de la institución así como las propuestas de mejora para aumentar la calidad universitaria. En el sistema universitario, la calidad entendida como mejora continua es un valor en alza, cuyo logro implica una serie de requisitos. (Rey García, A., 1998). Según este autor, uno de estos requisitos es disponer de información relevante y actualizada para la gestión, es decir, un sistema de indicadores que refleje el desenvolvimiento real de la institución y que incluya estadísticas relativas a la satisfacción de los usuarios, eficiencia interna de los procesos, y al nivel de innovación y aprendizaje del personal que la componen.

Dentro de la Universidad, la Biblioteca constituye un servicio clave de apoyo a las dos funciones que constituyen la razón de ser de la institución universitaria: la investigación o creación de conocimiento y la enseñanza de ese conocimiento, o lo que es lo mismo comunicarlo a la sociedad. No en vano, todo el mundo admite que las universidades más prestigiosas del mundo en términos de docencia e investigación son las que disponen de las mejores bibliotecas.

Por todo esto, podremos afirmar que si la biblioteca es una unidad tan importante dentro de la universidad, su gestión no lo es menos. Y, ya que son referentes para la sociedad no sólo deberían estar certificadas en calidad, también deberían estarlo en medioambiente, y por supuesto, en prevención de riesgos laborales, ya que en ellas trabaja mucho personal. 
Recordemos que estamos hablando de crear una forma unificada de gestionar en la organización las áreas de calidad, medio ambiente y prevención de riesgos laborales elaborando unas partes comunes a las tres y otras que serán específicas de cada una de ellas.

De esta idea se deduce que el sistema integrado contará con un tronco común para las tres áreas y de este tronco brotarán unas ramas específicas de cada área.

Es cierto que no es sencillo, pero no hay que tener miedo a la hora de empezar la labor de la integración, ya que el resultado merece la pena el esfuerzo. Recordando una frase célebre del considerado mayor filosofo de la administración, Peter Drucker: "dónde hay una empresa de éxito, alguien tomó alguna vez una decisión valiente".

Recordemos que una de las ventajas de tener un sistema de gestión integrado es la unificación del soporte documental. Pero no sólo se trata de unificar la documentación, hay que dotarla de coherencia para que se perciba la integración como efectiva y estable.

Las principales funciones del sistema documental unitario son establecer los mecanismos de identificación de todos los documentos que forman parte del mismo, la forma de elaborar los procedimientos e instrucciones, la aprobación y control de su difusión, la revisión documental, etc.

Cada organización es libre para elaborar sus propias instrucciones y los procedimientos que crean más convenientes. En este documento se utiliza un modelo de gestión integrada como propuesta, sin pretender ser el paradigma del perfecto modelo de gestión integral.

Se presentará a mostrar a continuación los niveles documentales que se pueden utilizar y la propuesta de procedimientos e instrucciones que se consideran pueden servir de modelo al lector para diseñar el sistema de gestión integrada adaptado a su propia organización. 


\section{HIPÓTESIS}

Con este trabajo pretendo demostrar cómo es posible hacer un Sistema de Gestión Integral de la Calidad, Medioambiente y Prevención de Riesgos Laborales en la Biblioteca de la Universidad de Granada, y como esto tendría muchas ventajas para la biblioteca y como consecuencia, para sus usuarios, el resto del mundo universitario y la propia sociedad.

Continuaré explicando cómo se puede hacer un sistema de Gestión Integrado de los tres sistemas. Y concluiré citando las ventajas que tendría.

Se hará un modelo ficticio pero específico de la Biblioteca Universitaria de Granada. (BUG).

\section{OBJETIVOS QUE SE PERSIGUEN}

- Elaborar una metodología para realizar la integración de la gestión de la prevención de riesgos laborales, la calidad y la gestión ambiental en las bibliotecas universitarias.

- Realizar un modelo para la gestión de la prevención, ambiental y de la calidad en las bibliotecas de las Universidades.

- Proponer un modelo específico integrado para la Biblioteca Universitaria de Granada que pueda servir para otras bibliotecas.

\section{METODOLOGÍA}

Analizar las tres normas ISO 9001:2015, ISO 14001:2015 Y OHSAS $18001: 2007$.

Conocer a partir de una encuesta a Rebiun (Red de Bibliotecas Universitarias Españolas) qué sistema o sistemas de gestión tienen implantados y si existen sistemas de gestión integrados en las bibliotecas universitarias españolas.

Empezaré haciendo un análisis de cada uno de los sistemas de gestión, Sistema de Gestión de la Calidad, de Gestión del Medioambiente y de Gestión de la Seguridad y Salud de los trabajadores, según la norma específica, ISO u OHSAS, que define los requisitos necesarios para implantar cada uno de ello.

Se hará un modelo teórico, pero específico de la Biblioteca Universitaria de Granada (BUG) 


\section{SISTEMA DE GESTION DE LA CALIDAD}

El concepto de calidad se ha ido transformando a lo largo del tiempo.

La gestión de la calidad fue la primera que se abordó desde la Organización Internacional para la Estandarización (ISO).

La Comisión Técnica 176 de la ISO fue establecida en 1980 para elaborar y mantener una serie integrada de normas básicas o normas genéricas de Gestión de la Calidad y de la Garantía de Calidad, junto con todas las normas esenciales de soporte que podrían hacer posible que las organizaciones la implantasen sobre una base integral.

Nacieron así, las normas 9000 con el objetivo de ser un instrumento que permitiese a las empresas suministrar productos o servicios que garantizaran la satisfacción de los clientes o usuarios. Daban respuesta a la necesidad de las organizaciones de precisar los requisitos que debería tener un sistema de gestión de la calidad.

La primera edición de estas normas se publicó en 1987. Posteriormente fueron modificadas en 1994, 2000, 2008 y 2015.Nacieron aunando los principios que existían en multitud de normas de calidad en distintos países, aunque su punto de referencia fueron las normas BS 5750 emitidas por el Instituto Británico de Normas de Gran Bretaña. El principal objetivo de esta norma era utilizar parámetros generales comunes en la mayoría de los países en los que se implementara. Por esto, quizás, desde su nacimiento se pretendía que fueran normas de aplicación a todo tipo de organización, independientemente de su tamaño o su sector de actividad. Persiguen involucrar a todo el proceso de producción, desde el principio de la idea.

Esta evolución nos ayuda a comprender de dónde proviene la necesidad de ofrecer una mayor calidad del producto o servicio que se proporciona al cliente, o a la sociedad, y como se ha ido involucrando a toda la organización en la consecución de este fin.

Lejos de la creencia general, son normas flexibles que permiten adaptarlas, ya sea agregando o eliminando componentes o requerimientos del sistema de calidad. No se pretende crear uniformidad en los sistemas de calidad.

La familia de normas ISO 9000 vigente actualmente está compuesta por:

- ISO 9000:2005 "Sistemas de gestión de la calidad. Principios y vocabulario"

- ISO 9001:2015 "Sistemas de gestión de la calidad. Requisitos.

- ISO 9004:2009 "Gestión para el éxito sostenido de una organización. Enfoque de gestión de la calidad. 
Según el modelo de la norma ISO 9000, la calidad es el "grado en el que un conjunto de características inherentes cumple con los requisitos", entendiéndose por requisito la "necesidad o expectativa establecida, generalmente implícita u obligatoria"

Es decir, y en un lenguaje de andar por casa, que la calidad es conformidad con los requisitos del cliente que es parte interesada. La calidad consiste en apreciar la manera en que un producto o servicio es visto por el cliente, ya sea este externo, o interno.

\section{Principios de la gestión de la calidad}

El sistema de gestión de la calidad está basado en 8 principios de gestión, que son el punto de referencia para que la dirección de la organización se oriente a la consecución de establecer una filosofía que garantice la mejora del desempeño y el éxito al implementar el sistema de gestión de calidad. Podríamos considerar que los principios son las premisas que la alta dirección transmite al resto de la organización para orientarla hacia la mejora de su actividad.

De nada sirve que una organización implante un sistema de gestión de la calidad que cumpla con los requerimientos detallados en la norma ISO 9001 si no sigue los principios de gestión de la calidad.

Estos principios no deben ser cerrados, deben ser flexibles para que al implantarse la norma ISO 9001 la empresa no se resienta. La norma debe tomarse como un sistema de referencia, como un proceso de mejora continuo que consiga que la empresa se auto organice con referencia a la norma ISO 9001.

\section{Estos principios son:}

1. Enfoque basado en procesos:

2. Mejora continuara

3. Documentación del sistema de gestión de la calidad

4. Compromiso de la dirección

5. Enfoque al cliente

6. Control de los cambios

7. Comunicación interna.

8. Formación del personal. 


\section{SISTEMAS DE GESTIÓN DE LA CALIDAD. ISO 9001:2015. REQUISITOS DEL SISTEMA}

Para especificar los requisitos de los sistemas de gestión de la calidad se actualiza la norma ISO 9001:2008 quedando esta anulada, y siendo sustituida por la ISO 9001:2015.

En ella se establecen los requisitos generales del sistema de gestión de la calidad y los requisitos de la documentación.

Especifica los requisitos para un sistema de gestión de la calidad cuando una organización necesita:

- Demostrar su capacidad para satisfacer al cliente/usuario ofreciéndole servicios y productos que satisfagan los requisitos de los clientes y los requisitos legales.

- Cuando aspira a mejorar la satisfacción del cliente/usuario a través de la aplicación eficaz del sistema.

Todos los requisitos de esta norma son genéricos y se pretenden que sean aplicables a cualquier tipo de organización.

\section{Introducción de la norma}

En su introducción, la norma ISO 9001:2015 explica el contexto de la organización y su influencia en la estructura del sistema de gestión de calidad (SGC). La norma no implica una necesidad de uniformidad en cuanto a la estructura del sistema. Esta clausula tambien señala el aumento en la satisfacción del cliente.

Menciona las normas de la serie 10000 como referentes y apoyo a la implementación de un SGC.

\section{Enfoque basado en procesos}

Refiriéndose al enfoque basado en procesos, nos dice la norma que se alcanzan resultados consistentes y predecibles de formas más eficaz y eficiente cuanto las actividades se comprenden y gestionan como procesos interrelacionados que funcionan con coherencia.

Además del enfoque basado en procesos, esta Norma Internacional, incorpora el ciclo Planificar-Hacer-Verificar-Actuar (PHVA) y el pensamiento basado en riesgos. 


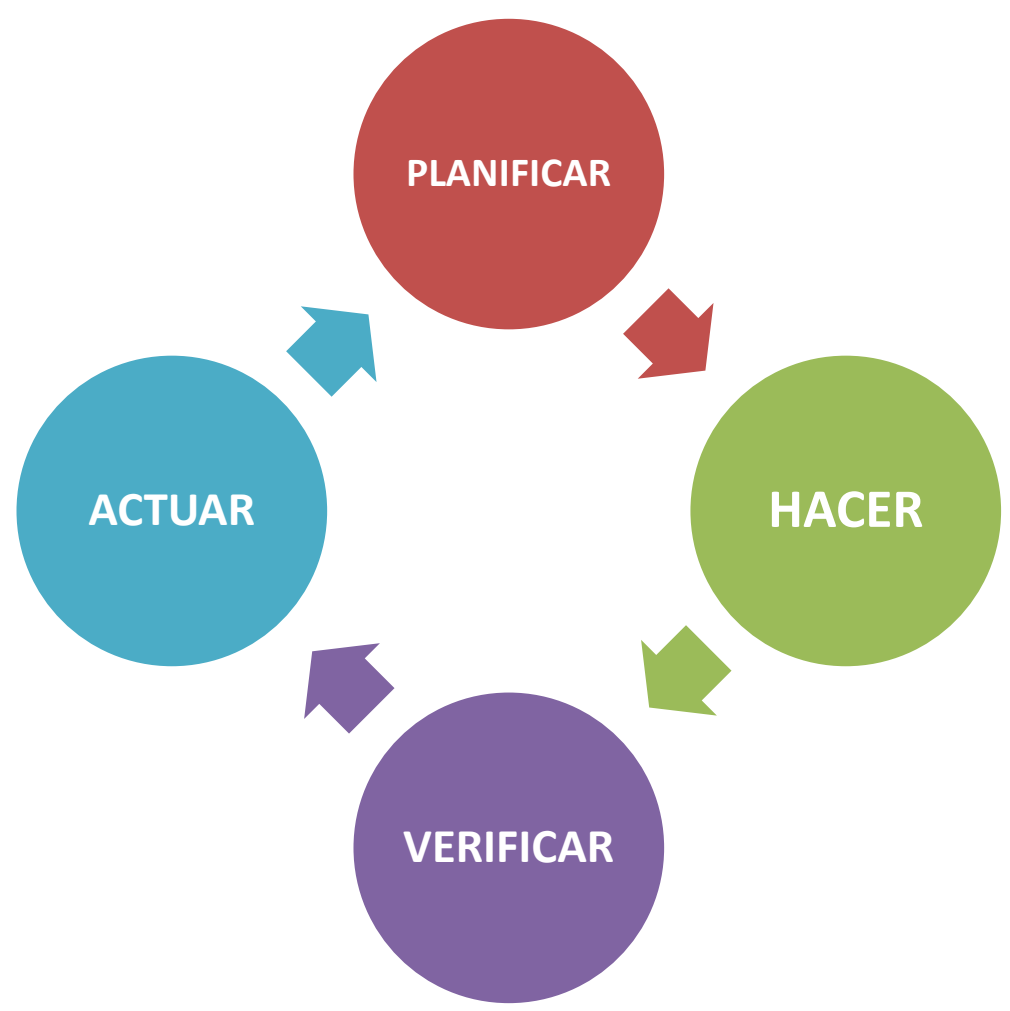

El ciclo PHVA permite a la organización asegurarse de que sus procesos cuenten con recursos y se gestionen adecuadamente, y que las oportunidades de mejora se determinen para actuar en consecuencia.

El pensamiento basado en riesgos es un requisito completamente nuevo de la norma. Esta clausula permite a la organización determinar qué factores que podrían ser causa de que sus procesos y sistema de gestión de la calidad se desvíen de los resultados planificados, para actuar poniendo controles preventivos para minimizar los efectos negativos y maximizar el uso de las oportunidades cuando vayan surgiendo. Hace referencia a la norma ISO 31000 que es la herramienta para evaluar la gestión de riesgos.

Continua la norma, enfatizando la importancia de cumplir los requisitos y de considerar constantemente las necesidades y expectativas futuras. Recuerda, que esto es un desafío para las organizaciones que se encuentran en un entorno cada vez más dinámico y complejo. $Y$ aconseja que para mejorar estos objetivos, la organización podría considerar necesario adoptar distintas formas de mejora además de la corrección y la mejora continua, tales como la innovación, la reorganización e incluso un cambio abrupto.

Todos los procesos se pueden gestionar utilizando el concepto PHVA.

La nueva versión de la norma contiene la nueva "estructura de alto nivel", lo que aumenta la compatibilidad con otras normas y su integración. 
Los requisitos para estos procesos se especifican en los puntos 4, 5, 6, 7 y 8 de la norma.

\section{La organización y su contexto}

El punto 4.1 de la norma requiere comprender la organización y su contexto. Se trata de un requisito nuevo. La organización tendrá que determinar el contexto externo e interno que le afecta.

El punto 4.2 indica que es necesario comprender las necesidades y expectativas de las partes interesadas. En la anterior sólo se enfocó al cliente. Ahora la norma presenta a las partes interesadas que son pertinentes al sistema de gestión de la calidad, y los requisitos pertinentes de estas partes para el sistema de gestión de la calidad.

La organización debe realizar el seguimiento y la revisión de la información sobre estas partes interesadas y sus requisitos pertinentes.

\section{Alcance del sistema de Gestión}

En el punto 4.3 se muestra la necesidad de determinar el alcance del sistema de gestión de la calidad. Este requisito se relaciona con el Manual de Calidad de la versión anterior. El Manual ya no es obligatorio, pero sí lo sigue siendo la necesidad de determinar y documentar el alcance del sistema de gestión de la calidad.

El punto 4.4 está relacionado con el sistema de gestión de la calidad y sus procesos. Se mantienen los requisitos de la versión anterior, y los nuevos están relacionados con la determinación de los riesgos y oportunidades, así como la asignación de responsabilidades y autoridades de los procesos.

En cuanto al control de la documentación y los registros se propone mantener información documentada para apoyar la operación de sus procesos y conservarla para asegurarse de que los procesos se realizan según lo planificado.

\section{Liderazgo}

El punto 5 promueve el compromiso de la dirección. Esta nueva versión enfatiza la importancia de impulsar el conocimiento y el apoyo de otras personas que contribuyen a la eficacia del SGC. Se requiere, y esto sí es nuevo con respecto a la norma anterior, que la alta dirección se haga responsable de la eficacia del SGC.

En cuanto al enfoque al cliente es un nuevo requisito la determinación de los riesgos y oportunidades en relación con la conformidad de productos y servicios. También es nuevo la consideración de los requisitos legales y normativos.

Ahora no se requiere designar a un representante de la dirección. Sin embargo, 
se describe muy detalladamente las funciones, responsabilidades y autoridades dentro del SGC, lo que implica que se pueden asignar a varias personas.

Los requisitos para la Política de Calidad siguen siendo los mismos que en la anterior norma. La organización debe establecer objetivos de calidad. Estos objetivos deben:

- Ser coherentes con la política de calidad.

- Ser medibles

- Tener en cuenta los requisitos aplicables

- Ser relevante para la conformidad de los servicios y productos y para alcanzar la satisfacción del cliente/usuario.

- Ser supervisados.

- Ser supervisados.

- Actualizarse.

La organización debe retener la información documentada sobre los objetivos de la calidad.

\section{Planificación}

El punto 6 se centra en la Planificación para el sistema de gestión de la calidad. Es un nuevo requisito que al planificar el SGC, la organización tiene que determinar los riesgos y oportunidades que afectan a la organización, así se garantiza que el sistema de gestión puede lograr sus resultados previstos y se pueden prevenir los efectos no deseados. Con esto se puede lograr la mejora continua.

Al planificar el sistema de gestión de la calidad, la norma pide que se consideren las cuestiones referidas en el punto 4.1 recordando que la organización debe determinar el contexto externo e interno que le puede afectar, y los requisitos del apartado 4.2 referido a la necesidad de determinar y documentar el alcance del sistema de gestión de la calidad.

Se determinarán los riesgos y oportunidades para:

- Asegurar que el sistema de gestión podrá lograr sus objetivos.

- aumentar los efectos deseables.

- prevenir o reducir efectos no deseados.

- lograr la mejora. 
La organización planificará:

- las acciones para abordar estos riesgos y oportunidades que puedan surgir.

- la manera de integrar e implementar las acciones en sus procesos del sistema de gestión.

- evaluar la eficacia de estas acciones.

Estas acciones serán proporcionales al impacto potencial sobre la conformidad de productos, o servicios.

Cuando se abordan los riesgos y oportunidades, no se olvidará la organización de evitar los riesgos, la toma de riesgos persiguiendo la oportunidad, la eliminación de la fuente del riesgo, cambios en la probabilidad o en las consecuencias...

\section{Objetivos}

En cuanto a los objetivos de calidad y la planificación para conseguirlos la organización debe establecer objetivos de calidad a las funciones pertinente, niveles y procesos. Esto ya se tenía en cuenta en la anterior versión de la norma, pero ahora se relatan más detallados.

Los objetivos de calidad deben:

- $\quad$ ser coherentes con la política de calidad.

- Tener en cuenta los requisitos aplicables.

- Ser relevantes para la conformidad de los productos y servicios y para alcanzar la satisfacción del usuario/cliente.

- Ser relevantes para la conformidad de los productos y servicios y para alcanzar la satisfacción del usuario/cliente.

- Ser relevantes para la conformidad de los productos y servicios y para alcanzar la satisfacción del usuario/cliente.

- Ser comunicados.

- Ser comunicados.

Al planificar como alcanzar los objetivos de calidad, la organización determinará:

- Qué se hará

- Que recursos necesita.

- Quién será el responsable.

- Cuando se completará.

- Cómo se evaluarán los resultados. 
Si la organización necesita hacer un cambio en el sistema de gestión, se hará de manera planificada y sistemática. Tendrá en cuenta:

- Cuál es la finalidad del cambio y sus posibles consecuencias.

- Si afectará la integridad del sistema de gestión.

- Si se disponen de recursos suficientes.

- A quién se asignarán o reasignarán la responsabilidad y autoridad para gestionar el cambio.

La norma también desarrolla e identifica los distintos recursos humanos y materiales, que intervienen en la realización de un determinado producto o servicio, y que la organización debe aportar si quiere estar conforme a las directrices de la norma. Esta nueva versión hace hincapié en la consideración de las capacidades y las limitaciones en recursos internos existentes, y en los recursos que se cubren con proveedores externos.

En cuanto a las personas la organización debe determinar y proporcionar las personas necesarias para la implementación eficaz del sistema de gestión. Debe definir y comunicar las funciones y responsabilidades del personal. Si es necesario se facilitará la formación necesaria. De esta formación se mantendrán registros. Se hará una campaña de difusión y sensibilización global a toda la organización para explicar la importancia del sistema de calidad, y las posibilidades de mejora de este. Y se mostrará las responsabilidades y consecuencias que se derivan de su incumplimiento.

En cuestión de infraestructura, la norma sigue teniendo los mismos requisitos que la anterior.

La organización determinará, proporcionará y mantendrá la infraestructura necesaria para conseguir la conformidad con los requisitos. Si es necesario, la infraestructura incluirá:

- edificios y servicios asociados.

- Equipos incluyendo hardware y software.

- El transporte.

- La información y las comunicaciones.

En lo referente al ambiente para el funcionamiento de los procesos la organización tiene que determinar, proporcionar y mantener el ambiente de trabajo necesario para el funcionamiento de sus procesos y logar la conformidad en sus servicios o productos. 
El término "ambiente de trabajo" está relacionado con aquellas condiciones bajo las cuales se realiza el trabajo, incluyendo factores físicos, ambientales y de otro tipo (ruido, temperatura, humedad, iluminación). En este aspecto la norma anterior y la actualizada no han cambiado.

Cuando se utilizan seguimiento o medición para evidenciar la conformidad de los productos y servicios con los requisitos especificados, la organización debe determinar que recursos serán necesarios para garantizar un control valido y fiable de la medición de los resultados. La diferencia con la norma anterior, ISO 9001:2008 es que esta última sólo se centra en el equipo de seguimiento y medición.

Ahora la organización se asegurará de que los recursos proporcionados:

- Son adecuados al tipo específico de actividades de seguimiento y medición que se están haciendo.

- Se mantienen para asegurar su continua adecuación a su producto.

Se conservará la información documentada apropiada como prueba evidente de que los recursos de seguimiento y medición son los adecuados para su propósito.

Cuando la trazabilidad de la medición sea un requisito legal, o una expectativa o requisito del cliente o usuario, o la organización considere que es una parte importante o esencial para dar confianza en los resultados de la medición, los instrumentos de medir deben:

- Estar verificados o calibrados a intervalos específicos, contra patrones de medición trazables a patrones de medición nacionales o internacionales. Si se da el caso de que no existan esos patrones, la base utilizada para la calibración se mantendrá como información documentada.

- Se identificarán para determinar su estado de calibración.

- Se protegerán contra daños deterioros o ajustes que pudieran invalidar su estado y por tanto sus mediciones posteriores.

La organización debe determinar la validez de los resultados de anteriores mediciones y si estos se han podido ver afectados por instrumentos defectuosos y tomará las medidas apropiadas en caso de ser necesarias.

Es un nuevo requisito el conocimiento organizacional. La norma actualizada lo reconoce como un recurso importante. La organización tiene que determinar los conocimientos necesarios para ejecutar sus procesos y lograr la conformidad de sus servicios y/o productos.

El conocimiento organizacional puede incluir información como la propiedad intelectual. 
Para obtener los conocimientos necesarios la organización puede considerar:

- Fuentes externas, como normas, instituciones académicas, conferencias).

- Fuentes internas como pueden ser los fracasos y proyectos exitosos y la experiencia de expertos dentro de la organización.

La competencia y la conciencia, a diferencia de la versión anterior, se dividen en diferentes cláusulas en esta versión de la norma. Esto es así para enfatizar su importancia y para proporcionar requisitos más detallados.

La organización para determinar la competencia de su sistema de gestión deberá:

- Determinar la competencia necesaria de la persona o personas que hacen el trabajo y que afecta al resultado de la calidad del servicio o producto.

Asegurarse de que estas personas son competentes sobre la base de una formación adecuada, capacitación y experiencia.

- Tomar acciones, si fuera necesario, para adquirir la competencia necesaria y evaluar la eficacia de las acciones tomadas.

- Retener la información documentada como prueba física de la competencia.

Para asegurarse de que la organización toma conciencia de la importancia de su sistema de gestión de la calidad las personas que hacen el trabajo bajo su control deben tener en cuenta:

- La política de calidad

- Los objetivos para la calidad que se quieran conseguir.

- Su contribución a la eficacia del sistema de gestión.

- Las consecuencias de no ajustarse a los requisitos del sistema de gestión de la calidad.

En lo relativo a comunicación, la versión anterior de la norma se refería a la comunicación interna. Esta nueva versión incluye tanto la comunicación interna, como la externa y requiere la definición de la responsabilidad y los métodos de comunicación.

Por esto, la comunicación incluirá:

- Qué se va a comunicar.

- Cuando se comunicará.

- A quién se comunicará.

- La forma de comunicarse. 
La información documentada requerida por la Norma Internacional ISO 9001:2015 y los registros ahora pertenecen a la misma categoría: Información documentada. Los requisitos siguen siendo los mismos que los de la anterior versión.

El sistema de gestión de la calidad debe incluir:

- La información documentada que requiera la ISO 9001:2015.

- La información documentada que la organización determine necesaria para la eficacia del sistema de gestión.

La cantidad de información documentada para un sistema de gestión de la calidad difiere de una organización a otra debido a:

- que el tamaño de la organización varia, así como su tipo de actividades, procesos y servicios o productos.

- La complejidad de los procesos y las interacciones

- La competencia de las personas que componen la organización.

Al crear y actualizar la información documentada, la organización se debe asegurar de que

- La identificación y descripción sean correctas (título, autor, número de referencia).

- El formato que va a utilizar (versión de software, gráficos, idioma).

- La documentación está revisada y aprobada y es idónea y adecuada.

La información documentada requerida por el sistema de gestión de calidad y por la ISO 9001:2015 se debe controlar para asegurar:

- Que esté disponible y adecuada para utilizarla donde y cuando sea necesario.

- Que esté protegida de manera adecuada, ya que debemos tener en cuenta que es importante mantener la confidencialidad, y evitar que se deteriore.

Para controlar la información documentada de manera adecuada, la organización puede responderse si:

- Podrá distribuirla, acceder a ella, recuperarla y utilizarla.

- Si su almacenamiento y conservación es el adecuado, incluyendo la preservación de la legibilidad.

- Si el control de los cambios, por ejemplo, de versiones es factible.

- Si la retención y disposición son las mejores. 
Si la organización determina que necesita información documentada de origen externo, y que sea necesaria para la gestión de la calidad, la tendrá que controlar también.

En cuanto a planificación, la organización debe ejecutar y controlar los procesos necesarios para cumplir con los requisitos de sus productos y sus servicios, tal y como se indica en el apartado 4.4. También debe implementar las acciones determinadas para abordar riesgos y oportunidades según el apartado 6.1.

Todo esto se llevará a cabo para:

- Determinar los requisitos para los productos y servicios.

- Establecer criterios para los procesos y para aceptar los servicios y productos.

- Aplicar el control sobre los procesos, de acuerdo con los criterios.

- Determinar los recursos que serán necesarios para lograr la conformidad.

- Retener la información documentada, en la medida necesaria, para tener la total confianza en que los procesos se han llevado a cabo según lo previsto, y para demostrar la conformidad con los requisitos.

Los requisitos de la norma actualizada en cuanto a planificación y control operacional, son los mismos de la versión anterior que se desarrollaban bajo el epígrafe: Planificación de la realización del producto.

La planificación será adecuada a las operaciones de la organización. Esta controlará los cambios planificados y revisará las consecuencias de estos cambios. Comprobará que las medidas tomadas para minimizar los efectos negativos son las adecuadas. Se asegurará de que los procesos externalizados se controlan de acuerdo con el punto 8.4 que se desarrolla más adelante.

\section{Determinación de los requisitos para los productos y servicios.}

Los requisitos son prácticamente los mismos que la norma ISO 9001:2008. La diferencia está en que ahora se hace hincapié en la comunicación sobre el tratamiento de la propiedad con el cliente.

Los procesos para la comunicación con el cliente, serán los relativos a:

- La información relacionada con los servicios y productos.

- Las consultas, contratos o atención de pedidos, incluyendo los cambios.

- La obtención de puntos de vista y percepciones de los clientes, incluyendo sus quejas. 
- La manipulación o el tratamiento de la propiedad del cliente.

- Requisitos específicos para las acciones de contingencia, si así se procede.

En cuanto a los requisitos relacionados con los productos y servicios, la organización debe establecerlo, implementarlos y mantener un proceso para que queden claros a todas las partes.

La organización se asegurará de que:

- Se definan los requisitos de los productos y servicios que la organización crea necesarios, y los requisitos legales y reglamentarios aplicables en cada caso.

- Se tiene la capacidad de cumplir con los requisitos definidos, y para tratar las quejas que surjan sobre los servicios y productos que ofrezca.

Según sea necesario, la organización revisará:

- Los requisitos que especifique el cliente.

- Los requisitos no establecidos por el cliente, pero necesarios para el uso especifico o previsto por él.

- Los requisitos normativos y legales adicionales.

- Los requisitos del contrato o pedido que difieran de los expresados anteriormente.

Los requisitos también pueden incluir aquellos derivados de las partes interesadas.

La organización llevará a cabo la revisión de los requisitos antes de comprometerse a suministrar un servicio, o un producto.

Se asegurará de que se resuelven los requisitos que difieran de los especificados para el producto o servicios que ofrece.

Si el cliente no aporta información documentada de los requisitos, la organización se encargará de que estos queden especificados y confirmados antes de la aceptación.

Se conservará la información documentada que describe o modifica los requisitos, y si alguno de ellos se modifica, la organización se asegurará de que queda documentado y de que el personal ha sido informado. 


\section{Diseño y/o desarrollo de servicios y productos}

Los requisitos de este apartado en la nueva norma, son los mismos que en la anterior.

Será necesario establecer un proceso de diseño y desarrollo cuando los requisitos detallados para los productos y/o servicios de la organización no estén especificados previamente, o no han sido definidos por el cliente. La organización establecerá, implementará y mantendrá un proceso para el diseño y/o desarrollo.

Para determinar las etapas y controles para el diseño y/o desarrollo, la organización debe considerar:

- La naturaleza, duración y complejidad de las actividades de diseño y desarrollo.

- Los requisitos específicos para etapas particulares del proceso.

- La verificación y validación requeridas.

- Las responsabilidades y autoridades implicadas en el proceso de diseño y/o desarrollo.

- La necesidad de participación de los clientes y usuarios en este proceso.

- La información documentada y necesaria para confirmar que se han cumplido los requisitos de diseño y desarrollo.

Los elementos de entrada deben ser los adecuados para el diseño y desarrollo. Las entradas serán completas. Si hay conflictos serán solucionados.

La organización determinara:

- Los requisitos esenciales para el tipo específico de productos y servicios que estén siendo diseñados o desarrollados.

- Los requisitos legales y reglamentarios.

- Las normas y códigos de prácticas que la organización se haya comprometido a cumplir.

- Los recursos necesarios para el diseño y desarrollo. Se tendrán en cuenta los recursos externos y los internos.

- Los posibles fallos y las consecuencias que tengan.

- El nivel de control que se espera en el proceso de diseño y desarrollo de los clientes $u$ otras partes pertinentemente interesadas.

\section{Control de diseño y desarrollo}

Esta cláusula, en la versión antigua de la norma se la denominaba Proceso de compras.

Aunque el nombre ha cambiado los requisitos son los mismos. Los controles que 
se apliquen al proceso de diseño y/o desarrollo deben asegurar que:

- Están claramente definidos los resultados que se quieran lograr con las actividades de diseño y desarrollo.

- Realizan las revisiones del proceso, según este previsto hacerlo.

- Realiza la verificación para asegurar que los resultados cumplen con los requisitos de las entradas del diseño y desarrollo.

- La validación se lleva acabo para asegurar que el producto o servicio resultante va a cumplir con los requisitos para su función específica o el uso previsto.

\section{Salidas (resultados) del diseño y desarrollo.}

Igual que en la anterior versión la norma pide a la organización que se asegure de que las salidas del diseño y desarrollo:

- Cumplen los requisitos de entrada.

- Son adecuados para los procesos subsecuentes para la provisión de los productos $\mathrm{y} / \mathrm{o}$ de los servicios.

- Incluyen o hacen referencia al seguimiento y medición y a los criterios de aceptación.

- Aseguran que los productos o servicios que se presten o produzcan, son aptos para el fin previsto y su uso seguro y adecuado.

La documentación que resulte del proceso de diseño y desarrollo será conservada adecuadamente por la organización.

Si hay cambios en el diseño y desarrollo la organización los revisará, controlará e identificará. Se evitará que haya un impacto adverso sobre la conformidad de los requisitos.

La documentación sobre todos los cambios en el diseño y desarrollo será debidamente organizada, protegida y conservada.

\section{Control de los productos y servicios obtenido externamente}

Aunque el nombre de esta cláusula ha cambiado, en la norma anterior se llamaba "Proceso de compras", los requisitos con respecto a esta no han cambiado.La organización debe asegurarse de que los procesos, productos y servicios obtenidos externamente, sean conforme a los requisitos especificados.

Se aplicaran los requisitos especificados para el control de productos y servicios obtenidos externamente o subcontratados cuando:

- Los productos y servicios son proporcionados por proveedores externos para 
su incorporación en los servicios y productos de la organización.

- En nombre de la organización se proporcionan directamente al cliente productos y servicios.

- La organización decide externalizar algún proceso, o parte de él.

Es responsabilidad de la organización establecer y aplicar criterios para la evaluación, selección, seguimiento del desempeño de los proveedores externos, en base a su capacidad para suministrar los productos o servicios, de acuerdo con los requisitos especificados.

De nuevo recordar que es responsabilidad de la organización la buena gestión de la información documentada.

\section{Tipo y alcance del control de los suministros obtenidos externamente}

Para determinar los controles que se aplicarán a la obtención externa de procesos, productos o servicios la organización tendrá en cuenta:

- El impacto potencial de estos sobre la capacidad de la organización para cumplir los requisitos del cliente y también los legales y reglamentarios aplicables en cada caso.

- La eficacia percibida de los controles aplicados por el proveedor externo.

La organización verificará constantemente que los productos, servicios y procesos obtenidos externamente no afectan negativamente a su capacidad de cumplir con los requisitos de sus clientes.

\section{Información para proveedores externos}

La organización debe comunicar a los proveedores externos los requisitos aplicables para:

- Los productos y servicios obtenidos o los procesos que se llevan a cabo en nombre de la organización.

- La aprobación de productos, servicios, procesos, métodos...

- La competencia y cualificación del personal.

- Sus interacciones con el sistema de gestión de calidad de la organización.

- El seguimiento y control del desempeño de los proveedores externos. Aquí, la norma hace más hincapié que en la versión anterior.

- Las actividades de verificación que la organización o su cliente, tengan la intención de realizar en las instalaciones del proveedor externo. 


\section{Producción y/o prestación del servicio.}

La organización implementará condiciones controladas para la producción y/o prestación del servicios, incluyendo las actividades de entrega y posterior a la entrega.

Esto incluirá desde la información documentada que defina las características del producto o servicio, pasando por las actividades a realizar y sus resultados, el uso de las infraestructuras, la competencia y cualificación de las personas implicadas y las actividades de liberación, entrega y posteriores a la entrega.

\section{Identificación y trazabilidad}

Igual que se pedía en la norma anterior, si es necesario, la organización debe utilizar medios adecuados para garantizar la conformidad de los productos y servicios desde la salida del proceso y a lo largo de toda la producción.

Las salidas del proceso son los resultados de todas las actividades que estén listos para su entrega al cliente o usuario, o para un cliente interno.

\section{Los bienes pertenecientes a los clientes o proveedores externos}

La organización debe cuidar los bienes o propiedad del cliente mientras estén bajo el control de ella o estén siendo utilizados por la misma. Los protegerá, y salvaguardará y en caso de deterioro la organización debe informar al cliente de ello y mantener registros. La novedad de este apartado es que los requisitos se extienden también a los bienes pertenecientes a los proveedores externos.

No olvidar que dentro de estos bienes no sólo nos referimos a cosas tangibles. La propiedad intelectual y los datos personales son también propiedad del cliente.

\section{Preservación}

La organización se asegurará de la preservación de las salidas del proceso durante la producción y prestación de servicios, para mantener la conformidad con los requisitos.

\section{Actividades posteriores a la entrega}

En la norma actualizada ISO 9001:2015 las actividades posteriores a la entrega son puestas aparte como una cláusula separada. En la anterior versión de la norma estas actividades se mencionaban en varias partes.

Las actividades posteriores a la entrega pueden incluir las acciones que cubra la garantía, las obligaciones contraídas por contrato como por ejemplo los servicios de mantenimiento y otros servicios suplementarios como puede ser el reciclaje.

La organización, y según la clausula $8,5,1$ de la norma, no sólo controlará las 
actividades de entrega. También se hará cargo de las actividades de post entrega ya que esto también puede afectar a sus productos o servicios y a que se cumplan o no los requisitos especificados.

Pues bien, esta cláusula, refiriéndose concretamente a las actividades posteriores a la entrega especifica que la organización debe cumplir con los requisitos para las actividades posteriores a la entrega asociados a sus productos y servicios. Teniendo esto en cuenta, la organización considerará:

- Los riesgos asociados con los productos y servicios.

- La naturaleza, el uso y vida útil de estos.

- La retroalimentación del cliente.

- Los requisitos legales y reglamentarios.

\section{Control de los cambios}

No sólo es importante que se controlen las actividades de post entrega. También lo es el control de los cambios. Por esto, la norma actualizada hace hincapié en este control definiéndolo en una clausula separada.

La organización debe revisar y controlar los cambios no planificados que sean esenciales para la producción y prestación de servicios. Así se asegura la continuidad de la conformidad con los requisitos especificados.

De nuevo se recuerda la importancia de la correcta y adecuada gestión de la información documentada. Esta describirá los resultados de la revisión de los cambios, el personal que los autoriza y cualquier acción que se estime necesaria.

\section{Entrega de productos y servicios}

En la anterior norma no se hacía mención a este requisito. Ahora se le menciona como una parte del proceso a la que prestar atención.

Es un requisito nuevo, que trata de la verificación del producto y la garantía de que este cumple con los requisitos.

La organización debe verificar que se cumplen los requisitos del producto y servicio, antes de su entrega. Lo hará aplicando las disposiciones planificadas por etapas. Se debe mantener evidencia de la conformidad con los criterios de aceptación.

Solamente se entregara el producto o servicio al cliente cuando las disposiciones planificadas para la verificación de su conformidad se hayan realizado satisfactoriamente, a menos que el cliente lo permita y los apruebe una autoridad pertinente.

Si esto ocurriera, la información documentada debe proporcionar trazabilidad hacia la persona o personas que autoricen la entrega del producto o servicio. 


\section{Control de los elementos resultantes del proceso, los productos y los servicios} no conformes.

Igual que en la versión anterior de la norma, se insta a la organización a controlar todas las salidas de procesos, productos y servicios que no se ajusten a los requisitos para poder identificarlas y controlarlas, para evitar su uso o entrega.

Se gestionarán las no conformidades y su impacto sobre la conformidad de sus productos y/o servicios. También se hará con los no conformes detectados después de la entrega, o durante la prestación del servicio.

Hay varias maneras de tratar los productos no conformes. Estas son:

- Corregir la no conformidad detectada.

- Informar al cliente.

- Tomar acciones apropiadas como pueden ser la segregación, contención, devolución o suspensión del suministro de los productos y/o servicios.

Cuando sean corregidas la no conformidades, se debe verificar la conformidad con los requisitos.

Se mantendrán registros de la naturaleza de las no conformidades y de cualquier medida que se haya tomado posteriormente, incluyendo cualquier concesión que se haya obtenido.

\section{Evaluación del desempeño. Seguimiento, medición análisis y evaluación.}

Como regla general la organización debe determinar:

- Qué elementos necesitan ser seguidos y medidos.

- Qué métodos de seguimiento, medición, análisis y evaluación, se van a utilizar para asegurar resultados válidos.

- En qué momento se van a ejecutar.

- En qué momento deben ser analizados y evaluados los resultados del seguimiento y la medición.

Se resaltan los requisitos de seguimiento y medición para los procesos y los productos o servicios en esta actualización de la norma.

La organización mantendrá la información documentada como evidencia de que se han implementado estos métodos de acuerdo con los requisitos determinados.

También se evaluará el desempeño de la calidad y la eficacia del sistema de gestión de la calidad. 


\section{Satisfacción del cliente}

Es importante hacer un seguimiento de la percepción de los clientes sobre el grado en que se cumplen sus requisitos.

Se obtendrá el punto de vista de los clientes y sus opiniones acerca de la organización y los productos o servicios que ofrece.

Será la propia organización la que determine que métodos quiere utilizar para obtener esta información. Como ejemplo se pueden citar: encuestas de satisfacción del cliente, encuestas de opinión, felicitaciones, informes de distribuidores, etc.

\section{Análisis y evaluación}

La organización debe determinar, recopilar, analizar y evaluar datos apropiados para demostrar la idoneidad y la eficacia de su sistema de gestión de la calidad. Se incluyen los datos generados del resultado del seguimiento y medición de otras fuentes.

Los resultados del análisis y la evaluación se utilizan para:

- Demostrar la conformidad de los productos y servicios.

- Evaluar y mejorar la satisfacción del cliente.

- Garantizar la conformidad y la eficacia del sistema de gestión de la calidad.

- Demostrar que la planificación ha sido un éxito.

- Evaluar el desempeño de los procesos.

- Evaluar el desempeño de los proveedores externos.

- Determinar la necesidad y oportunidades de mejora en el SGC.

Estos resultados también se usarán para dar información de entrada a la revisión por la dirección.

\section{Auditoria interna}

A diferencia de la exigencia de la anterior norma, ahora no se requiere un procedimiento documentado.

Las empresas que implantan sistemas de gestión tienen en las auditorias una de las herramientas más importantes de mejora. No sólo nos permiten detectar no conformidades. También nos permiten detectar oportunidades de mejora.

Se realizarán auditorías internas planificadas para proporcionar información sobre el sistema de gestión de calidad escogido e implantado, y comprobar si es:

- conforme con:

- los requisitos de la propia organización para su sistema de gestión de calidad 
- Ios requisitos de la Norma Internacional ISO 9001:2015.

- Se ha implementado y se mantiene de manera eficaz.

\section{Proceso de Auditoría}

La organización debe:

- Planificar un programa un programa de auditorías, que inlcuya la periodicidad, los métodos, los responsables, los requisitos de planificación y de presentación de informes, que deberán tener en cuenta los objetivos de calidad, la importancia de los procesos, los comentarios de los clientes/usuarios, los cambios que afectan a la organización.

- Definir los criterios de auditoría y el alcance de esta.

- Seleccionar auditores y desarrollar las auditorias para asegurar la objetividad e imparcialidad del proceso.

- Garantizar que los resultados obtenidos se reportan a la función pertinente.

- Proponer las correcciones necesarias y las acciones correctivas que se detecten.

- Conservar la documentación como evidencia de la ejecución de la auditoría y los resultados de esta.

A modo de orientación, la norma ISO 9001:2015 nos remite a la ISO 19011. Esta norma es ahora la guía y referencia internacional para la realización de auditorías de sistemas de gestión. Esta es una herramienta que nos ayudará a realizar auditorías, y a mejorar el proceso de las competencias de los auditores.

Tiene grandes ventajas:

- Es la referencia para hacer auditorías internas y auditorias por parte de los clientes a sus proveedores.

- Es aplicable a cualquier sistema de gestión y permite auditarlos independientemente o de forma integrada.

- Incorpora el concepto "riesgo de auditoria", concepto novedoso que está siendo incorporado en otras normas de gestión.

- Describe los métodos de realización de auditorías.

- Incorpora los criterios para la determinación de la competencia de los auditores que participan en auditorias de sistemas de gestión. 


\section{Revisión por la dirección}

La implicación de la alta dirección en esta versión actualizada de la norma también se debe dar en las auditorias.

Es responsabilidad de ella revisar el sistema de gestión de calidad, a intervalos planificados, para asegurarse de su continua conveniencia, adecuación y eficacia. Se asegurarán de que se toman las acciones correctivas necesarias y sin demora para eliminar las no conformidades detectadas y sus causas. También se verificarán las acciones tomadas como resultado de la auditoría. La eficacia de las medidas adoptadas para abordar los riesgos y las oportunidades. $Y$ las nuevas oportunidades para la mejora contínua.

Si fuera necesario cualquier cambio en el sistema de gestión de calidad, incluyendo las necesidades de recursos, la alta dirección realizará las acciones necesarias relacionadas con estos resultados.

De nuevo se dará el trato correcto a la conservación y difusión de la información documentada de los resultados de las auditorias.

\section{Mejora}

La organización determinará y seleccionará las oportunidades de mejora. Implementará las acciones que sean necesarias para cumplir con los requisitos y seguir mejorando continuamente.

\section{No conformidad y acciones correctivas}

Cuando se produce una no conformidad, incluyendo las que deriven de quejas del cliente/usuario, la organización debe:

- Revisar la no conformidad

- Determinar la causa de la no conformidad.

- Reaccionar a la no conformidad, bien tomando medidas para corregirla, o bien haciendo frente a las consecuencias.

- Evaluar la necesidad de adoptar acciones para asegurarse de que se elimina la causa de la no conformidad, para que no vuelva a ocurrir, o se produzca en otros lugares.

- Implementar cualquier acción que se crea necesaria.

- Revisar la eficacia de las medidas correctivas aplicadas.

- Si es necesario, se harán cambios en el sistema de gestión de calidad.

Las acciones correctivas serán apropiadas a los efectos de las no conformidades 
detectadas.

Se puede dar el caso de que sea imposible eliminar la causa de la no conformidad. Entonces la medida correctiva se encargará de reducir la probabilidad de recurrencia a un nivel aceptable.

La documentación obtenida se conservará como documento que demuestre la naturaleza de las no conformidades, las medidas tomadas para corregirlas y los resultados obtenidos.

\section{Mejora continua}

La organización, concretamente la alta dirección, debe mejorar continuamente la conveniencia, adecuación y eficacia del sistema de gestión de calidad implantado.

Como novedad en esta actualización, será necesario utilizar toda la información disponible para tener en cuenta los resultados de análisis y evaluación, confirmar si hay áreas de bajo rendimiento $u$ oportunidades que deben ser abordadas en el contexto de la mejora continua.

Se utilizará cualquier método y herramientas que la organización estime oportunos para apoyar la mejora continua.

Como resumen de todo lo visto en esta norma podremos afirmar que los objetivos de un sistema de gestión, y por tanto de un sistema de gestión de calidad son:

- hacer como rutina las cosas bien

- hacerlas según lo acordado o cumpliendo con los requisitos obligatorios

- hacer las cosas bien a la primera

- articular los medios para detectar y satisfacer las nuevas necesidades.

- Disminuir los costes de gestión, haciendo ésta más eficiente. 


\section{SISTEMA DE GESTION MEDIOAMBIENTAL}

En los últimos años, las necesidades de las organizaciones en desarrollar algún tipo de mecanismo interno para controlar el impacto de sus actividades sobre el medio ambiente se han visto incrementadas de una parte por el aumento de interés de la sociedad sobre el medio ambiente, y por otra, debido al incremento de obligaciones legales.

Las organizaciones han visto claro que en temas de medioambiente es el presente el que garantiza el futuro.

Por esto, la tendencia de las organizaciones ha sido incorporar a su gestión una sensibilidad ambiental a través de distintos mecanismos: definiendo una política ambiental específica, creando un área con funciones y responsabilidad para la protección ambiental, realizar auditorías ambientales y posteriormente implantando sistemas de gestión ambiental.

Un sistema de Gestión Ambiental (SGA) o medioambiental (SGMA) es esa parte del sistema general de gestión de la organización que se encarga de la estructura organizativa, las responsabilidades, las prácticas, los procedimientos, los procesos y los recursos para determinar e implantar una política medioambiental.

La normalización de los sistemas de gestión ambiental, realizada por la Organización Internacional de Normalización (ISO), hace que aparezca en 1996, la primera norma de ámbito internacional que especifica los requisitos para un sistema de gestión ambiental, cuya versión oficial en España fue la norma UNE EN ISO 14001:1996. Sistemas de Gestión Medioambiental. Especificaciones y Directrices para su Utilización.

La familia de normas ISO 14000 tienen el propósito de mejorar los resultados medioambientales en una organización. De todas ellas, la norma ISO 14001 es la única que indica los requisitos en función de los cuales se puede certificar la gestión medioambiental. No impone medidas sustitutivas de la legislación vigente, sino que pretende mantenerla actualizada, y tampoco es su propósito que las organizaciones que implanten el SGA alcancen un grado de contaminación cero, sino que se fijen unos objetivos coherentes y alcanzables para la organización.

Es una herramienta de aplicación voluntaria. La organización la implantará por decisión propia y será muy útil para cualquier organización que desee implantar, mantener al día y mejorar un SGA. También es útil para asegurarse de su conformidad con su política ambiental y demostrar a terceros esta conformidad consiguiendo la certificación de su sistema por una organización externa.

Esta norma ISO 14001:2015 introduce conceptos más avanzados y ambiciosos 
para la gestión del medio ambiente. Por ejemplo, habla de responsabilidad social corporativa, desarrollo sostenible, comportamiento ambiental demostrable, todos ellos conceptos medioambientales surgidos en los últimos tiempos.

Con el propósito de integrar todas las normas y que se realice una mayor comprensión del enfoque a procesos en el que está estructurada la norma, los capítulos se han dividido en 10 bloques, encontrando los requisitos normativos en el bloque cuarto hasta el décimo. Esta estructura se denomina de alto nivel HLS (siglas en ingles para estructura de alto nivel).

También es novedoso el concepto de "información documentada" que incluye los procesos, la documentación tradicional, los registros, etc. Ahora la norma es más flexible sobre el tipo de documento y el soporte en el que se mantendrá.

Se le da mayor importancia al desempeño ambiental como enfoque de mejora.

En cuanto al concepto de ciclo de vida, ahora la norma requiere ir más allá gestionar los aspectos ambientales asociados con la subcontratación o las compras. También pide influir positivamente sobre los impactos ambientales de las compras, el diseño del producto, la prestación del servicio y el uso posterior que vaya a dar a ese producto el usuario o cliente, hasta el final de su vida útil.

La comunicación externa se convierte en la nueva versión de la norma en una práctica de obligado cumplimiento si la requiere la administración o alguna parte interesada. Se dará información fiable, coherente y verificable.

Aparece el apartado de contexto de la organización, mostrando en él la importancia de que la organización tenga en cuenta donde opera a la hora de implantar el sistema de gestión, ya que otras normas, grupos de presión, partes interesadas, circunstancias cambiantes, condiciones ambientales locales y globales e incluso los límites físicos de la propia organización afectarán a todo el sistema de gestión ambiental.

El lenguaje utilizado en la norma es real, claro y adaptable a todo tipo de organizaciones. Se ha introducido esta actualización en la forma de redactar la norma para que todo el mundo la comprenda sin necesidad de ser un experto en material ambiental.

El sistema de gestión ambiental, al igual que el sistema de gestión de la calidad, está basado en el modelo Planificar-Hacer-Verificar-Actuar (PHVA). Es un modelo que proporciona un proceso interactivo usado por las organizaciones para lograr la mejora continua. Se puede aplicar al sistema en su conjunto y a cada uno de sus elementos.

Lo podemos describir de la siguiente manera:

- Planificar: establecer los objetivos ambientales y los procesos necesarios para 
generar y proporcionar resultados acordes con la política ambiental establecida por la organización.

- Hacer: implementar los procesos según lo que se haya planificado.

- Verificar: seguir y medir los procesos, los compromisos, objetivos ambientales y criterios operacionales, e informar de los resultados.

- Actuar: emprender acciones de mejora que lleven a la mejora continua.

La norma ISO 14001:2015, aunque es especifica de gestión ambiental, permite que una organización use un enfoque común y un pensamiento basado en riesgos para integrar su sistema de gestión con los requisitos de otros sistemas de gestión.

También contiene los requisitos usados para evaluar la conformidad. Si una organización quiere demostrar conformidad con esta norma internacional puede:

- Hacer una autodeclaración y una autodeterminación.

- Buscar la confirmación de su conformidad por terceros que tengan interés en la organización, por ejemplo sus clientes.

- Buscar la confirmación de su auto declaración por una parte externa a la organización.

- Buscar la certificación de su sistema de gestión ambiental por una parte totalmente externa a la organización.

Las directrices de la propia norma ISO, establecen la necesidad de revisarla cada 5 años, con el fin de introducir mejoras y adecuarlas a los mercados. Por eso la ISO 14001:1996 fue anulada y sustituida por la UNE EN ISO 14001:2004, y esta a su vez fue anulada por la norma UNE EN ISO 14001:2015, edición que se publicó en septiembre de 2015, periodo en el que comenzaron los tres años de transición hasta septiembre de 2018. Actualmente está en vigor. 


\section{UNE EN ISO 14001:2015 Sistemas de Gestión Ambiental. Requisitos con orientación para su uso.}

Esta norma específica los requisitos para implantar un sistema de gestión ambiental en una organización que quiera mejorar su desempeño ambiental.

Al aplicar la norma se conseguirán lograr los resultados previstos en el sistema de gestión y a su vez aportar valor al medio ambiente, a la propia organización y a terceros interesados.

Los resultados previstos incluirán:

- mejora del desempeño ambiental.

- el cumplimiento de los requisitos legales y otros requisitos sociales.

- el logro de los objetivos ambientales.

La norma, al igual que la ISO 9000, es aplicable a cualquier tipo de organización independientemente de su tamaño, naturaleza y aspectos ambientales de sus actividades, productos y servicios. No establece criterios de desempeño ambiental concretos.

Aunque la norma se puede usar en su totalidad o en parte, las declaraciones de conformidad con esta Norma Internacional no son aceptables a menos que todos los requisitos especificados en ella estén incorporados al sistema de gestión ambiental que la organización haya implantado, y que se cumplan sin exclusiones.

La propia norma define el Medio Ambiente como "el entorno en el que una organización opera, incluyendo el aire, el agua, la tierra, los recursos naturales, la flora, la fauna, los seres humanos y sus interrelaciones".

Entenderemos como desarrollo sostenible "aquel que satisface las necesidades las necesidades de la presente generación, sin comprometer la capacidad de las generaciones futuras para satisfacer sus propias necesidades".

Por lo tanto, una actividad realizada por el hombre forma parte del desarrollo sostenible siempre que sus efectos y consecuencias no superen los índices de renovación o consumo de los recursos naturales, ni su capacidad de acogida por el medio o asimilación de los componentes.

Para poder aplicar el sistema es necesario adaptar las exigencias de la norma a la organización, trasladando cada uno de sus requisitos a la realidad de la organización, sin perder nunca de vista el objetivo principal, que es la protección del medio ambiente. Se adaptarán y mejorarán los procesos y no nos centraremos exclusivamente en el cumplimiento de las especificaciones de la norma.

La norma especifica que requisitos debe tener la organización cubiertos antes de 
comenzar a desarrollar el sistema de gestión ambiental.

Estos son:

- Una estructura organizada en la que estén definidas las funciones y responsabilidades en relación con el medio ambiente.

- Un soporte documental que desarrolle la metodología a implantar.

- Recursos humanos y materiales suficientes para conseguir los objetivos.

- Una planificación de actividades y líneas de mejora, adecuados a su política ambiental y a los objetivos a alcanzar.

Los requisitos del sistema de gestión ambiental están recogidos en en la norma ISO 14001:2015. Pasamos a comentarlos.

Comienza la cláusula 4 hablando del Contexto de la organización. Esta es una cláusula totalmente nueva que ofrece mayor comprensión estratégica de todos los factores afectados por la manera en que la organización gestiona su responsabilidad ambiental. Están incluidos entre estos factores las condiciones ambientales capaces de afectar o verse afectadas por la propia organización.

La organización tiene que determinar:

- Las partes interesadas que son pertinentes al sistema de gestión ambiental.

- Los requisitos de estas partes.

- Cuáles de estas expectativas y necesidades de las partes son requisitos legales y cuales son otros tipos de requisitos.

La organización debe determinar los límites y la aplicabilidad del sistema de gestión ambiental para delimitar su alcance.

Para esto deberá considerar:

- Las partes externas e internas que son pertinentes para su propósito.

- Los requisitos legales y otros que puedan surgir.

- Los límites físicos de la propia organización.

- Sus actividades, servicios y productos.

- Su capacidad y la autoridad para ejercer influencia y control.

La norma actualizada da importancia a las partes interesadas y a la necesidad de considerar sus expectativas y lo que quieren de la organización, para después decidir si estas necesidades y requisitos se convierten en obligaciones de cumplimiento.

Una vez delimitados estos puntos, la organización incluirá en el sistema de gestión ambiental todas las actividades, productos y servicios que estén dentro de sus límites. 
De nuevo, y al igual que con los sistemas de gestión de calidad, se recuerda la necesidad de mantener información documentada y disponible para las partes interesadas.

\section{Liderazgo}

La norma atribuye una serie de requisitos específicos y responsabilidades a la alta dirección y a las personas con roles de alta dirección en el SGA.

La alta dirección debe demostrar liderazgo y compromiso con respecto al SGA:

- asumiendo su responsabilidad y que debe rendir cuentas relativas a la eficacia del sistema de gestión implantado.

- Asegurándose de que se establecen la política ambiental y los objetivos alcanzables, y que estos sean compatibles con el contexto de la organización y con la dirección estratégica que se haya decidido tomar.

- Asegurándose de que existen suficientes recursos disponibles.

- Comunicando la importancia de que la gestión ambiental sea eficaz y conforme a los requisitos del sistema de gestión.

- Cerciorarse de que el sistema de gestión ambiental logre los resultados previstos.

- Dirigiendo y apoyando a las personas para que contribuyan a la eficacia del sistema sintiéndose parte de él.

- Promoviendo la mejora continua.

- Apoyando otros roles pertinentes de la dirección para demostrar su liderazgo en otras áreas de su responsabilidad.

\section{Política Ambiental}

Establece la base para implantar y mantener el SGA. La norma especifica que debe ser establecida, implementada y mantenida por la alta dirección.

Debe estar documentada, se comunicará a todos los empleados y a las partes interesadas.

Será:

- apropiada al contexto y propósito de la organización.

- Dará el marco de referencia para el establecimiento de los objetivos ambientales.

- Incluirá un compromiso para la protección del medio ambiente, incluida la prevención de la contaminación y otros compromisos que la organización pueda adoptar en su contexto de actividad. Estos compromisos se refieren a el 
uso sostenible de recursos, protección de la biodiversidad y los ecosistemas y suavizar y adaptarse al cambio climático.

- Incluirá un compromiso de cumplir con todos los requisitos necesarios, tanto legales como otros impuestos por terceras partes.

- Se comprometerá a seguir un proceso de mejora continua.

\section{Roles, responsabilidades y autoridades en la organiza}

Desde el principio, la norma pide a la alta dirección que esté directamente implicada en la implantación del sistema de gestión ambiental. Es ella la encargada de asegurarse de que se asignen responsabilidades y autoridades pertinentes a otros miembros de la organización y será la responsable de que se les comuniquen su nueva asignación a todos los implicados.

Se asignará a otros miembros de la organización:

- La responsabilidad y autoridad para asegurarse de que el sistema de gestión ambiental implantado es conforme a los requisitos de la Norma Internacional, y

- La necesidad de informar a la alta dirección sobre el desempeño de todo el sistema de gestión ambiental.

\section{Planificación}

Esta cláusula se centra específicamente en una mayor concienciación y competencia a la hora de planificar todo el sistema de gestión ambiental.

La organización tiene la responsabilidad de establecer y mantener los procesos necesarios para planificar el sistema de gestión ambiental, determinar los riesgos y oportunidades que surjan, mantener la información documentada, determinar los aspectos ambientales de sus productos o servicios en los que puede controlar, en cuales puede influir, y el impacto ambiental que tendrán en su ciclo de vida. También debe tener en cuenta los requisitos legales y otros requisitos que le pidan terceros y planificar todas sus acciones considerando sus opciones tecnológicas y los requisitos financieros y de negocio.

Al planificar el sistema de gestión ambiental la organización tendrá en cuenta

- Su contexto.

- Las expectativas de las partes interesadas.

- El alcance de su sistema de gestión del medioambiente.

Relacionado con los riesgos y oportunidades, la organización de terminará:

- Los aspectos ambientales.

- Los requisitos legales y los que requieran terceras partes. 
- Los requisitos de su entorno y de otros interesados y afectados por su gestión.

Todo esto lo hará para:

- Asegurarse de que se van a poder lograr los resultados previstos.

- Prevenir y reducir los efectos no deseados, incluidos los de acciones efectas que afecten al sistema de gestión ambiental.

- Lograr la mejora continua.

Se mantendrá la información documentada que surga de:

- Los riesgos y las oportunidades que se presenten.

- Procesos de planificación de la actividad.

- Los aspectos ambientales significativos que supongan un cambio, o situaciones de emergencia.

- Los requisitos de terceros y legales que se determinen aplicables.

- La planificación para abordar acciones y evaluar la eficacia de estas.

\section{Objetivos ambientales y planificación para lograrlos}

Los objetivos ambientales los puede establecer la alta dirección a nivel estratégico, es decir, incluyendo los niveles más altos de la organización, o a nivel táctico y operacional, esto es, a nivel de un área o áreas especificas y tendrán que ser compatibles con su dirección estratégica. Esto lo hará teniendo en cuenta los objetivos ambientales significativos. Esto no quiere decir que se tenga que establecer un objetivo ambiental para cada aspecto ambiental significativo. No obstante, este objetivo ambiental significativo, tendrá una prioridad alta si se han establecido objetivos ambientales relacionados directamente con él.

Los objetivos ambientales deben:

- ser coherentes con la política ambiental, es decir, estarán avenidos con los compromisos adquiridos por la alta dirección en política ambiental, incluida la mejora continua.

- ser medibles ya que puede darse alguna situación en la que no sea posible medir un objetivo ambiental. Aún así, es importante que la organización tenga capacidad suficiente para determinar si un objetivo ambiental se ha logrado o no.

- ser objeto de seguimiento.

- ser comunicados.

- ser actualizados.

Cuando la organización planifique como va a conseguir cumplir con sus objetivos 
ambientales determinará:

- qué va a hacer.

- qué recursos necesitará.

- quién va a ser la persona o personas responsables.

- cuándo finalizará.

- cómo se van a evaluar los resultados.

Para información adicional sobre indicadores ambientales podemos consultar la Norma ISO 14031.

\section{Apoyo}

Se refiere a todo lo necesario para implantar el sistema, tanto interno de la organización, como externo a ella.

\section{Recursos}

Esta cláusula se refiere al soporte necesario para que se implante y funcione el sistema de gestión ambiental. Ahora es más preceptivo que en la versión anterior de la norma. Se fomenta la coherencia en toda la organización.

La organización determinará qué recursos necesita para establecer el sistema de gestión y los proporcionará a todos los que tengan responsabilidades en el. Al hablar de recursos, se incluyen los humanos, los recursos naturales, tecnología, infraestructura y recursos financieros. Si fuera necesario, se complementará con proveedores externos.

\section{Competencia}

Los requisitos de competencia de esta Norma se aplican a personas que trabajan bajo el control de la organización que pueden afectar a su desempeño ambiental. Se incluyen:

- a las personas cuyo trabajo tenga el potencial de causar un daño al medioambiente significativo.

- a las que se les asignen responsabilidades relacionadas con el sistema de gestión, como puede ser determinar los requisitos legales que afecten al logro de los objetivos, los que responden ante situaciones de emergencia, los responsables de las auditorías internas, o los que contribuyan directamente al logro de un objetivo ambiental. 
La organización:

- determinará la competencia necesaria de las personas que realizan trabajos bajo su control y que afecte a su desempeño ambiental y a la capacidad para cumplir con los requisitos legales otros requisitos.

- se asegurará de que estás personas son competentes en base a su formación y experiencia.

- determinará las necesidades de formación que surjan.

- si es necesario, se tomarán las acciones necesarias para que las personas responsables adquieran la competencia necesaria.

Para demostrar la competencia estas, la organización conservará la información documentada.

\section{Toma de conciencia}

Con esta cláusula, se pretende que las personas entiendan la importancia de conocer la existencia de la política ambiental de la organización en la que trabajan, su propósito y su función, y que tengan claro como su trabajo puede contribuir a la eficacia del sistema de gestión ambiental y que implica no satisfacer los requisitos del sistema de gestión ambiental, incluido el incumplimiento de los requisitos legales establecidos y otros que requieran terceras partes.

\section{Comunicación}

La comunicación es el proceso que va a permitir a la organización obtener información para sus sistema de gestión ambiental, incluida la información relaciona con aspectos ambientales significativos, los requisitos legales y otros requisitos, y las recomendaciones de mejora continua.

Al establecer el proceso o procesos de comunicación se debe considerar la estructura organizacional interna para asegurarse de que la comunicación fluye con los niveles y funciones más apropiados. La comunicación es un proceso de dos direcciones, una hacía afuera y otra hacía dentro de la organización.

La organización puede recibir información de las partes interesadas en forma de petición de información específica relacionada con algún aspecto de la gestión ambiental, o puede ser información expresando opiniones, impresiones e incluso quejas. Estas no se tratarán como información de poco valor o negativa, sino que se le dará respuesta rápida y clara. Debe tratarse toda la información como una herramienta para detectar oportunidades de mejora. 
La organización se planteará:

- qué comunicar

- cuando hacerlo.

- a quién comunicar.

- cómo va a comunicarlo.

Siempre se tendrán en cuenta los requisitos legales y otros de terceros, y se asegurará de que la comunicación es coherente con la información generada por el sistema de gestión ambiental.

La comunicación interna será la pertinente entre los distintos niveles y funciones de la organización, incluidos los cambios en el sistema de gestión ambiental.

La comunicación externa se hará de acuerdo con los requisitos legales y los establecidos por terceras partes.

\section{Información documentada}

La organización debe crear y mantener información documentada suficiente, de manera que se asegure que el sistema de gestión ambiental sea conveniente, adecuado y eficaz.

El enfoque principal no es crear un complejo sistema de control de la información documentada. Es más importante implementar un sistema de gestión ambiental eficaz.

Además de la información documentada que se especifica en las cláusulas de esta norma, la organización puede decidir crear información adicional documentada, pensando en mayor transparencia a la hora de tener que rendir cuentas, en coherencia, continuidad o para facilitar las auditorías.

Al crear y actualizar la información documentada, la organización se asegurará de que:

- la identificación y descripción son las apropiadas.

- el formato y los medios de soporte son los adecuados.

- Esté revisada y aprobada con respecto a la adecuación del sistema de gestión.

La organización controlará la información documentada para asegurarse de que:

- está disponible y es idónea para su uso, dónde y cuándo sea necesario.

- está protegida adecuadamente contra perdida de confidencialidad, uso inadecuado o pérdida de integridad. 
Para tenerla controlada, la organización establecerá la forma de:

- distribuirla, cómo acceder a ella.

- cómo recuperarla.

- que uso se le puede dar.

- cómo se almacenará.

- como conservará.

- quién controlará los cambios de versión.

La información documentada creada para el sistema de gestión ambiental, se puede integrar con otros sistemas de gestión. No es necesario presentarla en formato de manual.

\section{Operación}

La norma hace mayor énfasis en el concepto de "cadena de valor" que afecta al sistema de gestión ambiental. Analiza en este apartado cómo las organizaciones controlan los cambios y externalizan procesos específicos.

\section{Planificación y control operacional}

La organización debe establecer, controlar y mantener los procesos necesarios para cumplir los requisitos del sistema de gestión ambiental.

El tipo de control depende de la naturaleza de las operaciones, de los riesgos y oportunidades, de los aspectos ambientales significativos y de los requisitos tanto legales como otros requisitos.

La organización puede seleccionar el método de control que va a utilizar e incluso combinar varios para asegurarse que los procesos sean eficaces para el logro de los resultados deseados.

Los métodos pueden variar e incluir:

- diseñar procesos que prevengan errores y aseguren resultados coherentes.

- utilizar controles de ingeniería, es decir, usar tecnología que controle los procesos así prevenir resultados negativos.

- usar personal competente para asegurarse de obtener los resultados deseados.

- especificar la manera de llevar a cabo los procesos.

- realizar el seguimiento o la medición de los procesos para verificar los resultados. 
- determinar la cantidad y el uso de la información documentada que será necesaria.

Si la organización contrata procesos externos se debe asegurar de que estén controlados o por los menos se tenga influencia sobre ellos.

Recordando el concepto de ciclo de vida que incluye esta norma ISO, la organización debe:

- establecer los controles que determine necesarios para asegurarse de que sus requisitos ambientales se cumplen desde el proceso de diseño y desarrollo del producto y/o servicio hasta el final de su ciclo de vida y pasando por todas las etapas de este.

- determinar qué requisitos ambientales exige para la compra de productos y servicios.

- comunicar sus requisitos ambientales pertinentes a los proveedores externos, incluidos los contratistas.

- informar de los impactos ambientales potenciales asociados con el transporte, la entrega, el uso, el tratamiento al fin de la vida útil y la disposición final de sus productos o servicios.

Se debe mantener la información documentada para tener la certeza de que los procesos se han llevado a cabo según lo planificado.

\section{Preparación y respuesta ante emergencias}

La responsabilidad de estar preparada para responder ante situaciones de emergencia de manera apropiada recae sobre cada organización.

En la fase de planificación del proceso de preparación y respuesta ante emergencias, la organización debe considerar:

- el método más apropiado para responder al producirse una situación de emergencia.

- los procesos de comunicación interna y externa.

- las acciones que se requieran para prevenir o mitigar los impactos ambientales.

- las acciones de respuestas a tomar para distintos tipos de emergencia.

- la evaluación de la pos emergencia, determinando que se puede mejorar.

- la prueba periódica de las acciones planificadas de respuesta.

- la formación de las personas responsables de respuesta ante la emergencia.

- un listado de las personas responsables y de los servicios de emergencia, incluidos los detalles de contacto,(por ejemplo teléfono de emergencias). 
- las rutas de evacuación y los puntos de encuentro.

- la posibilidad de recibir ayuda por parte de organizaciones vecinas.

La organización debe:

- estar preparada para responder, planificando acciones para prevenir o minimizar los impactos ambientales producidos por situaciones de emergencia;

- debe responder a situaciones reales.

- tomar acciones para responder a las situaciones de emergencia que puedan surgir de acuerdo a la magnitud de la emergencia y al impacto ambiental potencial.

- $\quad$ poner a prueba las acciones de respuesta planificadas periódicamente.

- evaluar y revisar periódicamente los procesos y las acciones después de que haya ocurrido alguna situación de emergencia o de que se hayan hecho simulacros.

- formar e informar a las partes interesadas pertinentes de la preparación y respuesta ante una emergencia.

Una vez más, la información documentada se mantendrá para poder utilizarla en caso de tener que demostrar los procesos llevados a cabo ante estas situaciones.

\section{Evaluación del desempeño}

Esta es una nueva cláusula que incluye el seguimiento, la medición y la revisión por la dirección de los procedimientos implantados. Esto ayudará a las empresas a reunir los registros adecuados para demostrar que su sistema de gestión cumple con sus objetivos de negocio.

\section{Seguimiento, medición, análisis y evaluación}

Cuando una organización determina uno o más procedimientos para medir sus operaciones y el impacto significativo que pueden tener en el medioambiente, debe tener en cuenta sus objetivos ambientales, sus aspectos ambientales más significativos, los requisitos legales y otros requisitos y los controles operacionales.

Los métodos utilizados por la organización para hacer seguimiento, medir, analizar y evaluar se deben definir en el sistema de gestión ambiental para asegurarse de que:

- el cronograma de medición está coordinado con los resultados de análisis y de evaluación. 
- los resultados son fiables, reproducibles y trazables, para ello se asegurará de que los equipos de medición y seguimientos se utilicen y mantenga calibrados o verificados, y se deben conservar los registros asociados.

- el análisis y la evaluación son fiables, reproducibles y reales para permitir conocer las tendencias.

Se debe informar de los resultados obtenidos a los responsables de emprender acciones apropiadas.

Se conservará la información documentada para tener evidencia de los resultados del seguimiento y la medición.

\section{Evaluación del cumplimiento}

Aunque es cierto que la organización puede utilizar una variedad de métodos para mantener su conocimiento y comprensión de su estado de cumplimiento dependiendo de la importancia del requisito, de las variaciones en las condiciones de operación, de los cambios en los requisitos legales y otros requisitos y del desempeño de esta, es necesario que todos los requisitos legales y otros requisitos se evalúen periódicamente.

Si el resultado indica el incumplimiento de algún requisito legal la organización tiene que determinar las acciones necesarias para cumplirlo.

Un incumplimiento no se tiene que convertir en no conformidad obligatoriamente. Se puede identificar y corregir en los procesos del sistema de gestión ambiental. Las no conformidades relacionadas con el cumplimiento necesitan corregirse, incluso si no han generado no conformidades reales con los requisitos legales.

Cuando la organización establece, implementa y mantiene los procesos necesarios para evaluar el cumplimiento de sus requisitos legales y otros requisitos debe:

- determinar con qué frecuencia se evaluará el cumplimiento.

- evaluarlo y emprender las acciones necesarias.

- mantener el conocimiento de su grado de cumplimiento.

Deberá conservar la información documentada relativa a la evaluación del cumplimiento.

\section{Auditoría interna}

Los auditores deben ser independientes de la actividad auditada, y estarán libres de conflicto de intereses.

Las no conformidades identificadas durante las auditorias son objeto de 
acciones correctivas apropiadas.

La organización debe establecer, implementar y conservar un programa de auditoria interna especificando la frecuencia, los métodos, las responsabilidades, los requisitos de planificación y la elaboración de informes de sus auditorías internas.

La organización tendrá en cuenta la importancia ambiental de los procesos involucrados en la auditoria interna y los cambios que afecten a la organización.

Por esto, la organización debe:

- definir los criterios de auditoría y el alcance para cada una de ellas.

- seleccionar los auditores y hacer auditorías objetivas e imparciales.

- asegurarse de que los resultados se informarán a la dirección.

Como evidencia de la implementación del programa de auditoría y sus resultados se conservará la información documentada.

\section{Revisión por la dirección}

No es necesario que sea una revisión exhaustiva de información detallada, ni considerar de una sola vez todos los temas de la revisión por la dirección. Se puede hacer durante un periodo de tiempo y ser parte de las actividades de gestión programadas regularmente.

La alta dirección revisará la información obtenida y examinará las quejas recibidas para determinar las oportunidades de mejora.

La revisión incluirá:

- el estado de las acciones de las revisiones por la dirección anteriores.

- los cambios en:

- las cuestiones externas e internas que sean parte del sistema de gestión ambiental.

- los requisitos de las partes interesas, legales y otros.

- sus aspectos ambientales significativos.

- los riesgos y oportunidades.

- el grado de logro de los objetivos ambientales.

- la información sobre el desempeño ambiental de la organización incluida la información relativa a:

- las no conformidades y acciones para corregirlas.

- los resultados de seguimiento ,análisis y medición.

- el cumplimiento de los requisitos legales y otros requisitos.

- los resultados de las auditorías. 
- la adecuación de los recursos que se estimen necesarios.

- las comunicaciones pertinentes de las partes interesadas tanto las positivas como las negativas.

- las oportunidades de mejora continua.

La información obtenida de las revisiones por la dirección incluirá:

- las conclusiones obtenidas sobre la conveniencia, adecuación y eficacia del sistema de gestión ambiental.

- las decisiones tomadas con relación a la mejora continua.

- las decisiones relacionadas con los cambios en el sistema que se estimen necesarios.

- las acciones necesarias a tomar cuando no se hayan logrado los objetivos ambientales.

- las oportunidades de mejorar la integración del sistema de gestión ambiental a otros procesos de la organización.

- cualquier implicación para la dirección estratégica de la organización.

Se conservará toda la información documentada como evidencia de los resultados de la revisión por la dirección.

\section{Mejora}

Aunque la esencia es la misma de la anterior norma, en esta cláusula de detalla que se considera no conformidad y que acciones es necesario llevar a cabo cuando surge una.

La organización debe tener en cuenta los resultados del análisis y de la evaluación del desempeño ambiental, la evaluación del cumplimiento, los resultados de las auditorias y los resultados de la revisión por la dirección cuando se van a tomar acciones de mejora.

\section{No conformidad y acción correctiva}

Uno de los propósitos del sistema de gestión ambiental, es actuar como herramienta preventiva. Por esto, cuando se da una no conformidad la organización debe utilizarla como información que ayudará a solucionar un incumplimiento de un requisito, y así prevenir que el sistema de gestión ambiental implantado cumpla con los objetivos propuestos. 
Cuando ocurra una no conformidad, la organización debe reaccionar ante ella y:

- actuar para controlarla y corregirla.

- hacer frente a las consecuencias, incluido atenuar los impactos ambientales adversos.

- evaluar si es necesario tomar acciones para eliminar la causa de la no conformidad para que no vuelta a repetirse, mediante:

- revisión de la no conformidad.

- determinación de las causas.

- determinación de si existen no conformidades parecidas, o que potencialmente puedan ocurrir.

- implementar cualquier medida que sea necesaria.

- revisar la eficacia de cualquier medida correctiva tomada anteriormente.

- hacer los cambios necesarios en el sistema de gestión ambiental.

Las acciones correctivas que se tomen serán equivalentes a la importancia de los efectos de las no conformidades.

La organización conservará la información documentada como evidencia de la naturaleza de las no conformidades y la acción decidida posteriormente y los resultados de cualquier acción correctiva.

\section{Mejora continua}

La organización determina el ritmo, el alcance y el momento de las acciones que apoyen la mejora continua. El desempeño ambiental se puede mejorar implantando un sistema de gestión ambiental completo o mejorando alguno de sus elementos. 


\section{GESTION DE LA PREVENCIÓN DE RIESGOS}

\section{LABORALES}

El término gestión, tan utilizado en la actualidad puede referirse a las diligencias para hacer algo. Según Manuel López Cachero (1998:10) puede definirse como la "ordenación metódica de actividades interdependientes y procedimientos relacionados que posibilita el buen hacer de una organización".

El trabajo es la actividad necesaria e irrenunciable como medio de subsistencia del ser humano, y como creador de riqueza. Es decir, el ser humano no puede prescindir del trabajo para sobrevivir, pero sí puede hacer que la actividad que desarrolla en este se lleve a cabo en las mejores condiciones de seguridad y salud para él, de manera que se lleve a mínimos, e incluso, desaparezca, el peligro que caracteriza esta actividad.

El Diccionario de la Academia Española de la Lengua define el término seguridad como "cualidad de seguro". Si vamos al significado de seguro nos encontramos con que se trata de algo "libre y exento de todo daño, peligro o riesgo".

La seguridad tiene, por tanto, la misión de librar y evitar de todo peligro, daño o riesgo. Si le añadimos la expresión en el trabajo, hablaremos de evitar estos peligros, daños o riesgos en el entorno laboral. Así, que la creencia de que el accidente de trabajo es algo inevitable, que está incluido en el sueldo, y que no es posible prevenir es una creencia que debe cambiar.

Si una organización se plantea voluntariamente, el objetivo de eliminar o al menos reducir y controlar sus riesgos y los costes de los accidentes, incidentes y enfermedades profesionales, necesitará, desde el punto de vista técnico, gestionar las actividades dirigidas en este sentido.

La política en materia de prevención de riesgos laborales, en cuanto al conjunto de actuaciones de los poderes públicos dirigidas a la promoción de la mejora de las condiciones de trabajo para elevar el nivel de seguridad, tienen su pilar fundamental en la Ley 31/1995 de Prevención de Riesgos Laborales (LPRL), y se complementa articulándose sobre Reglamentos que de ella emana, en especial, destaca el Reglamento de los Servicios de Prevención (RSP).

La LPRL establece la obligación empresarial del diseño, aplicación y desarrollo de la actividad preventiva desde el momento en el que se piensa en un proyecto empresarial. Esta acción preventiva consiste en tomar las medidas necesarias ante los riesgos existentes con el propósito de impedir los accidentes y evitar daños y pérdidas. A esta dinámica se la conoce como Gestión de la Prevención de Riesgos Laborales, y es el motor de mejora en cuanto a la prevención de riesgos. 
- Para ser llevada a efecto, se deben cumplir unas responsabilidades concretas.

- Por parte del empresario, la responsabilidad de planificar la acción preventiva.

- Por parte de la línea jerárquica, la responsabilidad de integrar la acción preventiva en el conjunto de actividades de la organización.

- Por parte de los servicios de prevención, o de las personas asignadas, según proceda, la responsabilidad de prestar al empresario el asesoramiento y apoyo necesario en lo referente al diseño y aplicación de los planes y programas de prevención.

- Por parte de los órganos de participación (Delegados de Prevención y Comités de Seguridad y Salud) la responsabilidad y obligación de colaborar en la mejora de la acción preventiva y de participar en la elaboración y puesta en marcha de los planes y programas de prevención.

Así pues, podríamos decir que es el empresario el que planifica y lidera la gestión de la prevención, junto con la línea jerarquizada que la asume y la lleva a la práctica y el asesoramiento de los Servicios de Prevención o de las personas designadas, y con la participación de los Delegados de Prevención y Comités de Seguridad y Salud. Por esto es necesario implantar un sistema de Gestión de Prevención de Riesgos Laborales. Sistema que perseguirá producir más y mejor, disminuyendo el impacto sobre sus trabajadores, es decir, mejoraría la competitividad y la productividad. Por esto, la prevención de riesgos debe convertirse en un fin y no ser sólo un objetivo.

Es cierto, que la normativa de Prevención no exige que la empresa adopte un Sistema de Gestión para llevar a cabo las actividades preventivas, pero si tenemos en cuenta las responsabilidades que por exigencia legal, debe realizar la organización en materia de prevención, sí parece lógico que la forma más idónea de llevar a cabo estas actuaciones sea enmarcándolas en un Sistema de Gestión.

Al igual que en los anteriores sistemas de Gestión citados, calidad y medioambiente, los cuatro elementos básicos del ciclo de este sistema son: PlanificarHacer-Verificar-Actuar.

- Planificar: (Art. 16.1 y 16. 2.a) LPRL, Arts 3 al 7 del Reglamento de los servicios de Prevención (RSP). Con el plan de prevención se cumple esta cuestión. Se realiza una evaluación inicial de riesgos, para conocer cuál es la situación de la empresa en cuanto a seguridad y salud. Como consecuencia de 
esto se realiza la planificación preventiva, y según el Ar. 14.2 LPRL se establecen objetivos y metas.

- Ejecutar: (Art. 16. 2b LPRL y Arts 8 y 9 RSP). Las medidas tomadas en la planificación se llevan a cabo durante el periodo que se haya establecido, por los responsables asignados, utilizando los recursos necesarios.

- Verificar: Se hace un seguimiento de lo conseguido y se observa hasta qué punto el empresario está consiguiendo el objetivo de garantizar la seguridad y salud de los trabajadores a su servicio. Las auditorias son una herramienta muy útil para este fin, ya que son una evaluación de la eficacia e idoneidad del sistema.

- Actuar: se proponen acciones de mejora cerrando el ciclo. Con esto se implanta en concepto de mejora continua.

Todos conocemos la importancia de las normas ISO para la gestión de las organizaciones. Concretamente, han sido objeto de estudio en este trabajo, la norma ISO 9001:2015 para sistemas de gestión de calidad, y la norma ISO 14001:2015 para sistemas de gestión ambiental. Pero, ¿qué pasa con las normas ISO y los sistemas de Gestión de Prevención de Riesgos Laborales?

Son muchas las organizaciones de todo tipo que están cada vez más interesadas en alcanzar y demostrar un fuerte desempeño de la Seguridad y Salud en el Trabajo, mediante el control de sus riesgos para la SST, y de acuerdo con su política y objetivos de SST. Tanto la legislación, como las medidas tanto económicas como de fomento de buenas prácticas, son cada vez más exigentes. Además, las partes interesadas se preocupan cada vez más por lo que hace las acciones que toma la organización para promover la SST.

Aunque muchas organizaciones han comenzado a auditar y revisar su sistema de SST, parece, que por sí mismas estas medidas no son suficientes para proporcionar a una organización la seguridad de que su desempeño se cumple y se continuará cumpliendo. Para demostrar su eficacia, estas revisiones y auditorias necesitan estar desarrolladas dentro de un sistema de gestión estructurado que esté integrado en la organización.

Ante la demanda de las organizaciones surgieron dos modelos de gestión:

- El llamado Modelo de Control Total de Pérdidas y

- El modelo DuPont.

Además han surgido otros modelos de gestión bastante influyentes y que han sido bastantes significativos para gestionar la prevención de riesgos en las organizaciones. Pero sin duda alguna, y a la espera de que sea desarrollada y publicada la nueva ISO 45001, la especificación Técnica OSHAS 18001 es la más extendida. 
Veamos la historia de estos modelos.

\section{Control Total de Pérdidas}

Este modelo, iniciado por Frank E. Bird en 1969, fue desarrollado en Georgia, (USA) por el International Loss Control Institute (ILCI) en 1974, e introducido en España en 1975 por la Asociación para la Prevención de Accidentes (APA).

El Control Total de Pérdidas es un conjunto de herramientas de gestión al servicio de la Gerencia, cuyo principio es que la gestión preventiva debe priorizar el control sobre las causas últimas de los daños y no debe priorizarse la actuación sobre los resultados. Está enfocado al estudio de todas las pérdidas, englobando a la prevención de riesgos como un tipo específico de pérdida, y se controlan no sólo las lesiones o enfermedades, sino también el daño producido a las máquinas, al medio ambiente, a la seguridad del producto, etc.

La principal desventaja de este modelo es que implica una gran complejidad administrativa, lo que hace que sea difícil su implantación en ciertas estructuras poco organizativas. Además el Control Total de Pérdidas, no dispone de un elemento de gestión muy importante para la ley $\mathrm{PRL}$, la evaluación de riesgos, base de toda la planificación preventiva.

\section{El Modelo DuPont}

DuPont, es una de las mayores organizaciones químicas del mundo. Fundada en 1802, está reconocida como una de las compañías con mejores índices de seguridad. Este modelo surgió como método de gestión de la práctica, y a partir de ella se dotó al sistema empleado de un cuerpo metodológico y teórico propio recogiendo elementos de la Teoría de la Excelencia. Primero se homogeneizó el modelo en todas sus fábricas y después lo transformaron en un producto-servicio que se ofrecía mediante su consultoría, DuPont de Nemours, Safety and Environmental Management Services (SEMS).

El método está basado en el principio de que todo accidente se puede prevenir, y si no es así es que ha habido un fallo en la gestión. Su eslogan muestra muy bien esta idea: "si no lo podemos hacer de forma segura, no lo haremos". Es decir, no se vende ningún producto que no se pueda fabricar, utilizar y eliminar de forma segura. La seguridad, con este método, es el principio rector para todo el personal de la organización. La seguridad se convierte en condición de empleo. El enfoque DuPont forma y adiestra a sus empleados para que adquieran la seguridad basada en conducta. La mayor responsabilidad recae sobre los mandos intermedios, ya que entienden que en el trabajo diario la buena prevención de riesgos depende de ellos. 
Su filosofía la demuestran de forma muy gráfica con su símbolo Zer0, indicando su meta de cero lesiones con baja.

El método requiere para su implantación una serie de condiciones muy específicas, ya que se ha demostrado que sin estas condiciones no se ha obtenido éxito.

\section{Estas son}

- Que la empresa esté en unas condiciones económicas óptimas, que posibiliten hacer una inversión inicial de horas/hombre durante los dos primeros años de implantación del modelo

- Que la empresa pertenezca a un sector donde el riesgo sea alto y visible, como puede ser la industria química.

- Que la empresa tenga una política de personal muy definida, y no se permita bajo ningún concepto, ni siquiera político social, la negociación de la seguridad,

La aplicación del modelo DuPont, por una serie de derechos adquiridos, sólo se puede hacer a través de la firma consultora de la empresa, y los honorarios son bastantes altos.

Hay otros modelos significativos e influyentes para la gestionar la prevención de riesgos. Algunos ejemplos son los citados a continuación.

\section{La Guia BS 8800:1996}

Guide to: Occupational health and safety management systems. Es una guía con una redacción muy escueta que deja de lado o no profundiza lo suficiente en cuestiones como la gestión de los agentes peligrosos, selección de los proveedores y contratas, programa de vigilancia de la salud, evaluación del sistema y la documentación y los procedimientos.

\section{La norma UNE 81900:1996-EX}

La Asociación Española de Normalización y Certificación (AENOR) publicó la norma UNE 81900:1996 EX, con carácter experimental, para conocer el punto de vista de las organizaciones al aplicar unos principios de gestión nuevos, aunque ya conocidos para la materia que la norma queria cubrir. Esta norma quedó anulada en el mes de Junio de 2004.

\section{Directrices de la Unión Europea}

La unión europea publicó el documento 0135/4/99 EN en 1999 a través del Comité Consultivo creado ad hoc, titulado "European guidelines on the successful 
organisation of safety and health protection for workers at work (Safety and health managements systems). Es un documento de redacción breve, en el que se establece la necesidad de determinados procedimientos y documentos para implantar un sistema de gestión en concordancia con una serie de directrices, según las cuales los modelos de gestión deben decir que requisitos deben ser cubiertos y de acuerdo a qué criterios, pero no dice como deben cubrirse y lo deja a la decisión de la empresa.

A pesar de todos estos modelos, muchas organizaciones de los países desarrollados que son multinacionales, seguían demandando un modelo normalizado para la gestión de sus empresas a escala mundial.

Ante la demanda del mercado, algunos entes certificadores y empresas certificadoras como AENOR, SGS, Bureau Veritas, Lloyd's, y otras crearon un consorcio liderado por el BSI que desarrolló las actuales especificaciones OHSAS 18001 y 18002.

La propia OIT (Organización Internacional del Trabajo) redactó sus "Directrices sobre sistemas de gestión de la seguridad y salud en el trabajo ILO-OSH 2001". Estas directrices recogen textualmente que su "aplicación no exige certificación", pero no excluyen que se puedan certificar.

Las diferencias entre estas directrices y las normas OSHAS son:

- Las Directrices de la OIT son menos exigentes en su redacción que las normas OSHAS.

- Las Directrices son más explicitas en cuanto a los requisitos de vigilancia.

- Las Directrices de la OIT presentan algunos requerimientos redundantes.

- Las exigencias de participación de los trabajadores son mayores en la Directrices de la OIT.

- Las Directrices dan un enfoque más competitivo a la gestión ya que animan a las organizaciones a compararse con otras.

A pesar de esta demanda, la organización ISO descartó en varias ocasiones su participación en este ámbito de la normalización, considerando que no era la institución adecuada para el desarrollo de una norma de gestión de la Seguridad y Salud (inicialmente denominada ISO 18000) debido a su estructura tripartita (gobiernos-empresarios-trabajadores) y a los posibles conflictos que esta norma podría presentar en el ámbito sindical concluyendo que esta tarea era responsabilidad de la Organización Internacional del trabajo (OIT). Lo que sí señaló la ISO fue la necesidad de difundir documentos guía y normas desarrolladas por organismos nacionales de organización.

A día de hoy, podemos decir que la organización ISO, ha cambiado de opinión y está 
en marcha el borrador de la norma ISO 45001 de seguridad y salud en el trabajo.

\section{ISO 45001}

Esta norma persigue el mismo objetivo principal que su homóloga OHSAS 18001: prevenir los riesgos laborales y aquellos relacionados con la salud en el núcleo de las organizaciones, apostando por la mejora continua. Pondrá más énfasis en el contexto de la organización y reforzará el papel de la alta dirección en el liderazgo del Sistema de Gestión de la Seguridad y Salud en el trabajo. Esta norma se podrá aplicar a cualquier tipo de organización, independientemente de su tipo, tamaño o naturaleza.

Otra novedad de la norma es que comparte la estructura de alto nivel, común a todas las normas de gestión como la ISO 9001, y la ISO 14001 comentadas anteriormente. Esto será muy útil a la hora de integrarla con ellas.

También desarrollaría el requisito de acciones para abordar los riesgos y oportunidades. Se identificarán los peligros, se evaluarán los riesgos y se identificarán las oportunidades de mejora y los requisitos aplicables.

¿Cuándo se publicará esta norma para que entre en vigor?

En Octubre de 2013, un Comité Técnico, el ISO PC 283, se reunió en Londres para crear el primer borrador de la Norma ISO 45001. El primer borrador se presentó en 2014. Fue objeto de revisión y comentarios. Para que el borrador se convirtiera en proyecto de norma internacional se necesitaban que una mayoría de dos tercios lo aprobara. Esto no se consiguió y cómo muy bien cuenta la página de AENOR, más de 100 expertos acudieron a una reunión que tuvo lugar en Ontario (Canadá) para seguir debatiendo acerca de la norma Internacional de Gestión de la Seguridad y Salud en el Trabajo, ISO 45001.

Hubo un proceso de votación cuyo resultado ha hecho preciso una nueva ronda de debate ya que el comité responsable de esta norma, el ISO PC 283, con David Smith, como presidente, recibió más de 3000 comentarios, los cuales son necesarios analizar para modificar el texto de cara a lanzar el segundo borrador.

Entre los puntos tratados se encuentran la alineación de la norma con la estructura de alto nivel de la organización; la definición de representante de los trabajadores y de trabajador; los términos "participación y consulta", la nueva estructura de la planificación; la definición de peligro, matizando el concepto de peligro inminente; la formación y competencia; y la aplicación de la norma a todo tipo de organización sin importar su tamaño o naturaleza.

La siguiente reunión tendrá lugar el próximo mes de octubre de 2016 y se espera finalizar la redacción del segundo borrador. Hacía el mes de febrero de 2017 , se iniciará el proceso de votación de este segundo borrador que durará dos meses y 
hacía mayo se celebrará una nueva reunión del Comité ISO PC 283 en la que se decidirá si se publica el documento definitivo en torno a junio de 2017, o por el contrario se somete a un nuevo periodo de votación.

Así, pues, tendremos que esperar un año para que esta norma salga a la luz, aunque la publicación de la ISO 45001, como muy bien especifica AENOR, no supondría la anulación automática de la OSHAS 8001.

En una entrevista, publicada en la página de AENOR, hecha a David Smith, presidente del Comité ISO PC 283 que desarrolla la futura ISO 45001, el propio señor Smith nos ayuda a comprender qué ventajas tiene el implantar la ISO 45001 para la organización. Nos explica como esta norma reducirá los riesgos y creará mejores condiciones de trabajo en todo el mundo.

Según palabras del Sr. Smith "según el Congreso Mundial sobre Seguridad y Salud en el Trabajo, hay 860.000 accidentes de trabajo todos los días, con consecuencias en términos de lesiones. El coste de estos se estima en 2,57 billones de euros en todo el mundo. Las empresas tienen que garantizar que gestionan todos sus riesgos para sobrevivir y prosperar. La SST es un aspecto clave para esto. Una mala gestión de la SST puede tener muchos efectos negativos además de en la gente, en la organización".

¿Cómo funcionará la Norma ISO 45001 ?

El Sr. Smith contesta. " Es muy oportuno que la norma se haya desarrollado ahora, que también han sido actualizadas la ISO 9001 y la ISO 14001, ya que ambas utilizan un marco basado en el riesgo común.. Estos puntos en común permitirán a las organizaciones integrarse más fácilmente en sus procesos de negocio. Tiene el modelo PHVA que proporciona un marco a las organizaciones para planificar lo que necesitan y ponerlo en marcha para minimizar el riesgo de daños. La norma requiere que la alta dirección asuma la responsabilidad de demostrar el compromiso a través del liderazgo para asegurar que los trabajadores tengan las competencias adecuadas y que se pongan en marcha controles eficaces. Es muy valiosa la participación de los trabajadores".

¿En qué se diferencia la Norma ISO 45001 de otras normas de salud y seguridad en el trabajo?

"La norma no se ocupa de los productos y la forma en que deben ser utilizados o mantenidos. El enfoque es el lugar de trabajo. Se identifican los peligros ocupacionales para eliminarlos o minimizarlos. En este mundo de innovaciones rápidas, existe una necesidad de ser proactivo y anticiparse a la acción, en lugar de esperar a que se desarrollen regulaciones o códigos de buenas prácticas que pueden venir después de que muchos hayan sufrido lesiones. La norma está hecha para poder 
aplicarse a organizaciones grandes y pequeñas. Su enfoque basado en el riesgo será fácilmente adoptado por las pyme".

En la redacción de la norma han participado otras instituciones dedicadas a la seguridad como la Institución de Seguridad y Salud en el Trabajo (IOSH), la Sociedad Americana de Ingenieros de Seguridad (ASSE) y la Asociación Americana de Higiene Industrial (AIHA). Siempre que ha sido posible se ha procurado que no exista conflicto con otras normas que ya existen y están ampliamente adoptadas.

Para los usuarios de OSHAS 18001 la nueva norma no entra en conflicto con ella. Cómo explica el Sr. Smith "los beneficios de la adopción de la Norma ISO 45001, se alinea a los enfoques de gestión adoptados para otros riesgos empresariales. No existe un proceso formal de transición, como sí ocurre con las Normas ISO 9001 e ISO 14001, pero se están haciendo esfuerzos para ayudar a las organizaciones con la transición de la OSHAS 18001 a la Norma ISO 45001".

Se espera que la Norma ISO 45001 de mayor credibilidad a la gestión de la SST. Es de esperar que la norma reciba el respaldo dado a las normas ISO $9001 \mathrm{Y}$ 14001 por la comunidad empresarial. El comité ISO PC 283 está trabajado duro para poder publicarla en el año 2017. La amplia adopción de la norma debería reducir las horribles historias de mala gestión de la SST que llevan a la pérdida de vida, a lesiones y a grandes desastres.

Mientras se sigue trabajando en la redacción de esta norma ISO 45001, unos de los modelos más conocidos para desarrollar un sistema de Gestión de la Seguridad y la Salud Ocupaciones es la Especificación Técnica OSHAS 18001.

\section{SISTEMA DE GESTIÓN OSHAS 18001}

La publicación y desarrollo de la especificación técnica OHSAS 18001:2007 ha sido liderada por el British Standards Institution, aunque en su elaboración también han participado otras organizaciones como SGS, Bureau Veritas Quality Intenational, AENOR, entre otras, para dar respuesta a la demanda del mercado de un sistema de Gestión compatible con ISO 9001 (Calidad) e ISO 14001 (Medioambiente), y que pudiera ser auditable y certificable.

Los estándares OHSAS sobre gestión de la prevención tienen como objetivo facilitar a las organizaciones las herramientas de un sistema de gestión de la SST eficaz, que puedan ser integrados con otros requisitos de gestión, y que ayuden a la organización a conseguir estos objetivos. Estos estándares no se han pensado para crear barreras comerciales o arancelarias, o para aumentar las obligaciones legales de la organización.

La OHSAS especifica los requisitos para un sistema de gestión de la SST que 
permita a la organización desarrollar e implementar una política y unos objetivos que tengan en cuenta todos los requisitos legales y la información sobre los riesgos para la salud que pueden surgir en las organizaciones. Son aplicables a todo tipo de organizaciones, independientemente de su tamaño, tipo o naturaleza, y se pueden ajustar a cualquier diversidad geográfica, cultural y social.

Implantar un sistema de gestión de la SST en una organización, le permite desarrollar una política de SST, establecer unos objetivos y unos procesos para lograrlos, tomar las acciones de mejora que sean necesarias y demostrar la conformidad de su sistema de gestión de la prevención de riesgos laborales con los requisitos de OHSAS.

El mayor objetivo de OHSAS es apoyar y promover las buenas prácticas de SST, y sirve a la organización para garantizar a las partes interesadas que cuenta con un sistema de gestión de la SST apropiado.

Este estándar OHSAS, está basado en el ciclo P-H-V-A.

- Planificar: establecer los objetivos y procesos necesarios para conseguir resultados acorde con la política de SST de la organización;

- Hacer: se refiere a implementar los procesos;

- Verificar: hacer un seguimiento y medición de los procesos, los objetivos, las metas y los requisitos e informar de los resultados obtenidos.

- Actuar: tomar acciones para la mejora continua del sistema de gestión.

Esta metodología PHVA es totalmente compatible con la de ISO 9001, ya que ISO 9001 promueve el enfoque basado en procesos y la metodología PHVA se puede aplicar a todos los procesos.

Los estándares OHSAS se pueden auditar objetivamente. No se establecen requisitos absolutos para el desempeño de la SST más allá de los compromisos citados en la política de Seguridad y Salud en el Trabajo, y de los requisitos legales y otros que la organización haya suscrito para prevenir los daños y el deterioro de la salud.

Aunque OHSAS no incluye requisitos específicos para otros sistemas de gestión, como calidad o medioambiente, sus elementos son totalmente integrables con los de otros sistemas de gestión.

Su estructura es muy similar a la de las normas ISO 9001 Y 14004 y va en correlación con la LPRL.

Después de esta introducción la propia norma nos indica los requisitos para implantar un sistema de gestión de la SST. 


\section{Requisitos generales}

La organización debe establecer, documentar, implementar, mantener y mejorar continuamente un sistema de gestión de la SST de acuerdo con los requisitos de OHSAS y determinar cómo cumplirá estos requisitos.

\section{Política de SST}

La alta dirección debe definir y autorizar la política de SST y asegurarse de que ésta:

- es acorde con la naturaleza y la magnitud de los riesgos que puedan surgir.

- incluye un compromiso de prevención y de mejora continua de la gestión de la SST y del desempeño de esta.

- incluye el compromiso de cumplir al menos con los requisitos legales aplicables y otros que hayan pedido terceras partes.

- ofrece el marco de referencia para establecer y revisar los objetivos de SST.

- se documenta, implementa y mantiene.

- se comunica a todos los que trabajan en la organización.

- está a disposición de todas las partes interesadas.

- se revisa periódicamente para asegurarse de que sigue siendo actual y apropiada.

\section{Planificación}

La organización debe establecer, implementar y mantener los procedimientos necesarios para identificar los peligros, evaluar los riesgos y determinar cuántos controles sean necesarios.

\section{Identificación de peligros, evaluación de riesgos y determinación de controles}

Para identificar los peligros se tendrá en cuenta:

- todas las actividades.

- las actividades de las personas que tengan acceso al lugar de trabajo.

- cualquier factor humano.

- los peligros originados e identificados externos al lugar de trabajo, pero que pueden afectar adversamente la salud y seguridad de las personas pertenecientes a la organización.

- la infraestructura del lugar de trabajo.

- los cambios en actividades o materiales.

- los cambios en el sistema de gestión de la SST.

- cualquier obligación legal. 
- diseño de las áreas de trabajo incluyendo las instalaciones, maquinaria, equipamiento, procedimientos operativos y la organización del trabajo.

La metodología de la organización para determinar los peligros y evaluarlos deberá estar definida de acuerdo a su alcance, naturaleza y momento en el tiempo para asegurarse de que es preventiva más que reparadora.

La organización debe asegurarse de que se consideran los resultados obtenidos de las evaluaciones de riesgos determinando controles. La jerarquía de estos controles será:

- eliminación.

- sustitución.

- protección colectiva.

- protección individual.

Los resultados quedarán documentados y deberán estar actualizados.

\section{Requisitos legales y otros requisitos}

La organización deberá implementar procedimientos para estar al tanto de los requisitos legales que sean aplicables a la SST.

Se asegurará de que estos requisitos se suscriban, se cumplan, y que se tengan en cuenta en el establecimiento y la implementación del sistema de gestión de la SST.

Se mantendrá está información actualizada, y se comunicara a las personas que trabajan en la organización y a otras partes interesadas.

\section{Objetivos y programas}

La organización debe establecer objetivos medibles y coherentes con la política de SST, teniendo en cuenta los requisitos legales, sus opciones tecnológicas, sus requisitos financieros, comerciales y operacionales, y los requisitos de otras partes interesadas.

Se establecerán programas para alcanzar estos objetivos que incluyan:

- la asignación de responsabilidades y autoridad para lograr los objetivos en los niveles pertinentes de la organización.

- los medios y plazos para lograrlos.

Los programas se revisarán periódicamente para ver si es necesario hacer algún ajuste o para verificar de que se alcanzan los objetivos. 


\section{Implementación y operación}

La alta dirección es la responsable en última instancia de la seguridad y salud en el trabajo y del sistema de gestión. Debe demostrar su compromiso asegurándose de que existen los recursos necesarios disponibles para implementar y mantener el sistema de gestión de SST, y designando personal responsable y con autoridad.

Se designarán a uno o varios miembros de la organización con responsabilidad específica en el SST para asegurarse de que el sistema de gestión de SST se establece, se implementan y se mantiene. $Y$ para asegurarse de que el sistema de gestión de SST se revisa para conseguir la mejora continua.

\section{Competencia, formación y toma de conciencia}

La organización debe asegurarse de que cualquiera de sus miembros que realice tareas que puedan causar impactos en la SST, sean competentes y estén bien formados. Para ello, si es necesario, debe proporcionar la formación necesaria y adecuada.

\section{Comunicación, participación y consulta}

En cuanto a la comunicación es necesario que sea tanto interna como externa. Interna entre los distintos niveles y funciones, y externa con los contratistas y otros que visitan el lugar de trabajo.

La participación será de los trabajadores mediante:

- su adecuada involucración en la identificación de los peligros, la evaluación de los riesgos y determinación de controles.

- su adecuada participación en la investigación de accidentes.

- involucrándose en el desarrollo de las políticas de SST.

- dando su opinión ante los cambios que afecten a la SST.

- representación en los temas de SST.

\section{Documentación}

La documentación incluye:

- la política y los objetivos del SST.

- la descripción del alcance del sistema de SST.

- descripción de los elementos principales del sistema y la referencia a otros documentos relacionados. 
- registros y otros documentos requeridos por OHSAS.

- los documentos que determine la organización como necesarios.

\section{Control de documentos}

Todos los documentos se deben controlar. Se implementarán procedimientos para comprobar que son adecuados desde antes de emitirlos, cuando sean revisados y cuando existan versiones actualizadas.

Se mantendrán legibles y fácilmente identificables y se tomarán medidas para evitar el uso no intencionado de documentos obsoletos y conservados por alguna razón.

\section{Control operacional}

Se identificarán las operaciones y actividades relacionadas con los peligros identificados y para los que sea necesario implementar controles para gestionar el riesgo.

\section{Preparación y respuesta ante emergencias}

La organización debe identificar las posibles situaciones de emergencia y como se debe responder ante ellas para establecer, implementar y mantener los procedimientos adecuados.

Al planificar estas situaciones se tendrán en cuenta las necesidades de las partes interesadas externas a la organización como pueden ser los vecinos, o los servicios de emergencia.

Se harán simulacros de estas situaciones para comprobar si los procedimientos son los adecuados y la preparación de todos los miembros de la organización es la necesaria.

\section{Verificación. Medición y seguimiento del desempeño}

Se deben establecer procedimientos por parte de la organización para hacer un seguimiento y medición de forma regular del desempeño de la SST.

Estos procedimientos deben incluir:

- las medida cualitativas y cuantitativas apropiadas a las necesidades de la organización.

- el seguimiento del grado de cumplimiento de los objetivos de SST.

- el seguimiento de la eficacia de los controles tanto para la salud como de seguridad.

- las medidas preventivas del desempeño. 
- las medidas reactivas que evidencian un desempeño deficiente.

- registro de datos y de los resultados del seguimiento y medición para analizar y tomar medidas y acciones preventivas.

\section{Evaluación del cumplimiento legal}

La organización debe mantenerse al día con los cumplimientos legales que le sean de aplicación, y establecerá los procedimientos necesarios para evaluar su cumplimiento. También evaluará el cumplimiento de otros requisitos que suscriba.

Todos los registros de las evaluaciones periódicas se mantendrán.

\section{Investigación de accidentes}

La organización debe establecer, implementar y mantener los procedimientos convenientes para registrar, investigar y analizar los accidentes. Así:

- se detectarán deficiencias de SST.

- se identificarán las acciones correctivas necesarias

- se identificarán las acciones preventivas a llevar a cabo

- se identificarán las oportunidades para la mejora continua.

Se comunicarán los resultados de las investigaciones de accidentes y cualquier acción correctiva necesaria para implantar una acción preventiva.

\section{No conformidad, acción correctiva y acción preventiva}

Para tratar las no conformidades, la organización pondrá en funcionamiento procedimientos para registrarlos, investigarlas y analizarlas. Como resultado se podrán identificar y corregir. Se tomarán las acciones correctivas y preventivas necesarias, se registrarán y se revisarán estas acciones.

$\mathrm{Si}$ al tomar estas medidas se identifican nuevos peligros, el procedimiento debe requerir que esas acciones propuestas se tomen tras evaluar los riesgos.

\section{Control de los registros}

La organización debe establecer y mantener todos los registros que sean necesarios para poder demostrar la conformidad con los requisitos de su sistema de gestión de la SST, y de la especificación técnica OHSAS: 2007, y para demostrar los resultados logrados.

Se establecerán procedimientos para la identificación, el almacenamiento, la protección, la recuperación, el tiempo de retención y la disposición de los registros. 
Estos deben ser legibles e identificables.

\section{Auditoría interna}

Serán auditorias planificadas para determinar si el sistema de gestión de la SST es conforme a las disposiciones del sistema y de OHSAS, si se ha implementado correctamente y si es eficaz para cumplir con la política y los objetivos de la organización.

Los programas de auditoria deben estar planificados y mantenidos teniendo en cuenta los resultados de las evaluaciones de riesgos de las actividades de la organización.

Tanto los auditores como la auditoría debe asegurar la objetividad y la imparcialidad del proceso.

\section{Revisión por la dirección}

La alta dirección asume el papel de revisar el sistema de gestión de la SST de la organización. Se planificará cuando se hará para asegurar su conveniencia, adecuación y eficacia continuas. Estas revisiones incluirán la evaluación de oportunidades de mejora, y si es necesario efectuar cambios en el sistema de gestión de SST.

Los resultados de las revisiones por la dirección deben ser coherentes con el compromiso de mejora continua de la organización e incluir cualquier cambio o decisión que esté relacionada con el sistema de gestión de SST.

Los resultados quedarán recogidos en un documento archivándose como un registro del sistema de prevención. 


\section{GESTIÓN INTEGRADA DE SISTEMAS DE GESTIÓN DE CALIDAD, AMBIENTE Y RIESGOS LABORALES}

Según el diccionario de la Real Academia de la Lengua, integrar, entre otros conceptos, significa constituir un todo, constituir un todo con las partes que faltaban, hacer que alguien o algo pase a formar parte de un todo. Es decir, se trata de recoger en algo único, distintas partes, desempeñando las funciones que hacían dichas partes de modo unificado.

Está clara la economía de esfuerzos que conseguimos cuando un único elemento puede ejecutar las mismas funciones que hacían varios. Esta es una gran ventaja de la integración de los sistemas de gestión de calidad, ambiente y riesgos laborales.

Según la definición de Labein, en su libro La integración de la Calidad, el Medio Ambiente y la Seguridad en la Gestión Empresarial un Sistema Integrado de Gestión es el "conjunto de la estructura organizativa, la planificación de las actividades, las prácticas, los procedimientos, los procesos y los recursos necesarios para desarrollar, implantar, llevar a efecto, revisar y mantener al día la política de la empresa" y en el tema que ocupa este trabajo, añadiríamos "en materia de calidad, medio ambiente y prevención de riesgos laborales.

El objetivo de cualquier sistema de gestión empresarial, ya sea de calidad, medioambiente o prevención de riesgos es suministrar garantías del cumplimiento de las especificaciones, la legislación y la normativa, y proceder a la mejora continua del sistema, así como permitir que se pueda demostrar este cumplimiento mediante la información documentada y los registros adecuados.

Es decir, se trata de detallar en un solo documento un sistema que:

- aúne los requisitos que son equivalentes;

- permita la definición de sistemas de actuación similares antes aspectos o requisitos que estén especificados independientemente en los tres sistemas de gestión.

Las preguntas que cualquier organización se hará en el momento de decidir si implanta un sistema integrado de gestión son:

- ¿Cómo debo hacerlo?

- ¿Para qué?

- ¿Cuándo?

- ¿Qué recursos, físicos y humanos, necesitaré? 
¿Qué piensan las bibliotecas universitarias españolas de integrar los sistemas de gestión de calidad, medioambiente y prevención de riesgos?

Pues bien, para averiguarlo y cómo parte de esta investigación se ha hecho una encuesta a los76 los representantes miembros de 50 universidades de ámbito público y de ámbito universitario privado. integrantes de la red Rebiun (Red de bibliotecas Universitarias Españolas) preguntándoles si tenían implantados sistemas de Gestión de Calidad, Medioambiente y Prevención de Riesgos en sus bibliotecas. De los 76 miembros contestaron 62. De estas sólo 10 tienen sistema de gestión de calidad certificado, ninguna tiene sistema de gestión ambiental y el sistema de gestión de prevención es el de la propia universidad. También se les preguntó si tenían Sistema Integrado de Gestión y ninguna lo tiene, pero a todas les parecía interesante la idea.

\section{Fundamentos para la integración}

Es cierto que una de las diferencias entre los sistemas de gestión de calidad, ambiente y riesgos laborales, es el punto de vista de la exigencia. Los sistemas de gestión de calidad y ambiente (este con matices) son implantados voluntariamente por el empresario si así lo decide, ya que no hay una norma legal que sea de obligado cumplimiento. Sin embargo, el sistema de seguridad y salud viene impuesto por obligación legal. Pero, la ley de Prevención de Riesgos Laborales, no solo establece la obligatoriedad de que las empresas cuenten con un sistema de seguridad y salud. También apuesta por la integración citándola en su artículo 16.1 "la prevención de riesgos laborales deberá integrarse en el sistema general de gestión de la empresa, tanto en el conjunto de sus actividades como en todos los niveles jerárquicos de esta...".

En este mismo sentido el artículo 14.2 de la LPRL afirma que "el empresario realizará la prevención de los riesgos laborales mediante la integración de la actividad preventiva en la empresa"

Es decir, la prevención de riesgos se tendrá en cuenta en todo el conjunto de actividades que realice la empresa, en todos los niveles jerárquicos y en todas las decisiones que adopten.

Todos estos aspectos de la normativa legal, hacen que pensemos que la gestión de la prevención de riesgos está muy interrelacionada con los sistemas de gestión de calidad y de medio ambiente.

Cómo podemos observar, normativamente existen en los tres sistemas analizados, ISO 9001, ISO 14001 y OHSAS 18001, una gran cantidad de 
coincidencias. Por citar algunas, en los tres se expresa el necesario compromiso de la alta dirección y de las personas que componen la organización. En los tres sistemas de gestión es muy importante la participación de los trabajadores. Los tres sistemas tienen una percepción prevencionista, es decir, quieren solucionar los problemas antes de que ocurran alejándose así, de la percepción reparacionista de sistemas más antiguos en los que se aprendía del error cuando ya había sucedido.

Cómo se desprende del estudio de los tres sistemas, todos ellos se basan en la integración funcional, y buscan optimizar los recursos mediante la reducción de los costes que surgiría de una gestión deficiente.

Todo esto nos permite considerar que la integración de los tres sistemas es un proceso natural con inercia propia, que puede ser el marco de referencia que la organización necesite para alcanzar sus objetivos y situarse en una situación más ventajosa dentro de su campo de actuación.

Lo que propone el planteamiento de la integración, es recoger las reglas del juego en un único manual de gestión común, y jerárquicamente debajo de él, situaríamos unos manuales para cada uno de los sistemas de gestión de calidad, medio ambiente y seguridad y salud.

Estos sub manuales, servirían como referencia a los auditores mostrándoles dónde se ubican los procedimientos clave, pero necesarios, para cada sistema de gestión. El esquema sería así:

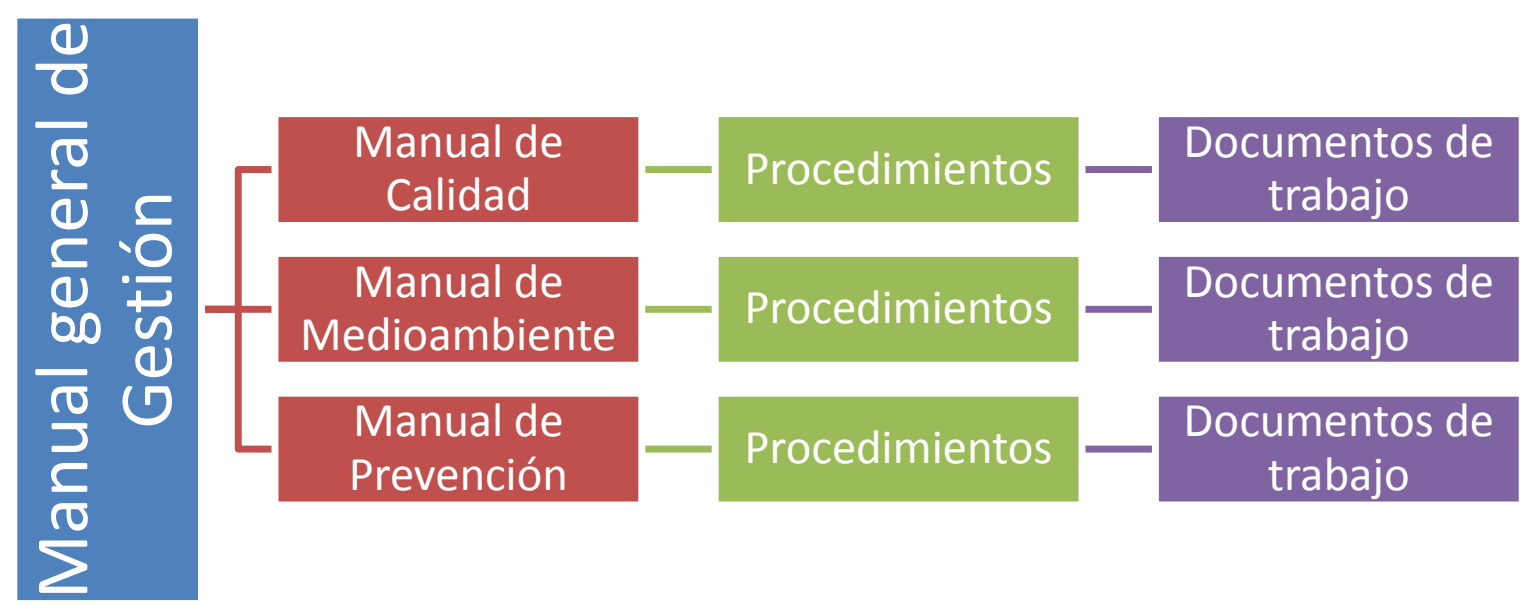




\section{Motivo económico}

No cabe duda, que el propósito de cualquier organización, es identificar y satisfacer las necesidades y expectativas propias, de sus clientes y de otras partes interesadas.

Todo esto se quiere conseguir para:

- conseguir ventajas competitivas, eficaces y eficientes.

- mejorar la capacidad y el desempeño global de la organización.

En un sistema en el que cada vez hay mayor sensibilización por los aspectos relacionados con la satisfacción del cliente, la protección del Medio Ambiente y la Seguridad y Salud de los trabajadores, es sin duda un factor diferenciador, un modelo de gestión conjunta de estos tres sistemas que contribuirán a la mayor competitividad de la organización.

\section{Implantación de un sistema de gestión integrado}

El fin que quiere conseguir la organización es:

- Un sistema de Gestión integrado que aproveche al máximo las similitudes que comparten los tres sistemas. Es decir, se deben establecer sistemas de actuación similares en aspectos como política, objetivos, estructura, responsabilidades, formación, información, documentación, no conformidades, acciones correctoras, auditorias...

- Certificar su sistema de calidad según la Norma ISO 9001:2015. Sistemas de gestión de calidad. Requisitos.

- Certificar su sistema de gestión ambiental según la norma ISO 14001:2015. Sistemas de gestión ambiental. Requisitos con orientación para su uso.

- Certificar su sistema de gestión de seguridad y salud mediante la norma ISO 45001 en un futuro cercano, y en estos momentos mediante la norma OHSAS 18001:2007. Gestión de la Seguridad y Salud laboral.

\section{Metodología y desarrollo}

El punto de partida serán los aspectos de las tres normas (ISO 9001:2015, ISO 14001:2015 y OHSAS 18001:2007) que estén directamente relacionados como son:

a) Compromiso por parte de la Alta Dirección y el reflejo en toda la organización. El éxito de la implantación del sistema de gestión integrado va a depender en gran medida, del compromiso que refleje la Dirección y del grado de responsabilidad que se logre inculcar a los miembros de la organización.

b) Carácter preventivo. La tendencia del sistema integrado de gestión será claramente preventiva, anticipándose a los errores. 
c) La metodología a seguir será el ciclo PHVA. Este método lo utilizan las tres normas proporcionando un modelo interactivo que permite a las organizaciones lograr la mejora continua.

En todo sistema de Gestión Integrado deben quedar recogidos unos elementos:

- Requisitos que el sistema debe cumplir. En el caso del sistema de calidad vienen exigidos por los clientes y por la propia organización. En el caso de medioambiente los requisitos vienen establecidos por la legislación y por otras partes interesadas. En el sistema de seguridad y salud hay unos requisitos exigibles legales y reglamentarios.

- Procedimientos. Son la base documental de las actividades que se realizan en la organización. Pueden ser comunes a los tres sistemas de gestión, o específicos para cada uno de ellos.

- Indicadores. Permitirán medir el grado de cumplimiento de los requisitos.

En el modelo de Gestión Integral propuesto quedarían especificados algunos elementos necesarios para lograr el éxito de su implantación.

Estos podrían ser:

1. Sistema de Gestión.

Especifica como la Dirección lidera, dirige y organiza el sistema de Gestión que ya tiene implantado y como los mantiene actualizados.

- Define el alcance y las normas de aplicación del sistema de gestión.

- Define como se establece un entorno adecuado para el establecimiento de los objetivos de la organización.

2. Políticas de Gestión.

Definen la autoridad y la responsabilidad delegada en las distintas posiciones en la organización.

- Señalan los objetivos y como se van a implantar.

- Señala a que aspectos de la organización aplica el sistema de gestión y como serán atendidas, aplicadas y actualizadas por quien corresponda.

3. Organización y responsabilidad.

Se especifican todos los procedimientos a seguir para alcanzar los objetivos.

Puede existir un Comité de Gestión que estudie los documentos que se le presenten y comenten y aprueben las acciones necesarias. 
Un comité de seguridad y salud y medioambiente que se ocupen de los aspectos relativos a la prevención de riesgos y a la gestión medioambiental.

Un comité específico para el sistema de gestión de calidad.

Los recursos tanto humanos, como físicos, de los que se disponen para cubrir las necesidades derivadas del sistema de gestión.

- Especificar cómo se llevará a cabo la revisión del sistema de gestión por parte de la Dirección.

4. Control de la información documentada.

Los tres sistemas exigen mantener información documentada para comprobar cómo se está desarrollando el sistema de gestión. Pues bien, será necesario establecer un sistema para controlarla, clasificarla y distribuirla si fuera necesario.

\section{Auditorías internas}

Se definirá el número de auditorías preciso para evaluar el sistema. También se establecerá la periodicidad, el método, la formación exigida a los auditores, el modelo de informe y cómo se hará el seguimiento de las auditorias.

\section{Registros}

- Es importante especificar como se controlarán los registros del sistema de gestión.

\section{Formación}

Se establecerá la mecánica para detectar las necesidades de formación continua de todo el personal propio de la organización y terceros que la visiten, así como las necesidades de formación que surjan cuando se produzcan movimientos en los puestos de trabajo.

\section{Acciones preventivas y correctivas}

Con estas acciones se fomenta la mejora continua de la eficacia del sistema de gestión ya que son la manera de detectar que acciones preventivas se tomarán para evitar no conformidades, y las acciones correctivas si estas se producen.

La información de estos elementos está recogida en la información documentada que se recopila en cada uno de los tres sistemas de gestión, Calidad, Medioambiente y Seguridad y Salud en el trabajo. Toda la documentación está previamente revisada por la Dirección. Es una herramienta de referencia fiable y apropiada a tener en cuenta en la implantación de un sistema de gestión integrado. 


\section{Ventajas e inconvenientes de la integración de sistemas de gestión}

En términos generales, podríamos citar la reducción de costes, la optimización de recursos, la mejora de la percepción de imagen, la simplificación de la documentación generada como ventajas de la implantación de un sistema integrado de gestión de calidad, medioambiente y seguridad y salud en el trabajo.

Pero no todo es positivo. No nos podemos olvidar de algunos inconvenientes como son las repercusiones organizativas e individuales, una insuficiente motivación de la dirección, la no disposición de recursos, humanos y materiales, para la gestión, y la falta de metodologías precisas para llevarla a cabo con éxito. Además del miedo que producen las novedades y los cambios.

Pero vamos a detenernos un poco más en este asunto.

Comenzamos con las ventajas o aspectos positivos de la integración:

1. La primera ventaja es la propia decisión de implantar el sistema de gestión integrado en la organización, ya que esto supone una disminución considerable de los costes asociados a la implantación de los tres sistemas por separado.

2. Otra consecuencia positiva es la simplificación y el menor coste del proceso de certificación, si se compara con el coste de certificar cada sistema por separado. Además, la certificación de cada área será más sencilla ya que sólo se tienen en cuenta los aspectos específicos del nuevo sistema.

3. Las auditorias de implantación, seguimiento y revisión de los tres sistemas se realizarían al mismo tiempo, por un equipo auditor polivalente. Esto también supone un ahorro considerable para la organización tanto en tiempo como en dinero.

4. El certificado de empresa certificada en las tres áreas, calidad, medioambiente y seguridad y salud, se conseguiría más rápido al ser uno sólo para todas

5. Se simplificaría la documentación necesaria al ser ésta única, esto conllevaría más facilidad de manejo, más transparencia y una reducción de costes de mantenimiento. Se optimizarían los recursos y el tiempo que se emplean en el cumplimiento de los requisitos. También se reducen los registros, por lo tanto, se reducen también la gestión y el control de los mismos.

6. La unidad de gestión se traduce en una mejora de la misma, aumentando la eficacia en la gestión y la eficiencia en la consecución de objetivos y metas definidos 
por la organización. Con esto se conseguiría resolver problemas de un área sin crear nuevas dificultades en las otras.

7. Se minimizan las distorsiones en la asignación de recursos en las tres áreas, ya que al estar integrados no se prioriza ningún sistema en detrimento de los otros.

8. Se proporciona valor añadido a las actuaciones de la organización. La disposición y el compromiso de las empresas a participar en la mejora de la calidad, el medioambiente y la prevención de riesgos laborales se traduce como una optimización de su funcionamiento y se concibe como un sistema más fácil de manejar, desarrollar y mantener. De hecho, cada vez, se exige más por parte de terceros ajenos a la organizaciones, que estas tengan certificado alguno de sus sistemas de gestión.

9. Puede ayudar a los poderes públicos a sensibilizarse para establecer medidas de fomento encaminadas a difundir la implantación de este tipo de sistemas en otras organizaciones.

10. El sistema integrado lleva implícito una mayor motivación y participación del personal que integra la organización ya que es más fácil conseguir que participen en un único sistema que en varios.

11. La medición, evaluación y seguimiento de los objetivos marcados se lleva a cabo de una manera más eficaz.

12. Supone un ahorro económico en aspectos tan importantes como el tiempo empleado en reuniones, en la gestión de sistemas, en formación o en personal.

13. Mejora la imagen de la organización ante la sociedad y esto genera confianza entre los clientes y consumidores.

Aunque es cierto que existen numerosas ventajas, también nos encontramos con algunos inconvenientes, sobre todo relacionados con las dificultades que para el personal puede suponer una innovación o un cambio. Son inconvenientes que deben estar previstos y que hay que darles solución.

Algunos de estas desventajas serian:

1. Falta de personal con la preparación suficiente para trabajar en las tres áreas. 
Por tanto habría que hacer una inversión en formación y habría que obtener un mayor compromiso por parte de la dirección.

2. Falta de concienciación del personal en las empresas en materia de prevención de riesgos laborales, y medioambiente. Si es difícil motivar al personal en alguna de estas dos áreas, mucho más difícil será hacerlo en las simultáneamente.

3. Mayor dificultad para poner en marcha un único sistema integrado en comparación con uno solo. 


\section{MODELO DE SISTEMA DE GESTIÓN INTEGRADO}

\section{DOCUMENTACIÓN DEL SISTEMA INTEGRADO DE GESTIÓN}

El sistema documental es el soporte del sistema de gestión integral. La unificación del sistema de gestión documental de las áreas de calidad, medio ambiente y seguridad y salud, es uno de los pilares básicos de la integración, a la vez que una garantía de su eficacia. No sería lógico pretender tener un sistema de gestión integrado y mantener la coexistencia de tres sistemas documentales diferentes.

\section{Manual de Gestión Integrada}

Aunque es cierto que con las nuevas ISO 9001 y 14001 no es obligatorio elaborar un manual, para integrar las tres áreas si sería oportuno crear un Manual de Gestión Integrada en el que se trate únicamente la sucesión de los procedimientos que son comunes a las tres áreas. No se debería ver la elaboración de este Manual como un paso atrás en la gestión, sino como una guía que describe ordenadamente los requisitos comunes a las tres áreas que vamos a unificar y tomar como ideas principales.

Sería el documento principal del sistema de gestión integrada. Define al propio sistema, la política integrada y establece las funciones y responsabilidades. Es un documento imprescindible en el proceso de implantación del sistema integrado, ya que establece el guión a seguir.

Debería ser sencillo y claro, y como mínimo debería incluir:

I. Índice del manual

II. Control de modificaciones del manual

III. Introducción

IV. Objeto y campo de aplicación

V. Normas para consulta

VI. Definiciones

VII. Política integrada

VIII. Compromiso de la dirección

IX. Planificación

X. Funciones, responsabilidad y autoridad

XI. Revisión por la dirección

XII. Procedimientos del sistema de gestión integrada

XIII. Instrucciones técnicas de trabajo

XIV. Registros del sistema de gestión integrada 
Vamos a pormenorizar cada una de estas partes.

\section{Índice del manual}

Enumera ordenadamente los apartados del manual, indicando la página en la que se encuentran.

\section{Control de modificaciones del manual}

Señala las distintas ediciones del manual, sus fechas, las revisiones y las modificaciones.

\section{Introducción}

Es una presentación de la organización, con mención al año de su creación, a las actividades que desarrolla, a los servicios y productos que presta, y una referencia a los recursos humanos y materiales con los que cuentan para cumplir sus objetivos.

\section{Objeto y campo de aplicación}

Este apartado enuncia los objetivos del manual y describe las actividades a que alcanza el campo de aplicación del manual de gestión integrada.

\section{Normas para su consulta}

Se especifican las normas cuya consulta puede ser clarificadora y complementaria a las normas que estamos integrando.

\section{Definiciones}

Se recogen los términos y definiciones aplicables al manual y propias de los tres sistemas a integrar.

\section{Política integrada}

Se expresa el compromiso de la dirección en materia de calidad, medio ambiente y seguridad y salud de los trabajadores. Proporciona el encuadre para el establecimiento de los objetivos y metas de la organización.

Es una declaración documentada a disposición del público que recoge los objetivos generales de la organización con respecto a las áreas a integrar y debe transmitir el liderazgo y compromiso de la dirección con el Sistema de Gestión Integrada, así como las directrices de actuación para conseguirlos. 


\section{Compromiso de la dirección}

El objetivo de este apartado es que la dirección documente su compromiso y obligaciones para asegurar el objetivo de las metas definidas en el manual de Gestión Integrada.

En este apartado se incluyen aspectos como la disponibilidad de recursos y la importancia del cumplimiento del manual por todo el personal.

Si la dirección nombra un representante, es imprescindible que este nombramiento sea conocido por todos los miembros de la organización y que conozcan sus funciones, responsabilidades y autoridad.

\section{Planificación}

Se indicarán como se cumplirán los requisitos del sistema de gestión integrada.

\section{Funciones, responsabilidad y autoridad}

Se definirán las funciones, responsabilidades y autoridades en materia de calidad, medio ambiente y prevención de riesgos laborales.

Funciones son tareas que corresponde realizar a una persona.

Responsabilidad es la obligación o cargo que se la atribuido a esta persona sobre el resultado de la realización de ciertas tareas. No se delegan responsabilidades.

Autoridad se refiere a las relaciones de jerarquía y mando que se establecen para tener la capacidad de exigir a otros el cumplimiento de ciertas tareas. La autoridad tampoco se delega.

La organización se encargará de que todos sus miembros conozcan las responsabilidades de cada uno. No sólo las comunicará sino que se asegurará de que todos las comprendan.

\section{Revisión por la dirección}

Periódicamente, la dirección revisará el Sistema de Gestión Integrada para valorar los resultados de las auditorías, analizar el nivel de cumplimiento de los objetivos, evaluar las no conformidades presentadas y buscar propuestas de mejora. Esto se debería hacer al menos una vez al año.

\section{Procedimientos del sistema de gestión integrada}

Se recogerían los procedimientos comunes a los tres sistemas y se relacionarían en el Sistema de Gestión Integrada.

Se haría lo mismo con los procedimientos exclusivos de cada área.

Cada procedimiento debe incluir: 
- Objeto: lo que se pretende conseguir.

- Alcance: que partes de la organización se verán afectadas por el mismo.

- Responsabilidades: las personas encargadas de hacer cumplir el procedimiento.

- Desarrollo: la descripción detallada del procedimiento.

- Referencias: todos los documentos tanto internos como externos, que se relacionan con el procedimiento.

\section{Instrucciones técnicas de trabajo}

Documentos de menor rango que los procedimientos que describen y detallan como se realizan ciertas actividades que incidan en alguna de las tres áreas a integrar.

\section{Registros del sistema de gestión integrada}

Son los formatos del sistema una vez cumplimentados. Cumplen la función de evidenciar la adecuación y eficacia del sistema de gestión integrado, y sirven como fundamento para tomar las decisiones pertinentes para la mejora del sistema. 


\section{MODELO DE SISTEMA DE GESTIÓN INTEGRADO DE} CALIDAD, AMBIENTAL Y SEGURIDAD Y SALUD PARA LA BIBLIOTECA DE LA UGR

\section{Historia de la BUG}

Para conocer la historia de la biblioteca universitaria de Granada hay que considerar el origen y evolución tanto de la biblioteca cómo de los fondos que la conforman.

Aunque la documentación que se conserva de la primera etapa de la biblioteca es escasa, debido a un incendio que se produjo en el Archivo Universitario en 1886, podríamos decir que la vida de la Biblioteca comienza con la fundación del Estudio General de Lógica, Filosofía, Teología y Cánones, que tuvo su origen en la visita que realizó Carlos V en 1526 a la ciudad de Granada.

Más adelante, la Universidad se ve afectada positivamente con la llegada de los Borbones y la influencia del pensamiento ilustrado, preocupados por elevar el nivel intelectual de sus súbditos.

Durante la segunda mitad del siglo SVIII y todo el siglo XIX, la Universidad se ve influenciada por una serie de Planes de Estudios y Reformas Universitarias que la hacen moderna, y más abierta a las corrientes intelectuales del resto de Europa.

Con la expulsión de la Compañía de Jesús, decretada por Carlos III en 1767 y la incautación de todo su patrimonio, y después, la desamortización de Mendizábal, la universidad se dota de unos recursos que hasta entonces no tenía.

Se trasladó al edificio del antiguo Colegio jesuita de San Pablo, instalándose allí la Biblioteca. Los fondos del colegio pasaron a ser parte de la Universidad, con lo que se obtienen un gran número de fondos, entre ellos varios incunables, además de algunos códices valiosos y numerosos legajos. Se nombra en 1780 al primer bibliotecario conocido, D. Juan Gil Palomino, sucediéndole el catedrático Juan Velázquez de Echevarría y después D. Antonio de Pineda y Barragán.

En el año 1841, la Biblioteca vuelve a enriquecerse con los fondos incautados a los conventos de la capital y provincia, que se pusieron bajo la custodia de la Universidad tras el fallido intento de crear un Museo de la Ciudad para ubicar en el todos estos bienes.

Ya durante la segunda mitad del siglo XIX y principios del XX, se van configurando las líneas de la moderna biblioteca universitaria. Se dio un paso importante en 1858 con la creación del Cuerpo Facultativo de Archiveros, Bibliotecarios y Anticuarios y el 1932 con la creación del cuerpo de Auxiliares. Así la actividad bibliotecaria se independiza de la labor docente y se profesionaliza 
encargándose de las tareas organizativas y técnicas. Además la estructura misma de la biblioteca se hace más compleja y van apareciendo bibliotecas de Facultades, Cátedras y Seminarios dotándose de su propio catálogo para controlar sus fondos.

Desde la segunda mitad del siglo XIX las Facultades se van independizando y formando sus propias bibliotecas y depósitos para ubicar sus fondos, y se dotan de partidas presupuestarias propias para adquirir estos.

En el siglo XX varias Facultades se trasladan a nuevos edificios y la geografía universitaria de la ciudad se dibuja en grandes campus que acogen a las distintas Facultades y Escuelas. En 1980 la Biblioteca General se trasladó al Hospital Real, nueva sede del Rectorado. Desde esa fecha, la Biblioteca ocupa el crucero superior, donde se expone el fondo antiguo. Además hay salas de lectura e investigación, la Dirección de la Biblioteca Universitaria y sus servicios centrales.

Así, podemos decir que en la Universidad de Granada, existe una Biblioteca Central con sede en el hospital real, y 22 bibliotecas repartidas en todos los edificios que se encuentran en los distintos Campus Universitarios, ocupando en todos ellos la Biblioteca un lugar importante.

La BUG realizó un gran esfuerzo para conseguir evaluar la calidad de su servicio. En el año 2007 obtuvo su primer Certifica ISO 9001, encontrándose actualmente en el tercer ciclo de renovación (cada ciclo tiene una duración de 3 años). Durante estos años, el Sistema de Gestión de Calidad ha ido evolucionando estableciendo nuevo objetivos de calidad, optimizando la definición de Indicadores, y como consecuencia del control de sus procesos, se han definido acciones de mejora resolviendo incidencias y No Conformidades. También es un área muy preocupada por llevar una adecuada gestión de los aspectos ambientales que originan sus actividades. De hecho como parte de sus grupos de mejora para analizar los aspectos en los que la biblioteca puede dar mejor servicio a toda la comunidad, creó un grupo de calidad ambiental, pasando después a formar parte del grupo de Ética, Responsabilidad Social y Comunicación externa, encargándose de garantizar los valores y respeto al medioambiente que se esperan de la BUG. La Biblioteca también gestiona los riesgos a los que se ven sometidos sus trabajadores trabajando mano a mano con el servicio de prevención de riesgos laborales de la UGR.

Entonces, ¿por qué no integrar estos tres aspectos?

Con la integración de la calidad, la gestión ambiental y la prevención de riesgos laborales, se pretendería conseguir:

- La seguridad y la salud en los puestos de trabajo de la Biblioteca universitaria.

- La protección ambiental.

- La satisfacción de los trabajadores y usuarios. 
- La integración de estos elementos en el sistema de gestión de toda la Universidad de Granada.

Antes de comenzar con el proceso de desarrollo e implantación de un SGI, debemos tener en cuenta una serie de cuestiones:

- Confirmar que contamos con el apoyo del equipo rectoral y en este caso con la dirección de la biblioteca.

- Recordar que al ser una estructura multidisciplinar tenemos que contar con profesionales del campo de la prevención de riesgos, del medio ambiente y la gestión de la calidad.

- Hay que tener claramente definidos los objetivos que se quieren conseguir con la implantación de este tipo de gestión.

- Al principio del proceso, dar publicidad a este.

- Mantener una comunicación fluida entre todas las bibliotecas y la sede central.

- A lo hora de implantar el modelo de gestión integrada, optar por el que más convengan.

Esto en términos generales. Pero además también deberemos conocer:

- La gran cantidad de tiempo que se tienen que invertir en las primera fases de implantación del SGI. Recordemos que estamos hablando de una sóla biblioteca pero con distintas sedes distribuidas por los distintos campus universitarios. Esto hará que la inversión de tiempo sea mayor.

- Los recursos humanos y económicos que necesitaremos. Puede ser que exista una partida presupuestaria para alguna de las áreas que queremos integrar, o puede ser que no exista partida presupuestaria para ninguna, por lo que será necesario que:

- se consiga que los recurso económicos necesarios figuren en el presupuesto como una partida más,

- el personal encargado de dirigir el proceso de integración pertenezca a la biblioteca universitaria.

\section{Estructura del modelo de gestión propuesto}

La estructura del modelo propuesto para la implantación de un SGI en la biblioteca universitaria está basada en el Ciclo de Mejora Continua o Ciclo de Deming en el que se basan las normas internacionales que vamos a tomar como referencia, es decir, la norma ISO 9001 para la gestión de la Calidad, la norma ISO 14001 para la Gestión Ambiental y la norma OHSAS 18001 para la Gestión de la Prevención de Riesgos Laborales. 
Para que el proceso sea sencillo se puede dividir como se muestra en el siguiente gráfico

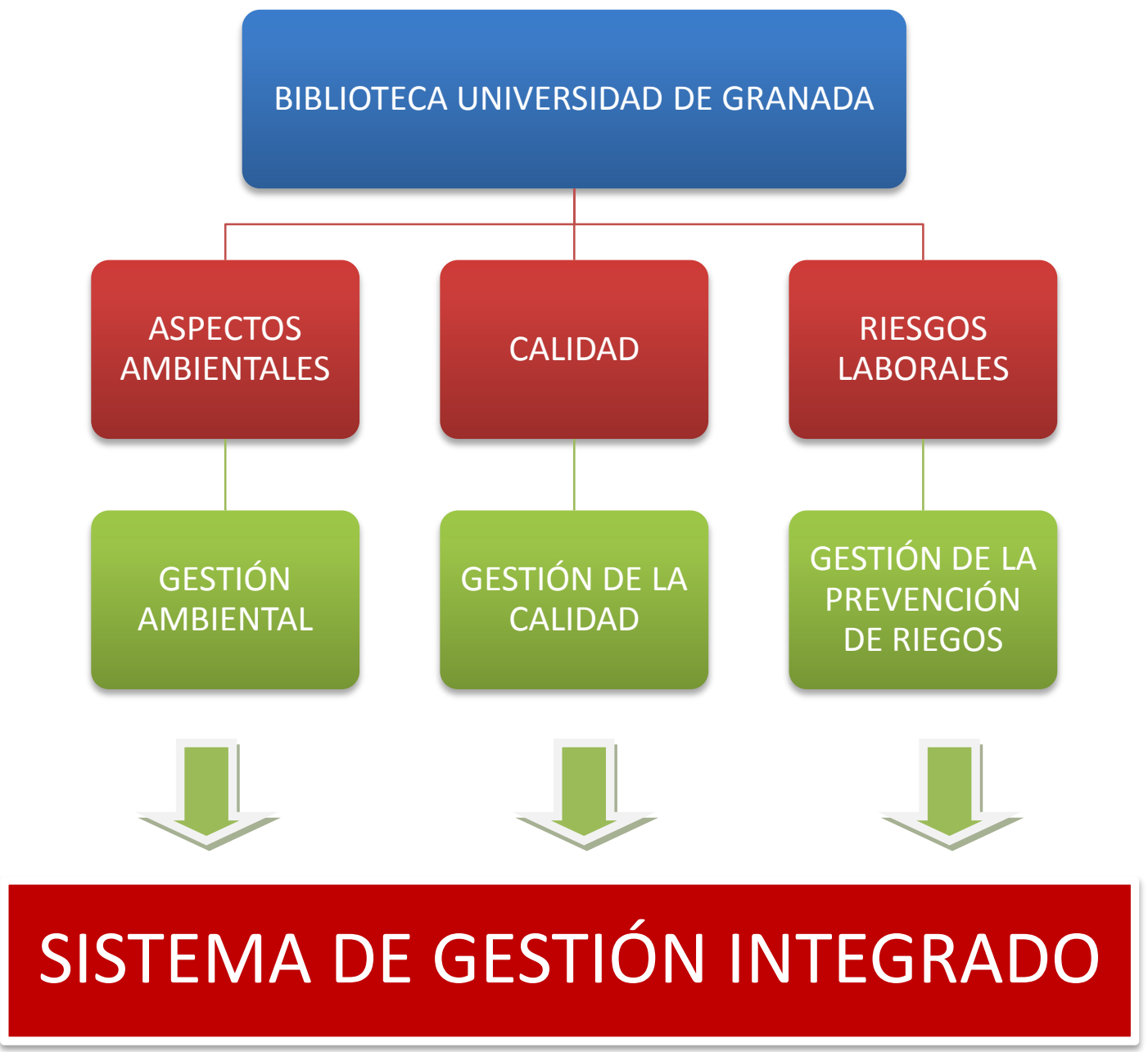

Se calcula que el periodo necesario para completar todas las fases puede ser de dos cursos académicos. En este tiempo se concienciaría a toda la comunidad que conforma la biblioteca universitaria sobre la importancia del SGI y cuál es su papel en este sistema.

Una vez conocida la estructura y las fases es necesario hacer un análisis en el que se describan las fortalezas y debilidades propias de la Biblioteca. Hay que conocer su estado actual en relación a la calidad de los servicios que presta, al medio ambiente y a la prevención de riesgos laborales.

La principal fortaleza, sin duda alguna, será el capital humano que integra la Biblioteca. Son personas cualificadas que deben impregnarse y transmitir a los usuarios las buenas prácticas que en estas áreas se vayan a implementar.

Algunas de las debilidades que podemos encontrar son:

- Comunicación entre las distintas bibliotecas. Es tónica general en las 
bibliotecas universitarias que las distintas personas que la conforman se comuniquen casi exclusivamente entre ellos, siendo difícil que haya comunicación fluida tanto horizontal como vertical con otras bibliotecas y con otros servicios.

- Horarios. La biblioteca está abierta al público 12 horas diarias de lunes a viernes. El personal que trabaja en ella lo hacen en dos turnos, mañana y tarde.

- Diversidad de puestos de trabajo: En la biblioteca universitaria, existen personal funcionario entre el que existen distintos niveles y personal laboral. Cada uno tiene una función dentro de la biblioteca. Esto puede ser una dificultad a la hora de asignar responsabilidades, identificar los riesgos y dar formación.

- Estructura organizativa: La Biblioteca universitaria tiene un equipo directivo de carácter político por lo que no es estable en el tiempo.

- Ritmo: Debido al número de personas que trabajan en la biblioteca, a las características de cada una de ellas y a su funcionamiento, el ritmo de cambio y la implantación de nuevas ideas y políticas es un proceso que se puede ver ralentizado.

\section{POLITICA DE GESTION}

La política es un documento público en el que se hace constar frente a terceros el compromiso de mejora continua que contrae la organización, en nuestro caso la Biblioteca Universitaria, y los objetivos que desea conseguir en materia de gestión de calidad, ambiental y de prevención de riesgos laborales.

Es el máximo exponente del compromiso de la dirección de estas materias y se podría aprovechar el momento de firma por la Dirección de la Biblioteca para dar a conocer el proceso que se está llevando a cabo a todos los integrantes de la Biblioteca Universitaria.

Los mínimos que debería contener la política de gestión son:

- Ser apropiada al propósito de la biblioteca, a la naturaleza de los riesgos laborales que se deriven de las actividades que se realizan en ella y ser coherente con el impacto ambiental que se deriven de sus actividades y servicio.

- Compromiso de cumplir con la legislación vigente y con otros requisitos que la biblioteca adquiera.

- Compromiso de poner a disposición de la Biblioteca Universitaria los medios necesarios para implantar un SGI. 
- Debe ser comunicada y entendida por todos los miembros de la Biblioteca.

- Es revisada para su continua adaptación.

- Debe estar documentada.

- Debe estar a disposición de todas las partes interesadas.

\section{COMPROMISO DE LA DIRECCIÓN}

Debemos obtener de forma documentada el compromiso de la dirección, no sólo de la BUG, sino también de la propia Universidad, consiguiendo el compromiso de, en el caso de la UGR, la rectora, de la disponibilidad y puesta a disposición de los recursos necesarios y del nombramiento de un representante al que conocerán todos los trabajadores y sabrán cuáles son las funciones específicas de este, y la autoridad que se le concede para llevar a buen puerto el éxito del Sistema Integrado de Gestión.

\section{PLANIFICACIÓN}

Se indicará como se van a cumplir los requisitos del Sistema de Gestión Integrada. Para ello se fijará la sistemática para establecer y mantener actualizados los objetivos y las metas a conseguir. Estos serán coherentes con la política de Gestión Integrada, para conseguir desarrollarla y lograr el compromiso de mejora continua.

Como parte del proceso de planificación se acometerán una serie de actividades en el marco de los procesos de la Biblioteca. Estas actividades requerirán la aplicación de unos recursos, que pueden suponer cambios en la organización interna de la biblioteca, asignar responsables, e identificar los procesos de implantación. Todo ello se recogerá en un documento que constituirá la planificación del proceso de implantación.

Para ello hay que empezar por evaluar el estado inicial de la gestión de la calidad, la gestión ambiental y de prevención de riesgos laborales en la biblioteca universitaria.

A continuación se detallan cada una de las etapas.

\section{Identificación de las actividades de la BUG}

Para identificar las actividades de la Biblioteca Universitaria, nada más util que acudir a su reglamento interno. Este está accesible a cualquier ciudadano desde la página web de la biblioteca universitaria a la que se accede desde la página principal de la Universidad de Granada.

En su artículo 1 se define a la Biblioteca Universitaria como "una unidad 
funcional, administrativa y de gestión en la que se conservan, organizan, procesan y ponen a disposición del usuario todos los recursos bibliográficos y documentales, así como otros recursos de información de la Universidad de Granada, para que la Comunidad Universitaria pueda cumplir sus objetivos en materia de docencia, estudio, aprendizaje, investigación, gestión y extensión universitaria”.

Es decir, facilita el acceso, la difusión y el uso de todos los recursos de información que forman parte del patrimonio de la Universidad, y colabora en los procesos de creación del conocimiento.

También es importante en este proceso de planificación, identificar y clasificar las posibles situaciones de emergencia a las que pueda verse sometida la Biblioteca Universitaria. Estas situaciones pueden ser: fallo en las instalaciones, gestión incorrecta de residuos, instalación eléctrica inadecuada, malas prácticas de trabajo, causas meteorológicas, etc.

\section{Flujograma de procesos}

En función de las actividades de la etapa anterior, la Biblioteca deberá elaborar un flujograma o mapa de procesos. En el caso de la Biblioteca de la UGR, ya lo tiene hecho.

\section{Identificación de los riesgos}

-Riesgos Laborales

En función de las leyes aplicadas en España en materia de prevención de riesgos, la Biblioteca llevará a cabo una identificación de los riesgos laborales existentes en todas las sedes de la misma en los distintos campus que hay en Granada.

En España, un método recomendable de identificación de riesgos es el desarrollado por el Instituto Nacional de Seguridad e Higiene en el Trabajo.

Una vez identificados se evaluarán. Siguiendo con el método del Instituto Nacional de Seguridad e Higiene en el Trabajo (INSHT), se cumplimentarán unos cuestionarios con unos criterios de valoración en función de los resultados quedando los riesgos evaluados en cuatro categorías: muy deficiente, deficiente, mejorable y correcta.

\section{-Riesgos ambientales}

Uno de los elementos más importantes de la gestión ambiental es la identificación de aspectos e impactos ambientales. La información que obtenemos de este proceso es útil para: 
- asegurar que la política del SGI de la Biblioteca es apropiada a la naturaleza, magnitud, e impactos ambientales de sus servicios y actividades.

- establecer objetivos y metas que sean parte del proceso de mejora continua,

- identificar las necesidades de formación del personal.

- establecer una comunicación interna entre las distintas bibliotecas de los distintos centros.

- identificar las actividades que estén asociadas a aspectos significativos relativos al medioambiente.

- calcular las posibles situaciones de emergencia que se puedan dar.

- vigilar las operaciones clave para ver qué impacto tienen en el medioambiente.

Estos riesgos, una vez identificados se evaluarán. En la Universidad de Granada, estos riesgos se evalúan siguiendo la fórmula $R=P \times G$, siendo $R$ el riesgo ambiental, $P$ la probabilidad de que ocurra y $G$ la gravedad del efecto. La probabilidad será:

- Alta, si el riesgo se producen todos los días.

- Media, si la situación se presenta varias veces al año.

- Baja si es improbable que ocurra.

\section{Gestión de la Calidad}

En el caso de la BUG, ha pasado varias evaluaciones de calidad, teniendo el certificado ISO 9000. Esta evaluación sirve como base para diagnosticar el estado en el que se encuentra la Biblioteca Universitaria en cuestiones de calidad.

Pero además, se encuentra muy conveniente analizar la satisfacción y/o quejas de los usuarios.

\section{Estudio de la satisfacción y/o quejas de los usuarios}

La biblioteca universitaria, para evaluar la satisfacción de sus usuarios ha puesto a su disposición en su página web, un banner llamado La Biblioteca responde. Se puede enviar un formulario que permite enviar una sugerencia, un comentario o una consulta asegurando una respuesta en un plazo máximo de 48 horas mediante correo electrónico.

Además, pone a disposición de sus usuarios la encuesta LibQual. Se eligió este tipo de encuesta ya que se buscaba un cuestionario que permitiera poder comparar con otras bibliotecas, y que tuviera un amplio respaldo entre los bibliotecarios. La encuesta LibQual cumplía con estos requisitos. De hecho es una encuesta que ha sido validada y que el "análisis estadístico confirma la universalidad de los conceptos medidos"[Kyrillidou et al. 2005]. Es un cuestionario en el que el 
usuario expresa su grado de satisfacción respecto de la Biblioteca Universitaria basándose en sus percepciones.

La encuesta consta de 22 preguntas que se agrupan en tres grandes dimensiones o aspectos:

- Valor Afectivo del servicio.

- La Biblioteca como Lugar.

- Control de la Información.

Además, se pide al usuario que exprese su opinión, en texto libre, sobre los servicios de la Biblioteca.

A esta encuesta se le da publicidad en la página web de la Biblioteca y en cada una de las bibliotecas de los centros, publicando la noticia en los monitores de televisión existentes en cada una de ellas, e informando el personal que atiende a los usuarios.

\section{Elaboración del informe final}

Con toda la información recogida el equipo evaluador redactará un informe en el que se indique de forma clara y precisa los resultados obtenidos.

\section{Requisitos legales y otros requisitos}

Al identificar los riesgos laborales y ambientales identificamos también los requisitos legales y otros requisitos que deben ser cumplidos. Se incluirán en un registro y se comunicarán a todo el personal implicado en la implantación y mantenimiento del SGI.

\section{Objetivos y Metas}

Los responsables de la gestión del SGI establecerán y mantendrán objetivos y metas de mejora continua. Serán medibles y coherentes con la política del SGI y con el Plan Estratégico de la BUG.

Los objetivos que se propongan llevarán implícitas unas metas y unas actuaciones para alcanzarlas. Se estructurarán en torno a un plan que contemple distintos programas de actuación para conseguir los objetivos. Podrá ponerse un plazo concreto, que puede ser un curso académico o varios.

Este plan concretará indicadores de seguimientos, responsables de llevarlos a cabo, plazas y recursos necesarios para conseguirlos. También, de cara a la auditoria interna, debe contener un apartado donde se indique el punto de la política al que se refiere.

Por último, y no menos importante, no olvidar que según el artículo 33 de la 
LPRL, la actividad preventiva ha de ser consultada a los trabajadores.

\section{Estructura del Sistema de Gestión}

La Biblioteca Universitaria dispone de recursos humanos y materiales para conseguir sus objetivos. Todos ellos forman una estructura. Pues bien, el SGI que se implante debe adaptarse a dicha estructura y no al contrario. Es posible que se necesiten hacer algunos cambios para adaptarse a las nuevas necesidades de gestión.

Para que la estructura esté bien organizada sería adecuado crear un Comité o una Comisión en la que estén representados los distintos colectivos que forman parte de la biblioteca. Esta Comisión debe asegurarse de que los objetivos propuestos se cumplen y se llevan a cabo las metas de mejora continua.

Es imprescindible que la dirección esté implicada en todo el proceso nombrando desde el principio del proceso de implantación del SGI un responsable con conocimientos y experiencia en sistemas de gestión.

\section{Información y aplicación de sugerencias de mejora}

Antes de empezar a formar a los trabajadores hay que informarles del proyecto que se va a poner en marcha, y de las consecuencias que esto tendrá en su trabajo diario.

Esta información no será un hecho aislado, sino que será un elemento principal a tener en cuenta a la hora de implantar el SGI.

La información debe ser:

- Imparcial: objetiva y no alterada por motivos externos.

- Permanente en el tiempo: estará presente en todas las actividades diarias que se realicen en la biblioteca y se tomarán como algo cotidiano.

- Comprensible: se pensará en los receptores y se adaptarán a ellos.

- Oportuna: se comunicará en el momento oportuno y dosificada adecuadamente. Para informar a los trabajadores se pueden utilizar distintos medios. Por ejemplo:

- Reuniones de grupo: en las que se pueden explicar conceptos. Se harán de forma dinámica para favorecer la participación del grupo.

- Correo electrónico institucional: es una vía de comunicación muy efectiva.

\section{Formación de los trabajadores}

Es necesario que sea una buena formación. Debe ser adecuada al grupo al que se le va a impartir, y a sus actividades diarias.

El responsable del SGI debe averiguar que funciones desempeña el personal de bibliotecas, que formación académica tienen, y que tipo de formación han recibido 
en materia de prevención de riesgos, gestión ambiental y gestión de la calidad. Además, se elaborará un Plan Anual de Formación en el que se especificarán:

- Las acciones formativas a realizar.

- El calendario previsto para llevarlas a cabo.

- El presupuesto.

- Los resultados esperados.

En el caso de la prevención de riesgos laborales, el artículo 19 de la LPRL establece que los trabajadores deben recibir formación en materia de prevención de riesgos laborales. También indica dicho artículo, que tipo de formación debe darse, en qué momento se impartirá y quien corre con el coste.

$\mathrm{Si}$ hay alguien que trabaje en tareas especificas asociadas a riesgos ambientales significativos o a riesgos que no se hayan podido evitar recibirá formación específica.

También se tendrá en cuenta el Plan de Autoprotección del Centro para saber cómo actuar en situaciones de excepción.

Para medir el grado de eficacia de la formación la Universidad de Granada utiliza cuestionarios al final de cada curso.

Ya que es muy importante la motivación de los trabajadores para que el Sistema de Gestión Integrada funcione se tendrá muy en cuenta su formación.

\section{Comunicación}

Tanto la norma ISO 9001, como la norma ISO 14001 y OHSAS 18001 destacan la importancia de los procesos de comunicación apropiados dentro de la organización.

No sólo es importante la comunicación entre compañeros, también lo es la comunicación con los usuarios del servicio. Además de seguir el procedimiento descrito para la comunicación entre trabajadores de la biblioteca, es necesario poner en marcha objetivos tendentes a mejorar las vías de comunicación dentro de la Biblioteca Universitaria con todos los miembros de la sociedad.

La comunicación interna de la biblioteca debe ser multidireccional, implantando los canales apropiados para que exista posibilidad de comunicación entre los distintos estamentos y entre los distintos turnos.

Para las comunicaciones recibidas de los usuarios la Biblioteca Universitaria ha puesto a disposición de ellos buzones de quejas y sugerencias. En la entrada de las distintas bibliotecas podremos ver unos buzones donde depositar cualquier sugerencia y/o queja que el usuario quiera hacer. También en la página web de la Biblioteca hay un apartado de quejas y/o sugerencias en el que el usuario puede tramitar su comunicación y mediante correo electrónico le será dada una respuesta en un plazo 
máximo de 48 horas.

En el caso de implantar un SGI, se dispondrán de procedimientos apropiados para la recepción, archivo y respuesta de las comunicaciones procedentes de las partes interesadas, que serán las personas que estén afectadas por el desempeño del SGI de la Institución.

También sería muy efectivo publicar al final del curso académico, las actuaciones llevada a cabo por la biblioteca en el ámbito del SGI, y que mejoras ha habido con respecto a años anteriores.

\section{Documentación}

En el análisis hecho al principio de este trabajo, notamos la importancia que le dan las normas ISO a la información documentada. Esta será la evidencia de cómo esta funcionando el SGI, de las medidas correctoras que se deben tomar y así conseguir la mejora continua.

Toda la información documentada se conservará y/o se difundirá teniendo en cuenta la legislación aplicable en este caso.

La estructura de la documentación para un sistema de Gestión Integrado podría mostrarse de la siguiente manera:

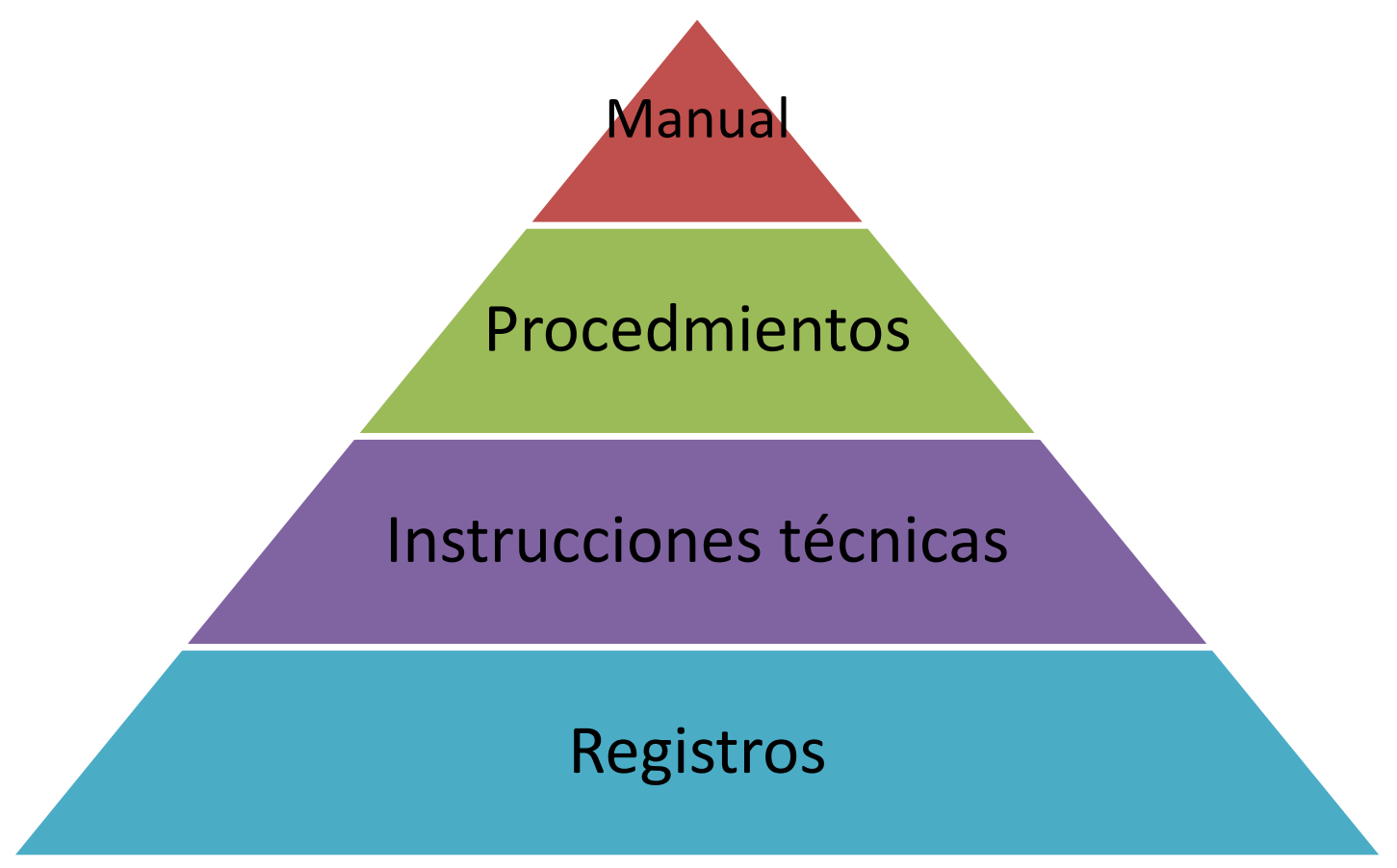




\section{Manual}

Aunque es cierto que en la nueva actualización de las normas ISO 9001 y 14001 ya no se exige la creación de un manual, sí es obligatoria la necesidad de determinar y documentar el alcance del sistema de gestión. Por esto, en la creación de un Sistema de Gestión Integrada sí sería útil hacerlo. Este nos puede servir como guía al principio, aunque después, como ha sucedido en los sistemas de Gestión de Calidad, y en los sistemas de Gestión Ambiental, este puede llegar a ser prescindible. También serviría al centro como presentación del tipo de gestión que realiza.

Sería una guía práctica sobre cómo realizar las tareas adheridas al SGI para todas las partes interesadas, tanto internas como externas. Incluiría también información adicional, como una breve descripción e historia de la Biblioteca Universitaria, la política del SGI, el organigrama de responsabilidades y un flujograma de procesos. Este último punto es importante sobre todo desde la perspectiva de la gestión de la calidad, ya que apuesta por una gestión basada en procesos, siendo estos el conjunto de fases sucesivas de una operación para conseguir ese proceso.

Por lo tanto, el Manual es un documento que expresa la interrelación de todos los elementos del SGI.

Podría constar de los siguientes apartados:

- Presentación de la Institución.

- Objeto y ámbito de aplicación.

- Normas de referencia.

- Definiciones y términos de referencia.

- Flujograma de procesos.

- Elementos del manual del SGI.

- Política de PRL.

- Objetivos y metas.

- Estructura y responsabilidades.

- Formación.

- Lista de documentos actualizados del SGPRL

- Control de operaciones.

- Verificación y acción correctiva.

- Revisión por la Dirección.

En el Manual se podrían recoger algunas definiciones como: accidente, auditoría, mejora continua, identificación de riesgos, peligros, incidentes, no conformidades, desempeño, riesgo, aspectos ambientales, usuarios. 


\section{Procedimientos}

Los procedimientos son documentos que recogen la metodología a seguir para poner en práctica el SGI. En ellos se describen las formas de actuación para vigilar los distintos procesos de la organización. Por ejemplo, en la Biblioteca Universitaria el préstamo de material al usuario es un proceso que está descrito en un procedimiento.

A la hora de elaborar los documentos combinados tendremos en cuenta los requisitos comunes de las normas de referencia.

No es lo mismo un procedimiento operativo que un procedimiento administrativo.

Procedimiento operativo: es aquel que controla las actividades que se desarrollan como parte del trabajo diario en la biblioteca.

Procedimiento administrativo: es aquel que dicta como funcionará el SGI y como se mantendrá.

El índice de un procedimiento, por ejemplo el de préstamo de un documento al usuario, podría contemplar los siguientes apartados:

\section{OBJETO \\ II. ALCANCE \\ III. DOCUMENTACIÓN DE REFERENCIA \\ IV. RESPONSABILIDADES \\ V. DEFINICIONES \\ VI. DESARROLLO}

1. Identificación y localización del ejemplar.

2. Reserva

2.1.1 Reserva desde el mostrador de circulación

\subsubsection{Reserva vía web}

3. Préstamo.

\subsubsection{Préstamo Normal}

3.1.2 Auto préstamo

4. Renovación

\subsubsection{Renovación indirecta}

4.1.2 Renovación vía web.

5. Devolución.

5.1.1Devolución en el mostrador.

5.1.2 Devolución en máquina de auto préstamo

5.1.3 Devolución en buzón 
VII. DIAGRAMA DE FLUJO

VIII. REGISTROS

IX. ANEXOS

\section{Instrucciones Técnicas}

Son documentos de menor rango que los procedimientos que describen como se realizan determinadas actividades que puedan conllevar especial riesgo para la salud y seguridad de los trabajadores. Por ejemplo, una instrucción técnica en la Biblioteca Universitaria, sería como manipular la carga cuando se tienen que coger varios libros a la vez.

Por lo general, es suficiente con que recojan el Objeto, es decir, la actividad a la que va a afectar, y el Desarrollo, en el que se explica cómo realizar la actividad y que medidas de protección se deben tener en cuenta.

\section{Registros}

Estos son las evidencias que muestran si el SGI está implantado. Para que tengan validez frente a terceros interesados deben estar claramente identificados, ser legibles, entendibles y estar fechados y firmados. Se custodiarán y archivarán convenientemente para evitar pérdidas o deterioros.

\section{Documentación de apoyo}

Esta documentación estará apoyada por la Documentación de Apoyo, que son las normas de referencia utilizadas. Pueden ser Notas Técnicas de Prevención aportadas por el Instituto Nacional de Seguridad e Higiene en el Trabajo, revistas especializadas en la materia, etc.

\section{Documentación básicas del SGI}

Podríamos decir, que para la Biblioteca de la Universidad de Granada, los documentos básicos serían los mostrados en la siguiente tabla.

Las celdas coloreadas en azul corresponden a documentos comunes a los tres ámbitos de gestión, las coloreadas en naranja a los que son comunes a las normas de referencia y las celdas coloreadas en verde son documentos específicos de cada una de las tres áreas, calidad, medioambiente o prevención de riesgos laborales. 


\section{MANUAL DEL SISTEMA DE GESTIÓN INTEGRADA}

PROCEDIMIENTOS

Dirección de la Biblioteca

Control de documentación y registro

Comunicación

Información y Formación del personal

Identificación de Reclamaciones y

Tratamiento de Incidentes y Acciones

Correctivas y Preventivas

Prestación de servicios

Identificación y Seguimiento de la

Legislación

Identificación y Evaluación de Riesgos

Laborales y Aspectos Ambientales

Control y Seguimiento

Lugares de Trabajo

Instalaciones

Vigilancia de la Salud de los Trabajadores

Riesgos Ergonómicos

Riesgos Psicosociales

Riesgos Higiénicos

Inspecciones de Seguridad

Señalización de Seguridad

Gestión de Residuos

Control de Consumos

Situaciones de Emergencia

extraordinarias
INSTRUCCIONES TECNICAS

Satisfacción de los Usuarios

Uso de Equipos de

Protección Individual

Gestión del papel desechado, de los cartuchos de toner utilizados, etc. 


\section{Control de la documentación}

Es importante, como ya hemos visto, mantener la información documentada debidamente archivada y custodiada ya que con ella se podrá comprobar cómo funciona el SGI.

La norma ISO 9001, ISO 14001 Y OHSAS 18001 establecen que la organización debe establecer y actualizar los procedimientos para controlar la documentación de cada sistema.

En el caso de un SGI es innecesario elaborar tres procedimientos independientes que expliquen el sistema de control de cada documento que integra cada uno de los sistemas. Los documentos los elaborará un mismo número de personas y los controlará el Comité o la Comisión del SGI.

Se tendrá en cuenta lo siguiente:

- La documentación debe estar físicamente disponible. Para ello e intentando ser coherentes con el respeto al medioambiente la biblioteca universitaria proporciona su información en formato electrónico a través de la página web de la biblioteca con acceso restringido al personal de la misma.

- La documentación debe ser revisada y modificada en las reuniones periódicas que mantenga la Comisión del SGI.

- Si hubiera modificaciones se darán a conocer a todo el personal por el medio que parezca más oportuno. Puede ser convocándolos a una reunión para informarles o via correo electrónico.

- Los documentos especificarán quien los elaboró y quien los ha revisado y aprobado y en qué fecha. También se incluirá si es la primera o es una revisión posterior.

\section{Control de los procesos llevados a cabo en la Biblioteca}

En un flujograma de procesos se pueden definir los procesos clave y esenciales para la documentación del SGI y tiene que tener como referencia los informes derivados de las evaluaciones de riesgos y de las encuestas analizadas de satisfacción de los usuarios.

Los procedimientos e instrucciones técnicas para controlar los aspectos que puedan influir en la calidad del servicio, en el medioambiente o en la seguridad y salud de los trabajadores derivados de las actividades que se llevan a cabo en la Biblioteca, también deben incluirse en la documentación del SGI. Se hará especificando que aspectos van a ser controlados y seguidos periódicamente y se indicará el código y el nombre de los procedimientos específicos donde se detallan esas actividades. 
¿Cuáles son estos procedimientos específicos?

- Lugares de trabajo: se incluye lo que establece la legislación vigente para los lugares de trabajo, las medidas preventivas adoptadas frente a los peligros derivados de la falta de orden y limpieza en los lugares de trabajo, la gestión del inventario, y la responsabilidad de cada trabajador en su lugar de trabajo.

- Gestión de Residuos: se incluye como se gestionarán los residuos que se derivan de las actividades realizadas en la biblioteca. Por ejemplo, como se retirarán los cartuchos de tóner utilizados en las impresoras y fotocopiadoras, como se gestiona la retirada de los tubos fluorescentes.

- Vigilancia de la Salud de los trabajadores: en este procedimiento se establecerá la periodicidad y el tipo de reconocimiento que se hará. Para ello se hará una descripción detallada del puesto de trabajo, de los riesgos detectados al analizarlo y de las medidas preventivas a adoptar.

En el caso de la Universidad de Granada se hace un reconocimiento médico previo al comienzo de la actividad en ella y periódicos ordinarios o especiales cuando sean necesarios.

- Control de consumos de recursos: Se recogerá el consumo de energía que se produce en la biblioteca con el fin de disminuir progresivamente este para que el impacto ambiental sea el mínimo. Se planificarán campañas o instalaciones de sistemas que minimicen el consumo y el impacto en el medioambiente.

- Control de los Riesgos Higiénicos. Se evaluarán obligatoriamente los puestos de trabajo en los que se detecte, bien por una evaluación de riesgos iniciales o a petición del trabajador, alguna condición higiénica que pueda ocasionar unos riesgos para el mismo.

- Control de Riesgos Ergonómicos: se relacionarán todas las actividades que puedan ocasionar riesgos de tipo ergonómico a los trabajadores y que medidas preventivas se adoptarán al respecto. Se hará hincapié en las Pantallas de Visualización de Datos, o en el manejo de cargas debido a la cantidad de libros que cada día se manejan y al peso de estos.

- Control de Riesgos Psicosociales: se especificará el protocolo a seguir para aquellos que sufran en su puesto de trabajo algún tipo de riesgo psicosocial.

- Señalización de Seguridad: se mantendrá debidamente señalizadas las salas de la biblioteca. Se hará con señales homologadas.

- Mantenimiento de las Instalaciones. Se especificarán que instalaciones deben pasar mantenimiento, cada cuanto tiempo y quien serán los responsables de hacerlas. 


\section{Situaciones de Emergencia}

Es obligatorio, como así especifica la norma ISO 14001 y OHSAS 18001, incluir un documento operativo de actuación en caso de que se produzca una emergencia.

Todas las bibliotecas como parte de un centro universitario que son deben contar con un plan de autoprotección que incluya un plan de emergencias. Estos se harán teniendo en cuenta las emergencias que puedan ocurrir tanto desde el punto de vista ambiental como de la seguridad y salud de los trabajadores y usuarios.

Este procedimiento debe recoger un plan de simulacros en el que se comprueben si el plan de emergencias está bien establecido y bien entendido por los trabajadores.

Los accidentes, incidentes y situaciones de emergencia deben quedar reflejadas por escrito en un formato que la biblioteca escogerá pero en el que se especifique que ha pasado, donde ha pasado, que actuaciones se derivan de esto y que medidas correctivas se tomarán.

\section{Evaluar}

La evaluación del Sistema de Gestión es la que nos va a dejar completar con éxito y con garantías el proceso de implantación. Nos permitirá comprobar si el Sistema de Gestión Integrada está funcionando y si se están cumpliendo los objetivos propuestos.

\section{Verificación}

Para comprobar la efectividad del sistema de gestión puede ser muy útil un modelo de autoevaluación basado en el Modelo Europeo EFQM de Excelencia. Este es un modelo diseñado para evaluar la gestión de la Calidad. La Biblioteca Universitaria, tiene certificado el Sello de Excelencia Europea 500+ basado en el modelo EFQM. Es una herramienta que le ha permitido realizar auditorías internas que la han ayudado a conocerse mejor a sí misma y a mejorar su funcionamiento, y que son obligatorias en el SGI propuesto.

El modelo propuesto consta de dos partes:

- Un conjunto de criterios que abarcan todas las actividades de la Biblioteca.

- Un conjunto de reglas para evaluar el comportamiento de la Biblioteca en cada criterio.

Para que la evaluación del Sistema de Gestión Integrado sea favorable habrá que tener en cuenta cinco criterios. Estos se revisarán periódicamente para mejorar y 
han de estar implantados en las operaciones de la Biblioteca para conseguir buenos resultados en todo el sistema.

Estos criterios son:

- Cumplimiento de la legislación aplicable.

- Formación e información del personal.

- Política y Planificación.

- Comunicación externa y recursos.

- Procesos.

Para que el modelo sea práctico y útil se aplicará en base a:

- La comprensión del modelo por parte de todos los miembros de la BUG.

- La evaluación de la situación del modelo en todas las actividades desarrolladas en la BUG.

El modelo a utilizar debe ser medible para poder recoger los datos y analizarlos. Para poder medir y mejorar el comportamiento de cualquier organización se utilizan indicadores, que sirven como instrumentos que aportan la información necesaria para conocer los avances en calidad, gestión ambiental y en prevención de riesgos laborales.

Los indicadores son importantes porque:

- nos ayudan a interpretar lo que está ocurriendo.

- Permiten introducir cambios y mejoras.

Para seleccionar los indicadores más adecuados debemos analizar la situación. Para ello servirán los datos obtenidos de una revisión inicial. Sería positivo para la organización preguntarse:

- ¿Qué debe medir?

- ¿Quién lo hará?

- ¿Dónde?

- ¿Cuándo?

- ¿Cómo?

- ¿Quién revisará los datos obtenidos? 


\section{Sistema de indicadores.}

Se pueden elegir uno o dos indicadores escogidos de los posibles indicadores que se hayan utilizado en otras instituciones.

Se concretará:

- Que queremos conseguir con cada indicador.

- Con que periodicidad será medido

- Como conservar los datos de estos indicadores el tiempo suficiente para poder comprobar cómo ha sido su evolución.

Los indicadores deberán cumplir unas características que deben tenerse en cuenta a la hora de establecerlos. Estas son:

- Que sean fáciles de medir.

- Que sean tangibles.

- Que la forma de obtener la información sea fácil y no sea costosa.

- Las mediciones se puedan repetir periódicamente.

- Que se puedan relacionar con otros indicadores.

Es buena costumbre documentar los criterios elegidos para recopilar los datos obtenidos por el indicador. Esto se puede hacer en un registro que ofrezca información sobre:

- El indicador,

- La fuente de datos,

- Como están clasificados los datos básicos y que valores de referencia se han escogido.

- La responsabilidad de recopilar los datos.

- Que indicadores son absolutos y cuales relativos.

Revisión del sistema de indicadores.

Debe ser revisado periódicamente para comprobar si sigue siendo el adecuado para medir y mejorar el SGI. Serán válidos si contestan las siguientes preguntas:

- ¿Reflejan las actividades realizadas en la Biblioteca?

- ¿Se pueden mejorar estos indicadores?

- ¿Se dispone de recursos suficientes para establecer indicadores?

- ¿Son actualizados frecuentemente?

- ¿Permiten cuantificar los objetivos? 
Una vez recopilada toda esta información, los responsables del SGI ya están en disposición de elegir los indicadores apropiados para medir la evolución y los resultados conseguidos con la implantación del Sistema de Gestión Integrada.

Una vez escogidos los indicadores para medir y analizar el comportamiento del SGI, se aplicarán a los cinco criterios que antes mencionábamos que harán que el SGI implantado funcione.

En la siguiente tabla se puede ver un ejemplo de criterios e indicadores a aplicar en la implantación del SGI en la Biblioteca Universitaria.

\begin{tabular}{|l|l|}
\hline \multicolumn{1}{|c|}{ CRITERIOS } & \multicolumn{1}{|c|}{ INDICADORES } \\
\hline Cumplimiento de la legislación & $\begin{array}{l}\text { № de suscripciones a revistas con contenido legislativo. } \\
\text { № de reuniones para actualizar la normativa vigente. }\end{array}$ \\
\hline Formación e Información al personal & $\begin{array}{l}\text { № de acciones de gestión del personal incorporadas al } \\
\text { plan estratégico. } \\
\text { № de reuniones realizadas con el personal para } \\
\text { establecer y controlar los objetivos. }\end{array}$ \\
\hline Política y Planificación & $\begin{array}{l}\text { № de empleados que participan en la realización de los } \\
\text { planes. } \\
\text { № de reuniones de comunicación de los planes del SGI } \\
\text { \% de presupuesto invertido en mejora del SGI } \\
\text { № ordenadores/№ de trabajadores }\end{array}$ \\
\hline Comunicación externa y Recursos & $\begin{array}{l}\text { № de procedimientos clave a controlar para cada } \\
\text { actividad. } \\
\text { Tiempo medio de solución de problemas }\end{array}$ \\
\hline Procesos &
\end{tabular}

\section{NO CONFORMIDADES, ACCIONES PREVENTIVAS Y CORRECTIVAS}

Tanto las normas ISO 9001 y 14001, como las OHSAS indican la importancia de identificar las no conformidades, y utilizarlas como herramientas hacia la mejora continua.

No podemos olvidar que cualquier alejamiento de los procedimientos, regulaciones normativas, prácticas, etc. puede tener como consecuencia directa o indirecta una lesión, enfermedad, un daño a la propiedad, o un perjuicio al medio ambiente. 
Una vez identificadas y analizadas las causas de las no conformidades se pueden proponer acciones correctivas y preventivas para evitar que se repitan. Estas acciones estarán claramente definidas, documentadas y se hará un seguimiento del cumplimiento de las mismas.

\section{RESULTADOS Y AUDITORIA}

Las auditorias se dividen en externas o internas dependiendo de quien las lleve a cabo. Esta división la establece la norma ISO 19011.

La Biblioteca puede hacer Auditorías Internas para utilizarlas en la revisión por la dirección e incluso para declarar su conformidad. En el Sistema de Gestión Integrada que se implante se deben establecer los procedimientos para llevarlas a cabo.

También se pueden hacer Auditorías Externas por las partes interesadas que tengan interés en saber el estado de la Biblioteca en las tres áreas que queremos integrar. O bien pueden ser ejecutadas por empresas auditoras independientes y externas a la Biblioteca que acreditarán o certificarán la conformidad con los requisitos de alguna de las normas internacionales, europeas o nacionales existentes.

En el caso de las auditorias, cuando el sistema de gestión no está integrado deben hacerse por separado y esto supone un incremento de costos, tiempo y esfuerzo. Esta es una de las razones por las que implantar un Sistema de Gestión Integrada sería una ventaja. Se ahorraría en costes, tiempo y esfuerzo. Recordemos que los requisitos mínimos en los procesos de auditoria para cada uno de los sistemas citados en las normas ISO y OHSAS son similares por lo que integrar las tres auditorias en una no debe resultar complicado.

En el caso de la Biblioteca Universitaria, para auditar las tres áreas a la vez, se podría consultar tanto al personal de la Unidad de Calidad Ambiental que tiene la propia Universidad, como al Servicio de Prevención de Riesgos Laborales propio del que dispone. Estos junto con la persona responsable del área de Calidad de la propia Biblioteca, proporcionarían los requisitos toda la información necesaria para poder auditar las tres áreas de una sola vez.

\section{Revisión por la Dirección}

Tanto las normas ISO como OHSAS, incluyen la revisión por la alta dirección. Especifican que la alta dirección debe revisar el sistema de gestión de la calidad de la organización, para asegurarse de su conveniencia, adecuación y eficacia continuas.

En nuestro caso, la Comisión o Comité que se encargará de implantar y mantener el SGI, pueden abordar los siguientes pasos: 
- Reunirse con la dirección para planificar la revisión,

- Enviar la convocatoria de reunión a los asistentes,

- Tratar al menos los siguientes puntos:

- Política, objetivos y metas,

- Programas de Gestión

- Resultados de las Evaluaciones de Riesgos Laborales

- Resultados de los diagnósticos ambientales

- Resultados del control, seguimiento y medición,

- Resultados de la formación

- Resultados de las auditorias

- Actuaciones en materia de comunicación

- Trato de las no conformidades, acciones correctivas y preventivas

- Índices de siniestralidad

- Retroalimentación entre personal y usuarios de la BUG

- Recomendaciones de mejora

Se debe elaborar un informe en el que se reflejen los resultados de la reunión. Este se hará llegar a todos los asistentes y se comunicarán todas las modificaciones que surjan a todos los trabajadores que les afecten.

\section{MATRIZ DAFO TRAS LA IMPLANTACIÓN DEL SGI}

Se puede hacer un análisis de las fortalezas y debilidades del SGI implantado.

\section{Fortalezas}

Una de las fortalezas que se pueden citar es que mejora la comunicación entre los integrantes de la Biblioteca ya que se establecen formas de comunicación accesible a todo el personal y se nombran responsables de la transmisión de la información para asegurarse de que esta fluye.

Otra fortaleza es la sensibilización, concienciación y formación del personal. Como los conceptos son transmitidos de forma progresiva se facilita que el personal los asimile poco a poco y que tenga claros unos antes de introducir otros nuevos.

También es más fácil tener los procesos controlados ya que todas las actividades están documentadas, planificadas y se hace un seguimiento de ellas y de las acciones para corregirlas.

Se asegura el cumplimiento de la legislación, y los medios para mantenerla actualizada evitando cualquier incumplimiento que pueda derivar en una sanción.

Se crea una estructura de responsabilidades y funciones aceptadas y asumidas 
por todos los integrantes de la organización, de forma que cada uno asume su misión por lo que se facilita la consecución de los objetivos.

\section{Debilidades}

Igual que hemos citado como fortaleza la sensibilización, concienciación y formación del personal, esta se puede convertir en debilidad si no se asume totalmente por todos y cada uno de los miembros que integran la Biblioteca Universitaria.

También la estructura de responsabilidades puede convertirse en debilidad ya que la dirección de la biblioteca es un cargo elegido electoralmente por un tiempo determinado. Esto hace que el equipo directivo que se hace cargo de implantar el SGI, tenga que dejar claramente definido como se va a actuar en el momento en que cambie la dirección porque si no se hace así el esfuerzo por implantar el SGI y la tarea de mantenerlo se pueden perder.

\section{CERTIFICACION DEL SISTEMA DE GESTION INTEGRADA}

Esta es la última fase del ciclo de implantación. No es obligatoria ya que el fin de implantar este SGI es que sirva como herramienta para mejorar continuamente y como guía para asegurarnos de que las cosas se hacen bien. Pero una vez que se está trabajando de acuerdo a lo establecido, y el personal está formado y sensibilizado, sí es momento de plantearse si se quiere la certificación del SGI.

Si la decisión es certificarlo se seguirán las siguientes fases:

- Presentación de ofertas

- Elección de la empresa certificadora

- Presentación del cronograma de auditoria

- Pre auditoria en la que la empresa certificadora pedirá al centro documentación relativa sus actividades, complejidad, tamaño y cualquier documentación que estime necesaria para poder completar su visión de cómo está estructurado el SGI.

- Auditoria de la documentación en la que pueden darse no conformidades que se podrán subsanar antes de auditar las instalaciones.

- Auditoria. Durante esta fase se pondrá a disposición del equipo auditor toda la documentación del SGI y se les acompañará durante las visitas que realizan a algunas bibliotecas de centros escogidas previamente. El proceso es el siguiente:

- Reunión de apertura

- Visita a las bibliotecas de algunos centros 
- Reunión de cierre: presentación de no conformidades y solicitud de acciones correctivas.

El equipo auditor presenta un informe en el que se incluyen los siguientes datos:

- Datos del informe: nombre de la organización a auditar, dirección, representante, fechas, lugares auditados, auditor, norma contra la que se desarrolla la auditoria, firma del auditor jefe.

- Objetivos de la auditoria: en este caso comprobar el grado de implantación del SGI.

- Alcance

- Conclusiones: si se recomienda o no obtener la certificación.

- Hallazgos en las funciones especificas de gestión

- Otros hallazgos en la verificación de procesos, actividades o funciones.

- Solicitudes de acción correctiva: se indicarán las cosas que deben resolverse para cerrar las no conformidades o las observaciones levantadas durante la auditoria. Se establecerá el plazo que se da a la Biblioteca para llevar a cabo las acciones correctivas. Este suele ser de tres meses.

- Observaciones y oportunidades de mejora.

- Emplazamientos auditados.

Tras hacerles llegar a los auditores las acciones correctivas propuestas y ser evaluadas por ellos, si lo ven conveniente la Biblioteca obtendrá la triple certificación según la ISO 9001:2015, ISO 14001:2015 y OHSAS 18001:2007 pudiendo ser esta última en pocos meses sustituida por la ISO 45001.

Este certificado tendrá una validez de tres años y los auditores externos harán una auditoria anual de mantenimiento del sistema. Se cerrará el ciclo con una Auditoría de Recertificación, en la que la Biblioteca puede decidir si lo estima conveniente cambiar de organismo certificador o continuar con el mismo.

$Y$ al final de todo el proceso se comunicará a todos los integrantes de la Biblioteca Universitaria, que su SGI ha sido certificado y por tanto un éxito. 


\section{CONCLUSIONES}

Es posible realizar un modelo de gestión integrada para las Bibliotecas Universitarias. Las normas ISO 9001, y 14001, y OSHAS 18001, han establecido las bases para que sea posible su implantación.

Es cierto que el proceso de implantación de un Sistema de Gestión Integrada de Calidad, Medioambiente y Prevención de Riesgos Laborales en la Biblioteca de la Universidad de Granada es complejo y laborioso. La propia fisonomía de la Biblioteca Universitaria de Granada, teniendo su sede en el Hospital Real, pero contando con 22 biblioteca más repartidas en los centros de los distintos campus universitarios hacen que sea complicado implantar un SGI único para todas, ya que no todas tienen el mismo tipo de instalaciones, o el mismo tipo de edificios, o atienden al mismo número de usuarios. Pero, recordemos que ha sido posible implantar un Sistema de Gestión de Calidad para todas, siendo pionera en la Universidad de Granada en obtenerlo y manteniéndolo a lo largo del tiempo desde el año 2007, además ha obtenido el Premio de Excelencia Europea 500+ otorgado por la Fundación Europea para la Gestión de la Calidad (EFQM) y el Club de Excelencia en la Gestión y también obtuvo el premio Plata de Calidad en la XXIII cumbre de Jefes de Estado y de Gobierno podemos afirmar que la Biblioteca Universitaria tiene experiencia en implantar sistemas de gestión con éxito.

Es cierto que pueden surgir algunos inconvenientes, pero el ahorro económico, de esfuerzo y de tiempo es algo que debe primar en una institución cuyo fin es facilitar el acceso, la difusión y el uso de todos los recursos de información que forman parte del patrimonio de la Universidad a todos los ciudadanos, así como colaborar en los procesos de creación del conocimiento. Y esto es lo que consigue implantando un SGI, demostrar a sus usuarios, y al resto de la comunidad que se preocupa por su interior para ser brillante en su exterior.

Y citando a Peter Drucker, abogado y tratadista austriaco, y considerado el mayor filósofo de la administración podemos afirmar que "La prueba de una innovación no es su novedad, ni su contenido científico ni el ingenio de la idea...es su éxito en el mercado".

Dejemos que sea el propio SGI el que demuestre si merece la pena o no el esfuerzo, tiempo y dinero que se tiene que invertir en su implantación. 


\section{AGRADECIMIENTOS}

Me gustaría expresar mi agradecimiento a todos los que de alguna manera habéis estado a mi lado en esta aventura.

En primer lugar me gustaría agradecer a Javier Machado Santiago, su ayuda y sus consejos para llevar a buen término este trabajo. Gracias por entender y respetar mi falta de tiempo y mi necesidad de independencia.

A todos los que de alguna manera me habéis dado ánimos y habéis aguantado mis malos momentos.

Y por último a mis padres y a mi abuela, "mami". A mis padres, porque aunque ya no están conmigo, los tengo presentes en cada paso que doy porque me enseñaron a confiar en mí, y a terminar cualquier cosa que empezara. $Y$ a ti, mami, por enseñarme que todos los días hay que aprender algo nuevo. Que sabia eras.

¡Muchas gracias a todos! 


\section{BIBLIOGRAFIA}

Abril Sánchez CE, Enríquez Palomino A, Sánchez Rivero JM. Integración de sistemas de gestión, calidad, medio ambiente, y seguridad y salud en el trabajo. Madrid: Fundación Confemetal; 2009.

Camisón Zomoza C, Cruz S, González T. Gestión de la calidad: conceptos, enfoques, modelos y sistemas estrategia y competitividad. Madrid: Prentice Hall; 2006.

Espinosa Hidalgo P, Rosua Campos JL. Guía para la gestión integrada en un centro de enseñanza superior :(prevención de riesgos laborales, medio ambiente y calidad). Granada: Oiudsma; 2006.

Fernández García R. Sistemas de gestión de la calidad, ambiente y prevención de riesgos laborales: su integración. Alicante: Club Universitario; 2005.

Herrera Viedma E, López Gijón J, Alonso S. Estudio de calidad de los servicios de la Biblioteca de la Universidad de Granada basado en satisfacción de usuarios (2006). Granada: Copicentro. -ISBN 2007:849685627-849685625.

La Integración de la Calidad, el Medio Ambiente y la Seguridad en la Gestión Empresarial. : Fundación Labein; 1998.

Ley 31/1995, de 8 de noviembre, de Prevención de Riesgos Laborales (BOE de 10 de noviembre de 1995).

López Cachero M. La gestión integral de la calidad, los riesgos medioambientales y los laborales: Ventajas de la gestión integrada frente a la gestión independiente. UNE 1998(121):9-11.

NORMA UNE-EN ISO 14001:2015, sistemas de Gestión Ambiental. Requisitos con orientación para su uso.

NORMA UNE-EN ISO 9001:2015, sistemas de Gestión de la Calidad. Requisitos.

OSHA (2007): Sistemas de Gestión de la Seguridad y Salud en el Trabajo.

Real Decreto 39/1997, de 17 de Enero, por el que se aprueba el Reglamento de los Servicios de Prevención (BOE de 31 de Enero de 1997). . 
Rey García AA. Cómo gestionar la calidad en las universidades: El Modelo Europeo de Excelencia Universitaria: Madrid: Club Gestión de Calidad; 1998.

Rubio Romero JC. Gestión de la prevención de riesgos laborales :OSHAS 18.001, directrices OIT para su integración con calidad y medioambiente. Madrid: Díaz de Santos; 2002. 